RAFAEL MIRANDA SOUSA

\title{
Potencial evocado visual multifocal em olhos com hemianopsia temporal por compressão quiasmática. Correlação com a perimetria computadorizada e a tomografia de coerência óptica
}

\author{
Tese apresentada à Faculdade de Medicina da \\ Universidade de São Paulo para obtenção do título \\ de Doutor em Ciências \\ Programa de Oftalmologia \\ Orientador: Prof. Dr. Mário Luiz Ribeiro Monteiro
}

(Versão corrigida. Resolução CoPGr 6018/11, de 1 de novembro de 2011. A versão original está disponível na Biblioteca FMUSP)

São Paulo 


\section{Dados Internacionais de Catalogação na Publicação (CIP)}

Preparada pela Biblioteca da

Faculdade de Medicina da Universidade de São Paulo

Creprodução autorizada pelo autor

\section{Sousa, Rafael Miranda}

Potencial evocado visual multifocal em olhos com hemianopsia temporal por compreesão quiasmática. Correlação com a perimetria computadorizada e a tomografia de coerência óptica / Rafael Miranda Sousa. -- São Paulo, 2017.

Tese(doutorado)--Faculdade de Medicina da Universidade de São Paulo.

Programa de Oftalmologia.

Orientador: Mario Luiz Ribeiro Monteiro.

Descritores: 1.Atrofia óptica/diagnóstico 2.Quiasma óptico/patologia 3.Fibras nervosas/patologia 4.Testes de campo visual/métodos 5.Tomografia de coerência óptica 6.Potenciais evocados visuais

USP/FM/DBD-071/17 
Este trabalho recebeu suporte financeiro da CAPES - Coordenação de Aperfeiçoamento de Pessoal de Nível Superior (número 9806-11-03), do CNPq - Conselho Nacional de Desenvolvimento Científico e Tecnológico (número 307393/2014-3) e da FAPESP Fundação de Amparo à Pesquisa do Estado de São Paulo (números 2009/50174-0 e 2013/26585-5). 


\section{DEDICATÓRIA}

Ao meu grande amor, Ana Carolina Rocha Garcia Miranda, esposa e amiga que trilha comigo esta jornada pela vida, partilhando de meus sonhos, conquistas e me apoiando em todos os momentos . Sua companhia dá sentido a minha vida!

Aos meus pais, Solange Miranda Sousa e Ubirani Sousa - in memoriam, por me ensinarem que com estudo e dedicação podemos transformar o mundo e tornar nossos sonhos realidade. Obrigado pelo amor e apoio ao longo de toda minha vida e em todos os momentos.

Ao Professor Mário Luiz Ribeiro Monteiro, por despertar o interesse de várias gerações de oftalmologistas pela ciência e servir de referencial de dedicação e amor pelo ensino e pela pesquisa. Sinto-me honrado de ser seu aluno e tenho certeza que a sua existência inspira e serve de referência a todos os docentes. 


\section{AGRADECIMENTOS}

Aos meus irmãos, Daniel Miranda Sousa, Carolina Miranda Sousa e Camila Miranda Sousa, por todo amor, carinho e amizade.

À Dra. Maria Kiyoko Oyamada por me ensinar as bases da eletrofisiologia e por todo suporte em todas as fases deste projeto, sem sua coorientação, nada disso seria possível. Muito obrigado!

À Regina Ferreira Almeida pela ajuda e incentivo através de todo este período, sua dedicação à pós-graduação torna nossas vidas durante este processo mais leve.

Às ortoptistas Sílvia Bernardoni e Clarice Ikedo pelo apoio e suporte na fase de coleta deste projeto.

Aos colegas e profissionais da Clínica Oftalmológica da FMUSP que de algum modo contribuíram para realização deste projeto. Em especial aos amigos que me antecederam nesta linha de pesquisa e aos colegas de pós-graduação que me ajudaram neste projeto, Leonardo Provetti Cunha, Luciana Virgínia Ferreira Costa Cunha, Kenzo Hokazono, Daniel Araújo Ferraz e André Carvalho Kreuz

Aos pacientes, que com sua boa vontade e compaixão pelo próximo contribuem para o desenvolvimento da ciência. 


\section{SUMÁRIO}

Lista de abreviaturas

Lista de figuras

Lista de tabelas

Lista de gráficos

Resumo

Summary

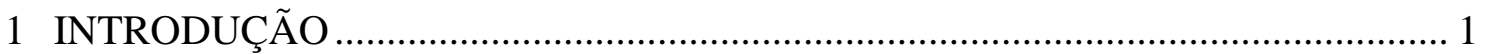

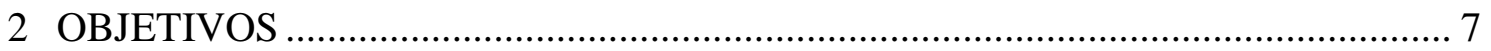

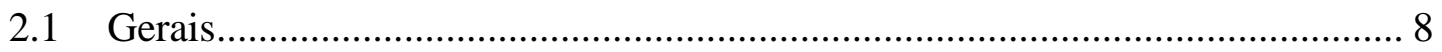

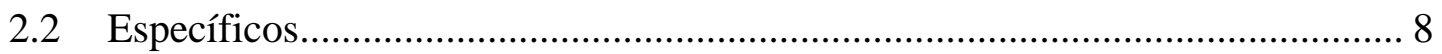

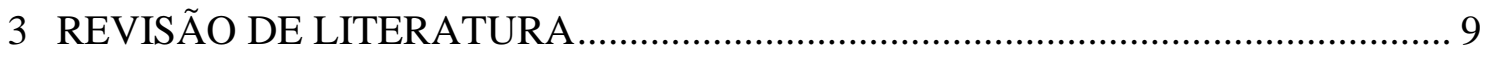

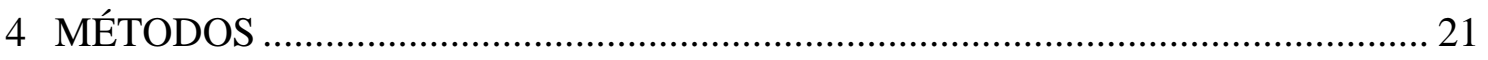

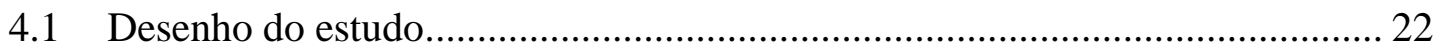

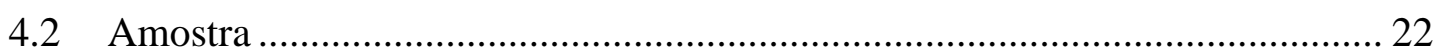

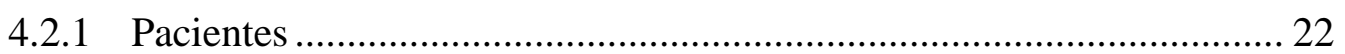

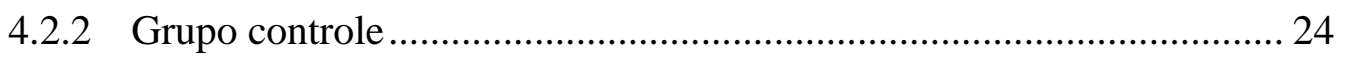

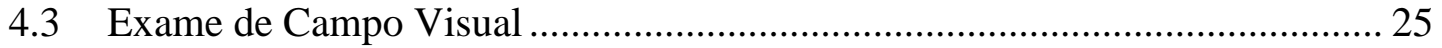

4.4 Tomografia de Coerência Óptica: ............................................................... 26

4.5 Potencial Evocado Visual Padrão-reverso ....................................................... 28

4.6 Potencial Evocado Visual Multifocal ............................................................. 30

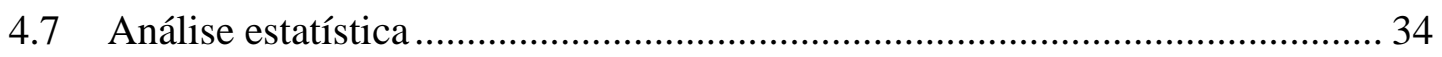

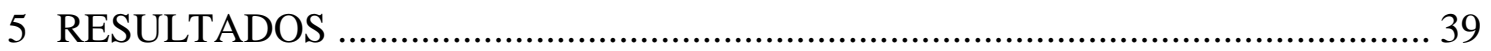

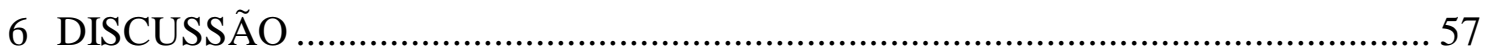

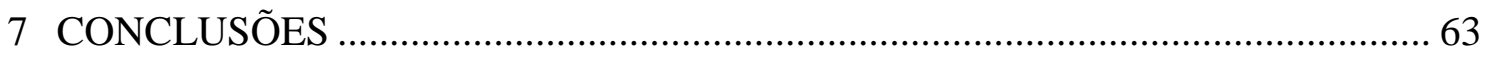

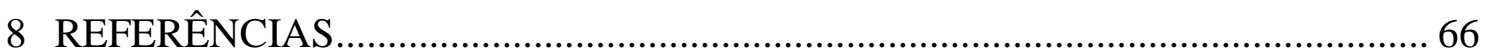




\section{LISTA DE ABREVIATURAS}

\begin{tabular}{|c|c|c|}
\hline $\mathrm{AB}$ & - & Atrofia em banda \\
\hline AFN & - & Analisador de fibras nervosas \\
\hline AROC & - & Área sob a curva Receiver Operating Characteristic \\
\hline AV & - & Acuidade visual \\
\hline CCG+ & - & $\begin{array}{l}\text { Camada de células ganglionares da retina mais a camada } \\
\text { plexiforme interna }\end{array}$ \\
\hline $\mathrm{CCG}++$ & - & Camada de fibras nervosas da retina macular mais CCG+ \\
\hline CFNR & - & Camada de fibras nervosas da retina \\
\hline CFNR-m & - & Camada de fibras nervosas da retina macular \\
\hline CGR & - & Células ganglionares da retina \\
\hline $\mathrm{CNI}$ & - & Camada Nuclear Interna \\
\hline $\mathrm{CV}$ & - & Campo visual \\
\hline CV 10-2 & - & Campo visual Humphrey® estratégia 10-2 \\
\hline CV 24-2 & - & Campo visual Humphrey® estratégia 24-2 \\
\hline $\mathrm{dB}$ & - & Decibéis \\
\hline $\mathrm{dF}$ & - & Domínio Fourier \\
\hline $\mathrm{F}$ & - & Feminino \\
\hline $\mathrm{Fd}$ & - & Fourier domain \\
\hline GEE & - & Generalized Estimating Equations \\
\hline GPAA & - & Glaucoma Primário de Ângulo Aberto \\
\hline HCFMUSP & - & $\begin{array}{l}\text { Hospital das Clínicas da Faculdade de Medicina da Universidade } \\
\text { de São Paulo }\end{array}$ \\
\hline $\mathrm{HN}$ & - & Hemicampo nasal \\
\hline RT & - & Heidelberg retinal tomography \\
\hline
\end{tabular}




\begin{tabular}{|c|c|c|}
\hline HT & - & Hemicampo temporal \\
\hline M & - & Masculino \\
\hline MD & - & Mean deviation \\
\hline $\mathrm{mmHg}$ & - & Milímetros de mercúrio \\
\hline NI & - & Nasal inferior \\
\hline $\mathrm{NO}$ & - & Nervo óptico \\
\hline NS & - & Nasal superior \\
\hline OD & - & Olho direito \\
\hline $\mathrm{OE}$ & - & Olho esquerdo \\
\hline PEV & - & Potencial Evocado Visual \\
\hline PEV-mf & - & Potencial evocado visual multifocal \\
\hline PEV-mf central & - & Potencial evocado visual multifocal central \\
\hline PEV-mf global & - & Potencial evocado visual multifocal global \\
\hline PEV-pr & - & Potencial evocado visual campo total \\
\hline $\mathrm{PIO}$ & - & Pressão intra-ocular \\
\hline ROC & - & Receiver Operating Characteristic \\
\hline TCO & - & Tomografia de coerência óptica \\
\hline TCO-1 & - & Tomografia de coerência óptica de primeira geração \\
\hline TCO-2 & - & Tomografia de coerência óptica de segunda geração \\
\hline TCO-3 & - & Tomografia de coerência óptica de terceira geração \\
\hline TCO-4 & - & Tomografia de coerência óptica de quarta geração \\
\hline $\mathrm{TD}$ & - & Time domain \\
\hline TI & - & Temporal inferior \\
\hline TS & - & Temporal superior \\
\hline $1 / \mathrm{L}$ & - & 1/Lambert \\
\hline
\end{tabular}




\section{LISTA DE FIGURAS}

Figura 1: Onda trifásica captada no exame de PEV-pr, onde são medidas duas deflexões negativas aos 75 ms e aos 135 ms (N75 e N135) e uma deflexão positiva aos $100 \mathrm{~ms}(\mathrm{P} 100)^{[74]}$

Figura 2: A- Tela de estimulação do PEV-mf que apresenta 60 setores escalonados com intuito de estimular áreas equivalentes no córtex occipital. B- Exemplo do padrão de estímulo de cada setor escalonado que sofrem variação pseudorandômica durante o período de aquisição do sinal. C- Resposta captada na região occipital gerada pelo estímulo ${ }^{[79]}$

Figura 3: Exemplo de aquisição de TCO captada ao redor do NO para obtenção da medida da espessura da CFNR peripapilar

Figura 4: Exemplo de aquisição de TCO captada por escaneamento de forma cúbica para obtenção da espessura macular em quadrados

Figura 5: Demonstração esquemática dos marcos anatômicos para realização dos exames eletrofisiológicos. Na figura está representada a linha média que liga o Nasion ao Inion, sendo identificados os pontos de referência $\mathrm{Fz} \mathrm{a} \mathrm{30 \% ,} \mathrm{Cz} \mathrm{a} 50 \%$ e Oz a $10 \%$ da distância medida na linha média estabelecida por estes marcos anatômicos e utilizados no exame de PEV-pr ${ }^{[74]}$

Figure 6: A- Representação esquemática da tela em xadrez de estímulo do PEV-

mf. B- Posicionamento dos eletrodos e os canais de respostas obtidas pelo exame

Figure 7: A-B Demonstração esquemática dos locais de resposta do CV 24-2 (a esquerda) e das respostas obtida no PEV-mf global (a direita) nos quadrantes (linha de cima, A ) e hemicampos (linha de baixo, B). C-D Demonstra o local das respostas do CV 10-2 (esquerda) comparado com o PEV-mf central (a direita) para os quadrantes (linha de cima, C ) e para os hemicampos (linha de baixo, D)....

Figure 8: Observa-se no alto à esquerda o paciente confortavelmente sentado com a coluna apoiada durante o exame de PEV-mf. No alto à direita, observa-se a distância do paciente de $30 \mathrm{~cm}$ do monitor de estimulação e, na imagem abaixo, pode-se observar a distribuição dos eletrodos na região occipital do paciente 


\section{LISTA DE TABELAS}

Tabela 1: Dados de idade, sexo, olho do estudo, acuidade visual e CV 24-2 em 21 pacientes (27 olhos) com defeito de CV temporal secundário a compressão quiasmática

Tabela 2: Valores médios ( \pm desvio padrão) da amplitude das respostas P1 e N2 $(\mathrm{em} \mu \mathrm{V})$ do PEV-mf global em 27 olhos de pacientes portadores de AB e em 43 olhos de controles normais com suas respectivas áreas sob a curva "receiver operating characteristic"(AROC)

Tabela 3: Valores médios ( \pm desvio padrão) da amplitude das respostas P1 e N2 $(\mathrm{em} \mu \mathrm{V})$ do PEV-mf central em 27 olhos de pacientes portadores de AB e em 43 olhos de controles normais com suas respectivas áreas sob a curva "receiver operating characteristic" (AROC)

Tabela 4: Valores médios ( \pm desvio padrão) da latência das respostas P1 e N2 (em ms) do PEV-m global em 27 olhos de pacientes portadores de AB e em 43 olhos de controles normais

Tabela 5: Valores médios ( \pm desvio padrão) da latência das respostas P1 e N2 (em ms) do PEV-mf central em 27 olhos de pacientes portadores de AB e em 43 olhos de controles normais

Tabela 6: Comparação entre a média \pm desvio padrão das medidas do CV 24-2 e 10-2 entre os pacientes portadores de $\mathrm{AB}$ e os controles normais.

Tabela 7: Correlação entre os parâmetros das amplitudes do PEV-mf global e central com os parâmetros de sensibilidade calculados a partir do CV 24-2 e do CV $10-2$

Tabela 8: Valores médios ( \pm desvio padrão) da espessura da CFNR peripapilar e da espessura macular (em $\mu \mathrm{m}$ ) obtidas pelo TCO em 27 olhos de pacientes portadores de $\mathrm{AB}$ e em 43 olhos de controles normais com suas respectivas áreas sob a curva "receiver operating characteristic" (AROC).

Tabela 9: Correlação entre os parâmetros de espessura macular da TCO e os parâmetros de sensibilidade calculados a partir dos 68 pontos de teste do CV 10-2 (perimetria subjetiva).

Tabela 10: Correlação entre os parâmetros de espessura macular da TCO e os parâmetros de sensibilidade calculados a partir das 24 respostas de amplitude em $\mu$ Volts da perimetria objetiva central (PEV-mf central) 


\section{LISTA DE GRÁFICOS}

Gráfico 1: Representação esquemática da curva ROC para um determinado teste diagnóstico

Gráfico 2: Gráfico de barras demonstrando a proporção de pacientes portadores de hemianopsia temporal $\mathrm{x}$ controles normais quanto ao sexo e lateralidade dos olhos estudados

Gráfico 3: Gráficos de dispersão das médias temporais (hemicampo e quadrantes) da perimetria objetiva 24-2 (PEV-mf global) em $\mu$ Volts para amplitude de P1 (coluna da esquerda) e para amplitude de N2 (coluna da direita) plotadas contra as médias da sensibilidade da perimetria subjetiva CV 24-2 em escala logarítmica (decibéis). Em cada gráfico de dispersão é dado o valor da correlação de Spearman (r) e a significância da associação (p)

Gráfico 4: Gráficos de dispersão das médias temporais (hemicampo e quadrantes) da perimetria objetiva 24-2 (PEV-mf global) em $\mu$ Volts para amplitude de P1 (coluna da esquerda) e para amplitude de N2 (coluna da direita) plotadas contra as médias da sensibilidade da perimetria subjetiva CV 24-2 em escala linear (1/Lambert). Em cada gráfico de dispersão é dado o valor da correlação de Pearson (r) e a significância da associação (p) 


\section{RESUMO}

Sousa RM. Potencial evocado visual multifocal em olhos com hemianopsia temporal por compreesão quiasmática. Correlação com a perimetria computadorizada e a tomografia de coerência óptica [Tese]. São Paulo: Faculdade de Medicina, Universidade de São Paulo; 2017. 75p.

OBJETIVO: Avaliar a capacidade do potencial visual evocado multifocal (PEV-mf) em diferenciar pacientes portadores de hemianopsia temporal de controles normais e avaliar a correlação entre o PEV-mf, o campo visual $(\mathrm{CV})$ realizado com a perimetria automatizada e a tomografia de coerência óptica de domínio fourier (TCO-dF). MÉTODOS: Vinte sete olhos de 21 pacientes com defeito de campo visual temporal secundário a compressão quiasmática e 43 olhos de 23 controles normais foram submetidos aos exames PEV-mf, CV e TCO-dF (3D OCT-1000 ${ }^{\circledR}$, Topcon) da mácula e da camada de fibras nervosas da retina (CFNR). Foi calculada a média das respostas do PEV-mf global, do PEV-mf central e a média de espessura do TCO-dF da mácula para cada quadrante e para cada hemicampo, enquanto a espessura da CFNR foi dividida em 12 setores ao redor do nervo óptico. A perda de CV foi calculada para os quatro quadrantes e para os hemicampos temporal e nasal no CV 24-2 e CV 10-2. Os dois grupos foram comparados utilizando equações de estimativas generalizadas (GEE) e as correlações entre o PEV-mf, CV e o TCO-dF foram calculadas. RESULTADOS: As médias das amplitude P1 e N2 do PEV-mf global e central para os hemicampos e os quadrantes temporais foram significativamente menores nos pacientes que nos controles ( $p<0.004)$. Não houve diferença estatística entre os grupos para os parâmetros de amplitudes do PEV-mf nos setores nasais. Não houve diferença estatística nas médias das latências do PEV-mf global e central entre os pacientes e os controles normais. Foi encontrada correlação moderada, estatisticamente significativa, entre os parâmetros de amplitudes temporais do PEV-mf - global e central com a perda de CV 24-2 e 10-2 temporal, assim como com as medidas de espessura macular e da espessura CFNR na TCO-dF. CONCLUSÕES: As médias das amplitudes do PEV-mf foram capazes de diferenciar olhos de pacientes com hemianopsia dos controles normais e apresentaram correlação significativa com os dados obtidos pela perimetria automatizada e pelo TCOdF. Estes dados sugerem que o PEV-mf global e central podem ser utilizados na detecção de anormalidades do campo visual em pacientes portadores de compressão quiasmática.

Descritores: Atrofia óptica/diagnóstico; Quiasma óptico/patologia; Fibras nervosas/patologia; Testes de campo visual/métodos; Tomografia de coerência óptica/métodos; Potenciais evocados visuais 


\begin{abstract}
Sousa RM. Multifocal visual evoked potential in eyes with temporal hemianopia from chiasmal compression. Correlation with standard automated perimetry and OCT findings [thesis]. São Paulo: "Faculdade de Medicina, Universidade de São Paulo"; 2017. 75p.
\end{abstract}

PURPOSE: To evaluate the ability of multifocal visual evoked potential (mfVEP) to differentiate patients with temporal hemianopia due to chiasmal compression from normal controls. To assess the relationship between mfVEP, standard automated perimetry (SAP) and fourier domain-optical coherence tomography (fd-OCT). METHODS: Twenty-seven eyes of 21 patients with permanent temporal visual field (VF) defects from chiasmal compression and 43 eyes of 23 healthy controls underwent mfVEP, SAP and fd-OCT (3D OCT-1000®, Topcon) macular and peripapillary retinal nerve fiber layer (RNFL) measurements. It was averaged the responses for global mfVEP, central mfVEP and fd-OCT macular measurements were averaged in quadrants and halves, while peripapillary RNFL thickness was averaged in 12 sectors around the disc. VF loss was estimated in four quadrants and each half of 24-2 and 10-2 strategy test points. The two groups were compared using generalized estimated equations (GEE). Correlations between mfVEP, VF and fd-OCT findings were verified. RESULTS: Global and central mfVEP P1 and N2 amplitude parameters of temporal measurements were significantly smaller in patients than controls $(\mathrm{p}<0.004)$. No significant differences were observed between the groups with respect to mfVEP amplitude parameters from the nasal measurements. No significant differences were observed in global and central mfVEP latency parameters for all averaged measurements between patients and healthy controls. A significant moderate correlation was found between global and central mfVEP amplitude parameters of temporal measurements and temporal VF 24-2 and 10-2 loss as well as with corresponding fd-OCT macular and RNFL thickness measurements. CONCLUSIONS: mfVEP amplitude parameters were able to differentiate eyes with temporal hemianopia from controls and were significant correlated with VF and fd-OCT findings. These data suggest that it is a useful technology for detecting visual abnormalities in patients with chiasmal compression.

Descriptors: Optic atrophy/diagnosis; Optic chiasm/pathology; Nerve fibers/pathology; Visual field tests/methods; Tomography, Optical coherence/methods; Evoked potentials, Visual 
1 INTRODUÇÃO 
Vários tipos de afecções podem causar danos para a via óptica anterior, entre elas, lesões compressivas, isquêmicas, inflamatórias, infiltrativas e traumáticas. Lesões compressivas são as que mais comumente acometem o quiasma óptico, destacando-se particularmente, os tumores supra-selares como adenomas hipofisários, o craniofaringioma e o meningioma supra-selar. ${ }^{[1]}$ Os tumores hipofisários, quase sempre adenomas, representam 7 a 17,8\% dos tumores intracranianos e pela sua freqüência merecem destaque entre as afecções que acometem a via óptica. ${ }^{[1]}$ Adenomas pituitários com diâmetro maior que $10 \mathrm{~mm}$, são denominados macroadenomas e podem apresentar além do quadro endócrino, sinais e sintomas decorrentes da compressão quiasmática.

Os tumores supra-selares que comprimem o quiasma óptico comumente levam à disfunção visual em ambos os olhos. Dentre as funções visuais acometidas, merece destaque o campo visual (CV), tanto no diagnóstico como para seguimento da doença. O defeito campimétrico característico das afecções quiasmáticas compressivas é a hemianopsia bitemporal, que pode ser completa ou incompleta. Apesar da perimetria computadorizada ser o exame padrão ouro no acompanhamento funcional da perda visual dos pacientes portadores de compressão quiasmática, é um exame subjetivo que depende da colaboração do paciente e pode apresentar parâmetros de confiabilidade insuficientes para a interpretação em pacientes pouco colaborativos ou com alterações motoras que atrapalhem o exame. Por outro lado, o Potencial Evocado Visual Multifocal (PEV-mf) não precisa de curva de aprendizado para sua realização e é um exame objetivo que reconstrói o CV através das ondas eletro-encefálicas. Estas ondas captadas no córtex occipital são obtidas por estímulos pré-estabelecidos feitos 
por uma tela em xadrez. No PEV-mf ocorre diminuição de amplitude e aumento da latência na neuropatia óptica compressiva na fase ativa, podendo levar a alterações mais precoces de perda de campo no PEV-mf, antes da alteração de sensibilidade ser detectada na perimetria computadorizada ${ }^{[2]}$. Além disso, em pacientes portadores de neuropatia óptica compressiva sequelar, foi demonstrada redução na amplitude de resposta do PEV-mf, apresentando correlação forte com os achados da perimetria computadorizada no quadrante temporal superior e correlação moderada com o quadrante temporal inferior ${ }^{[3]}$.

Somado aos achados da perda de CV, a investigação dos pacientes portadores de neuropatia óptica compressiva deve ser complementada com métodos neuroradiológicos que são fundamentais na avaliação da extensão da lesão compressiva do quiasma, sendo a imagem por ressonância magnética o principal exame de imagem para seguimento e esclarecimento diagnóstico dos tumores que afetam o quiasma ${ }^{[4]}$.

Por outro lado, existem dados objetivos que permitem estimar a possibilidade de melhora visual após o tratamento de um paciente com tumor supra-selar através de observações fundoscópicas do disco óptico e da camada de fibras nervosas da retina $(\mathrm{CFNR})^{[5-7]}$. A presença de atrofia óptica e da diminuição da CFNR são indicativos importantes da perda neural irreversível. Desta forma, foi observado que a presença de uma espessura maior da CFNR medida pela tomografia de coerência óptica (TCO) da retina correlaciona-se significativamente com uma maior recuperação da acuidade visual e de sensibilidade da perimetria automatizada após o tratamento cirúrgico ${ }^{[8]}$. Entretanto, a analise do grau de atrofia óptica é menos fidedigno para ser correlacionado ao resultado funcional após o tratamento destes pacientes ${ }^{[9]}$. Outro dado que se correlaciona com melhor resposta ao tratamento cirúrgico é idade mais jovem e menor tempo de duração dos sintomas ${ }^{[9-12]}$. Estes dados demonstram que é 
fundamental o conhecimento da disposição geral das CFNR em indivíduos normais e as alterações que nela ocorrem nas afecções da via óptica anterior.

A disposição geral da CFNR usualmente segue padrões predefinidos. Observase na fundoscopia utilizando filtro verde em indivíduos normais que a CFNR é mais visível na arcada temporal inferior, seguida da arcada temporal superior, da arcada nasal superior e por fim da arcada nasal inferior ${ }^{[6,13]}$. Este achado correlaciona-se com a localização levemente inferior da fovéola de $0,53+/-0,34 \mathrm{~mm}$ ao avaliar o posicionamento vertical passando pelo eixo do nervo óptico (NO), o que justifica uma maior espessura da CFNR na arcada temporal inferior ${ }^{[13]}$. Os axônios da camada ganglionar localizados no setor nasal ao NO se projetam de forma radial ao NO, ao passo que os axônios da CFNR do setor temporal ao NO seguem uma trajetória arqueada ao redor da fóvea na direção do $\mathrm{NO}^{[6]}$. Este arqueamento da CFNR temporal é dividida em superior e inferior respeitando a rafe horizontal que se estende da fovéola até a periferia da retina e desta forma estas fibras temporais adentram os polos verticais do $\mathrm{NO}^{[6]}$. Por outro lado, o feixe papilomacular formado mais cedo no olho embrionário, adentra diretamente, após leve arqueamento, o setor temporal do $\mathrm{NO}^{[6,14]}$. Este padrão de disposição correlaciona-se significativamente com o achado que a espessura da CFNR do NO é maior no polo inferior, seguido pelo polo superior, pelo setor nasal e, por fim, pelo setor temporal do disco óptico ${ }^{[6,13]}$.

O CV apresenta um padrão retinotópico caracterizado pela divisão da retina nasal e temporal por uma linha vertical que passa pela fóvea e não pelo NO, sendo este padrão observado em diversos estudos e demonstrando correspondência com o mapa topográfico obtido no córtex occipital através de estudos experimentais e de neuroradiologia ${ }^{[15-17]}$. A CFNR originada nasalmente à fóvea cruza no quiasma óptico, ao passo que a CFNR originada no setor temporal a fóvea não cruza ${ }^{[18,19]}$. 
O conhecimento destas particularidades anatômicas é de fundamental importância para compreensão das alterações observadas clinicamente em diversas afecções da via óptica.

Nas afecções quiasmáticas de longa duração, a observação fundoscópica revela uma palidez do disco óptico "em banda", ou seja, nos setores nasal e temporal, além de uma diminuição do aspecto estriado da CFNR nos mesmos setores ${ }^{[20]}$. $\mathrm{O}$ fato das fibras nasais que se cruzam no quiasma óptico ocuparem principalmente, os setores nasal e temporal do disco óptico é a justificativa para este achado fundoscópico. Entretanto, apesar da preservação das fibras da hemi-retina temporal que penetram o disco óptico pelas arcadas superior e inferior, ocorre também diminuição da CFNR dos polos verticais do NO, uma vez que parte das fibras destes setores também se origina da hemi-retina nasal acometidas nas afecções do quiasma óptico ${ }^{[21]}$.

Devido à importância da avaliação da CFNR, formas objetivas de sua análise foram desenvolvidas, como a documentação fotográfica utilizando filme branco e preto de alto contraste ${ }^{[22]}$. No entanto, esta técnica depende da experiência do examinador para sua obtenção, reprodutibilidade e interpretação. Com isso, a cada dia aumenta a busca por métodos que permitam avaliar objetivamente a CFNR e integridade da via óptica com máxima precisão. Dentre os instrumentos utilizados para avaliar a CFNR e a integridade da via óptica, se destacam o analisador de fibras nervosas (AFN; nerve fiber analizer - GDx® -(Laser Diagnostic Technologies, Inc), as TCOs de domínio Fourier (TCO-dF), o eletrorretinograma de padrão reverso, o potencial evocado visual de padrão-reverso (PEV-pr) e o PEV-mf.

Ao longo dos últimos anos, diversos estudos de correlação estrutura-função foram desenvolvidos no sentido de melhor avaliar afecções que acometem a via óptica anterior ${ }^{[23-25]}$. O método de avaliação estrutural de maior destaque na analise de perdas da CFNR é a TCO que vem sendo aplicado na detecção de perdas em diversas 
afecções da via óptica anterior, como o glaucoma, neuropatia óptica isquêmica e nas neuropatias compressivas das vias ópticas ${ }^{[26-28]}$. Por outro lado, para avaliação funcional, a principal técnica utilizada é a perimetria computadorizada, sendo um exame rápido, de baixo custo, que tem grande utilidade para quantificar a perda de sensibilidade e acompanhar a evolução das doenças que acometem a via óptica anterior, apesar de quantificar as alterações visuais de forma subjetiva ${ }^{[23,29,30]}$. O resultado da perimetria computadorizada depende da colaboração do paciente em responder de forma confiável aos estímulos luminosos padronizados projetados sobre uma cúpula padrão de exame, sendo um exame subjetivo de avaliação do CV.

Outra forma de avaliar a integridade da via óptica anterior é através de exames eletrofisiológicos que permitam quantificar de forma objetiva alterações de resposta de CV. Recentemente, alguns estudos de eletrofisiologia demonstraram a capacidade do PEV-mf detectar progressão no glaucoma ${ }^{[31]}$, e de detectar a redução na amplitude das respostas do PEV-mf em casos de neuropatia óptica compressiva ativa e sequelar ${ }^{[2,3]}$. Além disso, alguns estudos já demonstraram uma boa correlação entre as respostas obtidas no PEV-mf e as perdas de CV quantificadas pela perimetria computadorizada $^{[32]}$.

A correlação entre as respostas centrais do PEV-mf, do CV Humphrey estratégia 10-2 (CV 10-2) e da TCO macular foi avaliada em pacientes portadores de glaucoma, demonstrando boa concordância entre os dados obtidos pelos exames ${ }^{[33]}$. Contudo, poucos estudos avaliaram a correlação entre o PEV-mf, a perimetria computadorizada e as medidas da CFNR obtidos na TCO em pacientes com hemianopsia bitemporal secundária a neuropatia compressiva. Além disso, nenhum estudo avaliou a correlação existente entre a resposta central do PEV-mf com os dados de CV 10-2 e das medidas de espessura macular obtida com a TCO nestes pacientes. 
2 OBJETIVOS 


\subsection{Geral}

Avaliar o desempenho diagnóstico do PEV-mf em olhos de pacientes com neuropatia óptica compressiva quiasmática sequelar e com hemianopsia bitemporal.

\subsection{Específicos}

1. Avaliar a capacidade do PEV-mf de diferenciar olhos normais daqueles de pacientes com neuropatia óptica compressiva quiasmática.

2. Avaliar a correlação entre os achados do PEV-mf global e os do CV Humphrey estratégia 24-2 (CV 24-2) e a correlação entre os achados do PEV-mf central e aqueles do CV 10-2.

3. Correlacionar os achados do PEV-mf global com os dados obtidos a partir do CV 24-2 e com os dados obtidos da TCO da CFNR peripapilar.

4. Correlacionar os achados do PEV-mf central com os dados da TCO de espessura macular em hemicampos e quadrantes, assim como com a espessura da CFNR peripapilar e com os dados do CV 10-2. 


\section{REVISÃO DE LITERATURA}


Nas síndromes quiasmáticas a perda visual geralmente é uma das primeiras manifestações a ocorrer e deve ser investigada de forma atenta pelo exame do CV, comumente realizado pela perimetria computadorizada, geralmente, usando-se a estratégia 24-2 $2^{[4]}$. Além disso, é necessário nestes casos complementar a investigação das causas de lesões quiasmáticas através de protocolos de aquisição de imagem por ressonância magnética com e sem contraste que permitam esclarecer a etiologia, sendo as mais frequentes as causas compressivas ${ }^{[4,34]}$. Os avanços tecnológicos tem permitido maior entendimento da correlação estrutura-função da via óptica anterior em diversas doenças, como o glaucoma, as doenças desmielinizantes e as neuropatias compressivas, fornecendo maior arsenal de exames complementares para o diagnóstico e acompanhamento de indivíduos com tais lesões ${ }^{[35-37]}$. Neste sentido, os estudos de exames complementares de avaliação estrutural da integridade da via óptica anterior, assim como os exames eletrofisiológicos vem ganhando destaque na investigação de lesões da via óptica anterior.

Um dos métodos mais utilizados para quantificação da CFNR é a TCO, uma técnica de obtenção de imagem não-invasiva, de não-contato e transpupilar, que usa um interferômetro com luz de baixa coerência, próxima da faixa da luz infravermelha $(810 \mathrm{~nm})$ gerada por uma fonte de Diodo. A TCO produz imagens unidimensionais, bidimensionais e tridimensionais de corte coronal ou "en face" da retina com resolução de 3-10 mícrons de onde se pode medir a espessura da CFNR e a espessura macular ${ }^{[38-41]}$. De forma simplificada, pode-se dizer que a TCO utiliza a luz refletida do tecido estudado para gerar imagens da mesma maneira que a ecografia utiliza o som $^{[42]}$. 
A espessura da CFNR é quantificada através de um algoritmo computadorizado, que identifica as bordas anterior e posterior da CFNR. Os dados são apresentados em quadrantes, em horas e na média global e calculados por um software existente no própria $\mathrm{TCO}^{[43]}$. Atualmente, existem dois tipos de aparelhos: o tomógrafo Stratus que utiliza a tecnologia domínio do tempo (Time Domain) e vários aparelhos que utilizam a tecnologia de domínio Fourier (Tecnologia Fourier Domain) ${ }^{[38,44]}$. Estes aparelhos funcionam através da emissão de dois feixes de laser, um feixe irá incidir sobre o tecido estudado e outro será direcionado a um espelho de referencia, estes feixes de luz, após refletirem na superfície, seja do tecido ou no espelho de referência, retornam e combinam-se sofrendo um fenômeno conhecido como interferência. A mensuração desta interferência permite a reconstrução da imagem no aparelho, sendo que no time domain o espelho de referencia é móvel e no fourier domain o espelho é fixo, porém o principio matemático da transformada de Fourier permitiu uma maior velocidade e melhor qualidade na aquisição da imagem quando comparado ao time domain ${ }^{[38,44]}$.

Vários trabalhos já mostraram a importância diagnóstica da TCO na avaliação da CFNR em paciente com glaucoma ${ }^{[45-47]}$ e também nas afecções quiasmáticas. Monteiro et al. ${ }^{[48]}$ estudaram a perda de CFNR em olhos com atrofia em banda por compressão quiasmática usando a TCO, na sua versão comercial inicial (TCO-1). Esse estudo mostrou que a TCO, na sua versão comercial inicial (TCO-1) foi capaz de identificar a perda axonal nos quatro quadrantes, bem como em cada um dos 12 segmentos de $30^{\circ}$ do disco óptico dos pacientes com atrofia em banda do NO quando comparados com controles normais. Este achado foi confirmado por Kanamori et al. ${ }^{[49]}$ que também verificaram a habilidade da TCO de detectar o padrão de perda da CFNR nos olhos com atrofia em banda (AB). Os autores encontraram valores para CFNR (média e por setores) semelhantes aos encontrados por Monteiro et $\mathrm{al}^{[48]}$. Além disso, baseados na área sob a 
curva ROC ("receiver operating characteristic"), demonstraram que a CFNR horizontal (setores nasal e temporal) sofre uma diminuição mais importante do que a CFNR vertical (setores superior e inferior) em olhos com atrofia em banda do $\mathrm{NO}^{[49]}$.

Estudos posteriores compararam diretamente em um grupo maior de olhos os resultados da TCO-1, do GDx e da TCO-3 mostrando a superioridade da TCO sobre o GDx e da TCO-3 sobre a TCO- ${ }^{[50]}$. Foi observado também que a TCO-3 produz resultados significativamente diferentes da TCO-1 ${ }^{[51]}$. No entanto, ao comparar a TCO-dF com a TCO-3 (Time Domain), observou-se similaridade na habilidade de discriminar os pacientes portadores de $\mathrm{AB}$ entre as duas tecnologias, apesar da espessura da CFNR e da região macular ter sido menor na TCO- $\mathrm{dF}^{[52]}$.

Como citado anteriormente, outra habilidade da TCO é de quantificar a espessura macular. A mácula corresponde a uma área circular ao redor do centro da fóvea com cerca de 4-5 mm de diâmetro, na qual se encontram, aproximadamente, $50 \%$ das células ganglionares da retina $(\mathrm{CGR})^{[53]}$, com um pico de densidade ocorrendo 750-1100 micras do centro da fóvea, onde a densidade celular pode estar arranjada em 4-6 camadas de células ganglionares ${ }^{[54]}$. Portanto, a camada de CGR juntamente com a CFNR contribuem com 30-35\% da espessura retiniana da região macular ${ }^{[55]}$. A diminuição da espessura macular no glaucoma é atribuída, principalmente, à atrofia das CGR e CFNR ${ }^{[56]}$.

Em pacientes portadores de compressão quiasmática ativa, já foi demonstrado que a diminuição de espessura da CFNR peripapilar medida pela TCO antes e após a resseção cirúrgica indica, de forma estatisticamente significante, um pior resultado funcional de recuperação da acuidade visual e da sensibilidade em decibéis do CV 24-2 nestes pacientes ${ }^{[5]}$. Estes achados estão em concordância com estudo realizado em portadores de compressão quiasmática sequelar que demonstrou a existência de boa correlação entre a espessura da TCO na CFNR peripapilar e da espessura macular total com os dados da perimetria computadorizada em seis setores do CV 24-2 e nos 
16 pontos centrais do CV 24-2, respectivamente ${ }^{[57]}$. Neste estudo foi demonstrado que a melhor correlação estrutura-função foi encontrada entre a espessura macular total no quadrante nasal inferior com a perda de $\mathrm{CV}$ central temporal superior ${ }^{[57]}$. Recentemente, Akashi A et al. demonstraram que a segmentação da região macular obtida na TCO da espessura da CFNR macular (CFNR-m), da camada de CGR mais a camada plexiforme interna $(\mathrm{CCG}+)$ e $\mathrm{CCG}++(\mathrm{CFNR}-\mathrm{m}+\mathrm{CCG}+)$ tiveram boa habilidade em diferenciar os portadores de lesões compressivas quiasmáticas dos controles normais, sendo maior essa habilidade ao utilizar os parametros de espessura macular interna da hemirretina nasal do que da hemiretina temporal, o que é esperado devido ao padrão de perda de fibras nervosas encontrado nessa afecção ${ }^{[58]}$. Neste sentido, Monteiro et al além de demonstrarem que a CFNR-m e a CCG+ se correlacionam fortemente com a perda visual nos 16 pontos centrais do CV 24-2, também observaram que a camada nuclear interna (CNI) no hemicampo nasal é maior no pacientes do que nos controles, sendo identificados microcistos nessa camada uma porcentagem significativa dos pacientes e em nenhum dos controles ${ }^{[59]}$. Ainda faltam mais estudos para entender o significado clínico desse espessamento na CNI e a presença destes microcistos na CNI, os quais ocorrem em outras neuropatias do $\mathrm{NO}^{[60-68]}$.

Todos os estudos acima evidenciam a capacidade da avaliação através da TCO dos olhos com perda axonal decorrente de compressão quiasmática bem como de outras afecções da via visual anterior. No entanto, ainda se observam dificuldades na semiologia destas afecções já que existe uma superposição muito grande de valores normais com aqueles de pacientes com formas mais discretas de AB. Desta forma, o aperfeiçoamento do método com novos protocolos de análise e com versões mais novas e com melhor resolução se faz necessário.

Outra forma de se avaliar a função da CFNR, da camada de CGR e a integridade da via óptica é através de testes eletrofisiológicos ${ }^{[69-72]}$. O PEV-pr tem como função básica a avaliação da integridade na condução dos estímulos na via óptica, além de 
fornecer dados para a medida estimada da acuidade visual dos pacientes examinados ${ }^{[73]}$, sendo constituído pelo o potencial elétrico oriundo da retina e captado no córtex occipital. O exame é realizado utilizando-se estímulos estruturados constituídos por quadrados brancos e pretos que se revertem de forma pré-definida. A resposta resultante é uma onda promediada trifásica com duas deflexões negativas ao redor de 75 e 135 mseg e uma deflexão positiva ao redor de 100 mseg (Figura 1), denominadas de $\mathrm{N}_{75}, \mathrm{~N}_{135}$ e $\mathrm{P}_{100}$. Esta última sofre pouca variação inter-ocular e inter-individual, mas apresenta variação com a idade e sexo ${ }^{[73,74]}$. Uma onda única é gerada pela estimulação da área central da retina $\left(15^{\circ}\right)$ constituindo portanto resposta de massa, sendo esta onda típica do PEV-pr (Figura 1) similar em morfologia as ondas obtidas nos setores do PEV-mf e a compreensão desta morfologia serve de base para interpretação das respostas obtidas no exame de PEV-mf e que apresentam amplitudes menores.

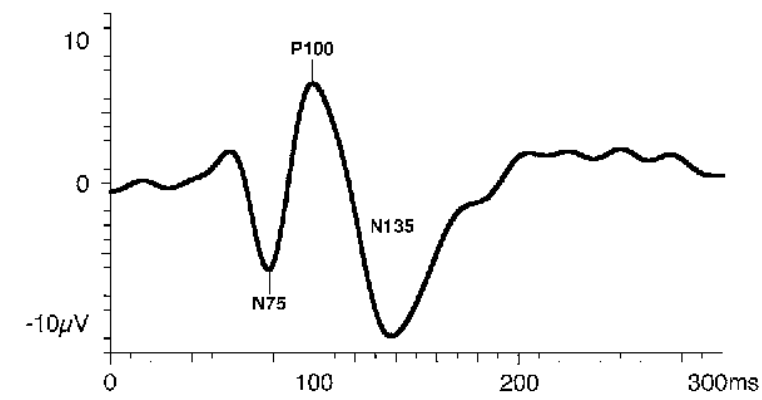

Figura 1: Onda trifásica captada no exame de PEV-pr, onde são medidas duas deflexões negativas aos 75 ms e aos 135 ms (N75 e N135) e uma deflexão positiva aos $100 \mathrm{~ms}(\mathrm{P} 100)^{[74]}$

Atualmente, o desenvolvimento da perimetria objetiva tem sido impulsionado devido a necessidade de exames de avaliação do CV mais objetivos, pois a perimetria convencional depende muito da colaboração do paciente e apresenta um efeito aprendizado na sua realização ${ }^{[75]}$. A perimetria objetiva é constituída pelo registro 
simultâneo de múltiplas ondas de potenciais evocados visuais gerados através da estimulação retiniana e conduzidos pela via óptica ao córtex visual (área 17,18 e $19)^{[73,76,77]}$. Denominado de PEV-mf é realizado utilizando-se os mesmos princípios estabelecidos para o Eletrorretinograma multifocal ${ }^{[76,78]}$.

$\mathrm{O}$ registro do PEV-mf é formado por um conjunto de pequenas respostas de PEV dispostas como um mapa semelhante ao do CV. O estímulo é constituído por um padrão circular composto por 60 tabuleiros, com 16 quadrados (08 pretos e 08 brancos), escalonados considerando-se a magnificação cortical da representação retiniana (Figura 2-A). Através da reversão dos quadrados brancos e pretos, numa variação pseudo-randômica a cada 13,3 mseg, estimula-se os 25 graus centrais da retina. Cada setor apresenta uma sequência predefinida de alternância dos quadrados brancos e pretos e tem uma probabilidade de 0,5 de se alternarem ou permanecerem estacionários a cada mudança do frame (Figura 2-B , 2-C) ${ }^{[79]}$, gerando múltiplas respostas corticais. Este exame permite uma correlação direta com os pontos do CV subjetivo (perimetria automatizada padrão) ${ }^{[79]}$.

B.

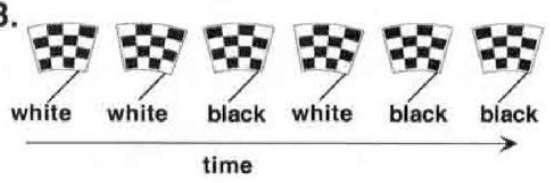

C.
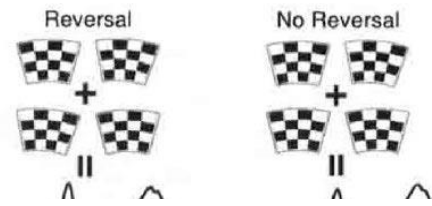

B.

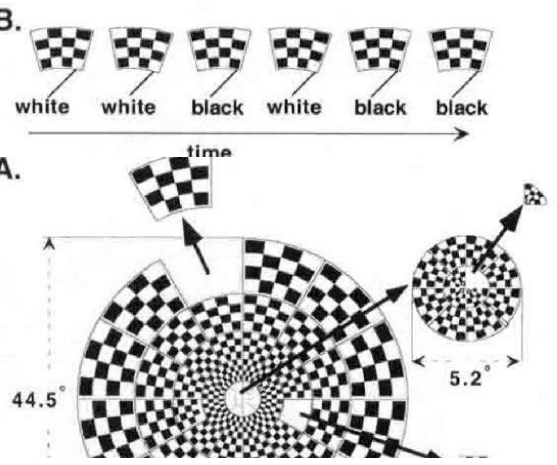

Figura 2: A- Tela de estimulação do PEV-mf que apresenta 60 setores escalonados com intuito de estimular áreas equivalentes no córtex occipital. B- Exemplo do padrão de estímulo de cada setor escalonado que sofrem variação pseudo-randômica durante o período de aquisição do sinal. C- Resposta captada na região occipital gerada pelo estímulo $^{[79]}$ 
Apesar de ter sido descrito atraso na resposta do PEV há cerca de 40 anos em pacientes com neurite óptica e esclerose múltipla ${ }^{[80,81]}$, somente com o desenvolvimento do PEV-mf baseado no eletrorretinograma multifocal de $\operatorname{Sutter}^{[79]}$ foi possível correlacionar os pontos de respostas do $\mathrm{CV}$ automatizado às respostas obtidas no $\mathrm{PEV}^{[76]}$. Com a introdução da análise de comparação da resposta interocular do PEV-mf foi possível a interpretação dos dados de normalidade ou não na resposta encontrada nos exames, uma vez que a resposta normal do olho direito e esquerdo são virtualmente idênticas $^{[82]}$.

Além disso, estudos em pacientes com glaucoma com avaliação monocular isolada pelo PEV-mf possibilitaram o acompanhamento objetivo deste grupo de pacientes com possível utilidade clínica ${ }^{[83-85]}$. Wangsupadilok et al. ${ }^{[31]}$ estudaram 87 pacientes com glaucoma primário de ângulo aberto (GPAA), tendo colocado no grupo I, 44 pacientes e no grupo II, 43 pacientes. Os pacientes do grupo I fizeram dois exames de PEV-mf com intervalo de 50 dias e os do grupo II com intervalo de 6 meses. No grupo II foi observado diferença no escore total da resposta entre a visita 1 e 2 tanto na comparação interocular e monocular, assim como diferença na resposta em grupo de pontos do CV (cluster) na comparação interocular, todas com significância estatística $(\mathrm{p}<0,05)$. Não ocorreu diferença entre as visitas 1 e 2 nos pacientes do grupo I, podendo se pensar na utilidade no PEV-mf no seguimento da progressão do glaucoma. Nesse sentido, um estudo recente de reprodutibilidade do PEV-mf, em pacientes portadores de GPAA e controles normais, demonstrou que o PEV-mf apresentou boa reprodutibilidade no grupo controle entre os exames com intervalo de dois anos de realização, diferente do que ocorreu nos pacientes portadores de GPAA ${ }^{[86]}$. Essa variabilidade nos portadores de glaucoma pode ser devido a progressão, instabilidade de resposta ou por ambos os motivos, demonstrando uma possível aplicação clínica na 
analise de progressão em portadores de glaucoma ${ }^{[86]}$. Já em portadores de esclerose múltipla o PEV-mf demonstrou boa reprodutibilidade similar tanto nos doentes como no grupo controle ao ser realizado periodicamente ao longo de um ano ${ }^{[87]}$.

Tendo em vista a relação estrutura e função visual, foi realizado um trabalho correlacionando os parâmetros de estrutura fornecidos pela oftalmoscopia confocal por varredura a laser (Heidelberg retinal tomography - HRT) com a resposta obtida pelo PEV-mf em pacientes portadores de GPAA e indivíduos normais. Assim, foi encontrado relação direta estatisticamente significante entre a rima neural e a média da espessura da CFNR no setor inferior do disco óptico com a amplitude obtida no hemisfério superior pelo PEV-mf. Por outro lado, observou-se correlação inversa significante entre a escavação medida no setor inferior do disco óptico com a amplitude medida no hemisfério superior pelo PEV-mf ${ }^{[88]}$. Dados similares e com significância estatística, também, foram observados ao correlacionar os valores de amplitude do hemisfério inferior obtidos pelo PEV-mf aos valores estruturais medidos no HRT no setor superior do disco óptico.

Entretanto, a perimetria objetiva é um exame que demanda muito tempo para o preparo e realização, por isso novos protocolos com o objetivo de diminuir o tempo de aquisição da resposta sem prejudicar a qualidade do estudo vêm sendo desenvolvidos. Recentemente, foi conduzido um estudo testando um protocolo de exame de 8 minutos por olho e comparando ao protocolo de rotina que dispende 16 minutos por olho em pacientes hipertensos oculares e portadores de glaucoma inicial $^{[89]}$. Observou-se concordância entre a resposta nos dois protocolos executados, tendo o protocolo de 16 minutos apresentado sensibilidade ligeiramente maior que o protocolo de 8 minutos. Porém, o protocolo de 8 minutos apresentou especificidade ligeiramente maior que o protocolo de 16 minutos, sugerindo que a redução do tempo 
de aquisição da resposta na avaliação da extensão da perda visual em pacientes com glaucoma moderado ou avançado é eficiente, podendo ser realizada em pacientes nos quais a perimetria computadorizada padrão não é confiável.

A resposta do $\mathrm{PEV}$-mf já foi comparada àquela da perimetria convencional em pacientes portadores de glaucoma e hipertensos oculares ${ }^{[32,90,91]}$, quer seja no seguimento de pacientes portadores de glaucoma após abaixar a pressão intraocular $^{[90]}$, ou na análise comparativa dos resultados obtidos entre os dois métodos em pacientes hipertensos oculares e glaucomatosos ${ }^{[32,91]}$.

Atualmente, vem sendo muito estudado o padrão de resposta ao PEV-mf em pacientes portadores de esclerose múltipla, somado aos achados de alteração estruturais na CFNR medidos com os aparelhos de TCO-3 ${ }^{[92]}$ e aos dados sobre a integridade da via óptica e sua correlação com a perimetria convencional. Esta associação de exames na avaliação de pacientes portadores de esclerose múltipla resultou em aumento da sensibilidade e especificidade na detecção do acometimento visual mesmo que sub-clínico nesta doença ${ }^{[93]}$. Aprofundando estas observações, um estudo mostrou que pacientes portadores de esclerose múltipla sem histórico de neurite óptica e que apresentavam redução de espessura da camada ganglionar da mácula pela TCO-4 ao serem submetidos ao PEV-mf, demonstraram amplitude e latência estatisticamente menor do que os controles normais, sugerindo uma aplicação do PEV-mf na detecção de neurite óptica subclínica ${ }^{[37]}$.

No entanto, apenas poucos trabalhos avaliaram a resposta ao PEV-mf em pacientes portadores de compressão na via óptica, sendo este um modelo de estudo que proporciona uma boa avaliação e permite correlacionar os defeitos detectados na perimetria convencional e as alterações observadas na TCO aos achados obtidos na resposta do PEV-mf. Os defeitos de origem compressiva da via óptica secundários ao 
meningioma, foram estudados através do PEV-mf, sendo demonstrado prolongamento de latência nas respostas ${ }^{[94,95]}$. As alterações nas respostas no PEV-mf, em pacientes com adenoma de hipófise, também, foram investigadas em poucos trabalhos, demonstrando atraso na latência e diminuição de amplitude nas respostas ${ }^{[3,96]}$. Jayaraman et al. ${ }^{[96]}$ estudaram 8 olhos de 4 pacientes portadores de compressão quiasmática correlacionando os resultados da perimetria convencional aos achados do PEV-mf, observando redução da amplitude e aumento da latência na resposta do PEV-mf. Outro trabalho, comparou o grau de concordância da resposta por quadrante entre a perimetria convencional e o PEV-mf, obtendo maior concordância entre as técnicas no quadrante súpero-temporal ao analisar 15 olhos de pacientes portadores de adenoma de hipófise com compressão quiasmática ${ }^{[3]}$. Em outro modelo de neuropatia óptica compressiva, foram estudados pacientes portadores de orbitopatia de Graves com neuropatia óptica compressiva ativa subclínica submetidos a PEV-mf e comparados os achados deste exame com os da TCO e da perimetria computadorizada, não sendo encontrada relação entre os dados obtidos pelo PEV-mf com os da TCO e da perimetria ${ }^{[97]}$.

Recentemente, foi publicado um trabalho avaliando a concordância entre a espessura da CFNR peripapilar na TCO-dF com as respostas obtidas no PEV-mf e na perimetria 30-2 em pacientes portadores de neuropatia óptica compressiva, sendo demonstrado boa concordância entre os exames de PEV-mf e a CV 30-2 e correlação moderada entre o PEV-mf e a CFNR medida pela $\mathrm{TCO}^{[98]}$. Entretanto, nesse trabalho não foram informados o número de pacientes arrolados no estudo e nem o dos controles utilizados para a analise estatística, o que prejudica sua interpretação. Por outro lado, a correlação estrutura-função entre o PEV-mf e a TCO foi melhor estudada no glaucoma, sendo que um trabalho avaliou a concordância das respostas centrais obtidas pelo PEV-mf com as medidas da área macular feito pela TCO e com as respostas da CV 10-2, tendo demonstrado boa concordância entre os exames ${ }^{[33]}$. 
O modelo de perda de CV na compressão quiasmática é muito interessante na comparação entre o PEV-mf e PEV-pr com as técnicas de avaliação do dano da via óptica, CFNR e da camada de CGR previamente descritas, como a perimetria convencional, o HRT e a tomografia de coerência óptica da retina. Neste sentido a perimetria objetiva pode agregar novas informações quanto ao comprometimento quiasmático e ajudar na tomada de conduta e seguimento dos portadores deste tipo de afecção. 
4 MÉTODOS 


\subsection{Desenho do estudo}

Estudo transversal, observacional, prospectivo e descritivo. O estudo seguiu os critérios da Declaração de Helsinki e obteve aprovação da comissão de ética para análise de projetos de pesquisa (CAPPesq) da diretoria clínica do Hospital das Clínicas da Faculdade de Medicina da Universidade de São Paulo em 2013.

\subsection{Amostra}

\subsubsection{Pacientes}

Foram estudados 27 olhos de 21 pacientes consecutivos, avaliados no período de fevereiro de 2013 até fevereiro de 2014, com defeito de CV temporal secundário a compressão quiasmática já tratados, com evidências neuro-radiológicas de compressão da via óptica no momento em que a afecção foi diagnosticada e com documentação de descompressão da via óptica após o tratamento. Os pacientes eram provenientes do serviço de neuroftalmologia do Hospital das Clínicas da Faculdade de Medicina da USP (HCFMUSP). Os pacientes foram submetidos a exame oftalmológico completo incluindo medida da AV com melhor correção, reações pupilares, biomicroscopia, tonometria de aplanação e exame fundoscópico.

Foram incluídos somente pacientes com defeito campimétrico seqüelar caracterizado por: (1) defeito campimétrico estável por pelo menos um ano; 
(2) estudo neuro-radiológico mostrando ausência de compressão ativa da via óptica. Estas informações estavam presentes nos prontuários dos pacientes de tal forma a permitir a classificação correta como defeito seqüelar. Assim, os pacientes tinham que ter sido previamente tratados e obedecer aos seguintes critérios:

\subsubsection{Critérios de inclusão}

1. Pacientes com defeito campimétrico secundário a compressão quiasmática caracterizado por defeito permanente restrito ao hemicampo temporal respeitando o meridiano vertical.

2. Idade acima de 18 anos;

3. Acuidade visual melhor que ou igual a 20/30;

4. Ausência de anormalidades oculares a não ser por erros de refração, menores que seis dioptrias esféricas e três dioptrias cilíndricas;

5. Ausência de glaucoma, opacidades de meios ou anomalias de papila;

6. Boa colaboração para os exames e exame campimétrico confiável.

\subsubsection{Critérios de exclusão}

1. Diabetes mellitus

2. Diagnóstico de doença retiniana.

3. Uso de fármacos que interfiram na condução nervosa ou que causem lesões maculares como cloroquina e hidroxicloroquina.

4. Condições médicas ou psicológica que impeçam o paciente de concluir o estudo ou assinar o consentimento informado.

5. Exame de CV 24-2 apresentando alteração no hemicampo nasal com três ou mais pontos contíguos dentro do mesmo hemicampo com PSD com $\mathrm{P}<1 \%$, pelo menos um deles com $\mathrm{P}<0,5 \%$, excluindo os pontos adjacentes a mancha cega e limites do CV. 


\subsubsection{Grupo controle}

Para formação do grupo controle, indivíduos foram recrutados entre acompanhantes de pacientes e funcionários voluntários do HCFMUSP. Foram, no total, 43 olhos de 23 controles normais, emparelhados por sexo e idade ao grupo de estudo. Todos foram submetidos ao exame oftalmológico de forma similar ao realizado no grupo de pacientes.

\subsubsection{Critério de inclusão}

1. Indivíduo apresentando idade pareada com o respectivo paciente do grupo em estudo com um desvio de mais ou menos cinco anos;

2. Acuidade visual corrigida de $20 / 20$ e erro refracional menor que seis dioptrias esféricas e três cilíndricas;

3. Pressão intraocular menor que $22 \mathrm{mmHg}$;

4. Aspecto normal do NO (ausência de escavação glaucomatosa e defeitos da CFNR) e da mácula à oftalmoscopia;

5. Exame de CV 24-2 confiável e normal definido como MD (do inglês Mean Deviation) e CPSD (do inglês Corrected Pattern Standard Deviation) dentro de $95 \%$ da normalidade e resultado normal do GHT (do inglês Glaucoma Hemifield Test);

6. Ausência de doença ocular prévia e doenças sistêmicas que acometam o NO ou mácula;

7. Boa colaboração para realização dos exames de CV, TCO e PEV-mf. 


\subsection{Exame de Campo Visual}

O exame de $\mathrm{CV}$ foi obtido através do perímetro computadorizado de Humphrey ${ }^{\mathrm{TM}}$ (Humphrey systems, San Diego, CA, modelo HFA II 750), com correção apropriada para perto, utilizando-se teste tipo limiar com a estratégia 24-2 SITA Standard (Swedish Interactive Threshold Algorithm). Essa estratégia examina os 52 pontos dentro de 24 graus centrais e dois pontos na periferia nasal utilizando estímulo de tamanho III de Goldman apresentados em um plano de fundo com luminância de $10 \mathrm{~cd} / \mathrm{m} 2$ (31.5 apostilb). Para inclusão no estudo, os pacientes e controles tiveram de apresentar campos visuais confiáveis definidos como índices de perda de fixação, falsos positivos e falsos negativos menores que $30 \%$ cada. Os pacientes também foram avaliados usando-se a estratégia 10-2 SITA Standard do mesmo aparelho.

Para todos os pacientes e controles, cada ponto testado no $\mathrm{CV}$, representa a sensibilidade em decibéis $(\mathrm{dB})$ do ponto testado. A análise do $\mathrm{CV}$ foi realizada utilizando a média da sensibilidade. A sensibilidade em cada ponto testado foi medida em $\mathrm{dB}$ e, para todas as análises, esta sensibilidade foi convertida de $\mathrm{dB}$ para 1/Lambert (1/L). Isto é feito dividindo o valor em decibel por 10 e calculando o unlog do quociente. Isso significa transformar os valores dos pontos testados no $\mathrm{CV}$ de uma escala logarítmica $(\mathrm{dB})$ para uma escala linear (1/L). Dessa forma, seguimos sugestões da literatura que demonstram existir uma correlação linear e contínua entre o número de CGR e a perda de sensibilidade no CV expressa pela unidade $1 / \mathrm{L}^{[99]}$.

A perda de sensibilidade do $\mathrm{CV}$ nos pacientes com $\mathrm{AB}$ foi avaliada para os 50 pontos do perímetro computadorizado de Humphrey ${ }^{\mathrm{TM}}$ em áreas equivalentes do $\mathrm{CV}$ ao obtido pelo PEV-mf em quadrantes e hemicampos (excluindo 2 pontos 
imediatamente acima e abaixo da mancha cega). Os valores de sensibilidade obtidos na perimetria computadorizada Humphrey ${ }^{\mathrm{TM}}$ foram calculados pela média dos valores de sensibilidade obtidos em todos os pontos em cada quadrante (12 pontos testados por cada quadrante temporal e 13 pontos testados cada por quadrante nasal) e em cada hemicampo temporal e nasal (26 pontos testados para o setor nasal e 24 pontos testados para o setor temporal).

A gravidade do defeito de $\mathrm{CV}$ nos pacientes com $\mathrm{AB}$ foi também obtida através da perimetria computadorizada Humphrey ${ }^{\mathrm{TM}}$ 10-2 padrão que avalia os 68 pontos centrais do CV e uma área equivalente da resposta central obtida no PEV-mf também foi calculada, sendo a sensibilidade obtida na perimetria 10-2 calculada como a média de sensibilidade obtida nos quadrantes (17 pontos testados por quadrante) e nos hemicampos temporal e nasal (34 pontos testados por hemicampo).

O desvio médio da normalidade ("mean deviation") fornecido em decibéis e em 1/L pelo aparelho foi usado nos testes de correlação com os achados à TCO tanto para avaliação dos achados da perimetria 24-2, assim como para avaliação dos dados obtidos na perimetria $10-2$.

\subsection{Tomografia de Coerência Óptica:}

Todos os pacientes e controles estudados submeteram-se ao exame de TCO-dF com escaneamento da região da cabeça do NO e da área macular através de um equipamento comercialmente disponível (3D OCT-1000, Topcon Corp, Tokyo, Japan). O protocolo de varredura consistiu da aquisição de um grupo de 2 imagens de alta definição da cabeça do NO e da mácula num padrão de rastreamento cobrindo 
uma área de $6 \times 6 \mathrm{~mm}$ com uma densidade de 512x128 pixels em 3,5s $(27.000$ scans $\mathrm{A}$ por segundo). Todas as imagens foram revisadas pelos autores com respeito à sua qualidade objetiva e subjetiva das imagens.

A espessura da CFNR peripapilar foi obtida usando um mapa circular ao redor do NO de diâmetro de $3,4 \mathrm{~mm}$ e automaticamente calculada pelo programa incluindo média de $360^{\circ}$ e a espessura em cada um dos 12 segmentos ao redor do NO, sendo cada setor correspondentes a $30^{\circ}$ (Figura 3). Foi utilizada a distribuição das 12 horas de relógio da espessura da CFNR peripapilar para análise dos dados ( Figura 3), sendo a hora de relógio superior a das 12 horas e as demais horas de relógio foram colocadas no sentido horário para o gráfico da CFNR peripapilar do olho direito e no sentido anti-horário para o olho esquerdo.

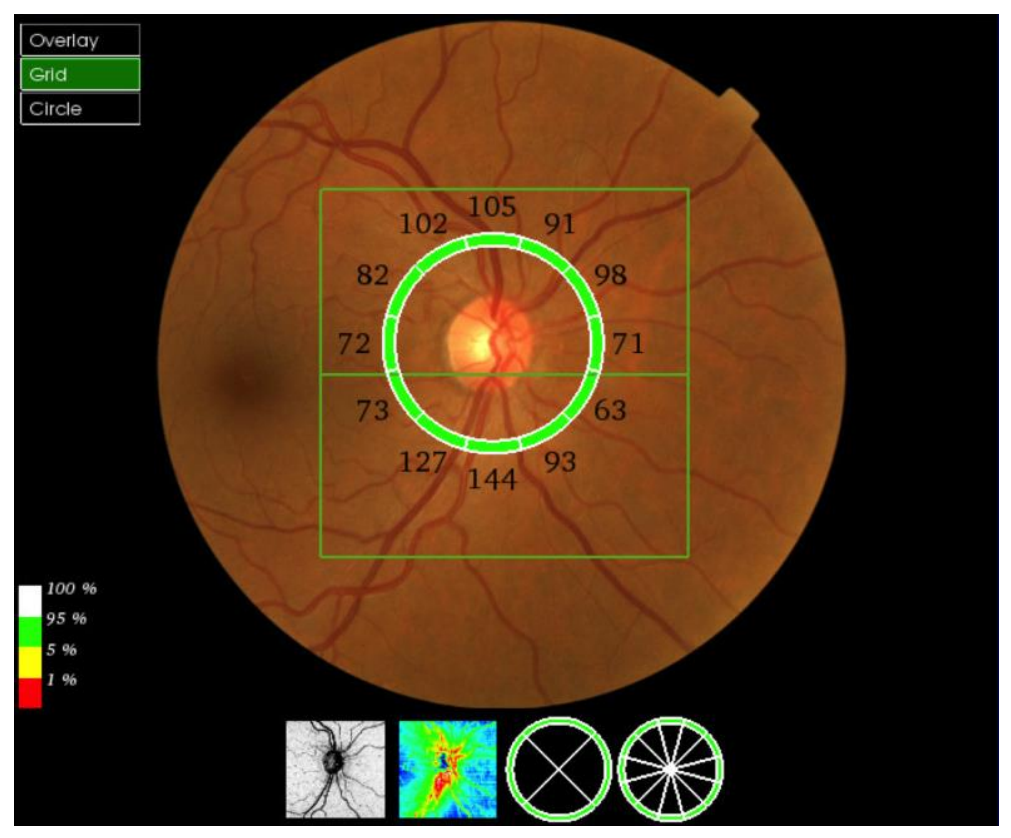

Figura 3: Exemplo de aquisição de TCO captada ao redor do NO para obtenção da medida da espessura da CFNR peripapilar 
A região macular foi estudada através de sua espessura total obtida pelo mapa de 36 quadrados (Figura 4) oriundo do protocolo de rastreamento macular cúbico 3D incluso no aparelho. Nesta analise foi calculada a média da espessura macular em quadrantes (cada um contendo 9 quadrados) e nos hemicampos temporal e nasal (cada um contendo 18 quadrados).

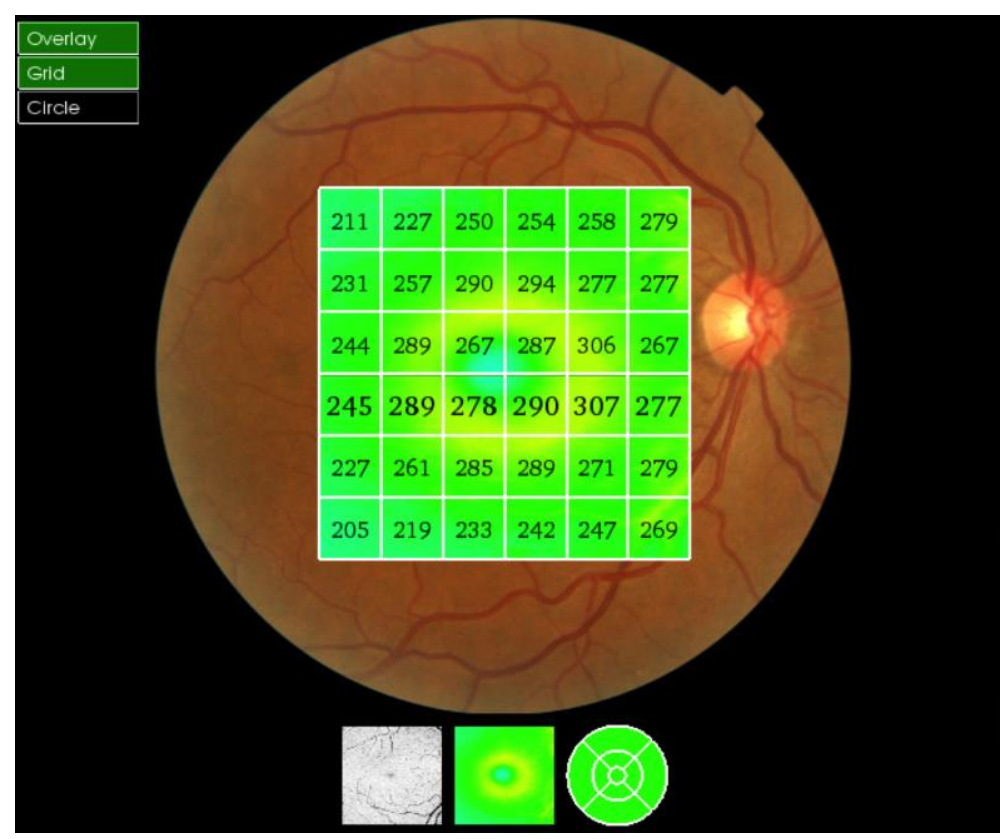

Figura 4: Exemplo de aquisição de TCO captada por escaneamento de forma cúbica para obtenção da espessura macular em quadrados

\subsection{Potencial Evocado Visual Padrão-reverso}

No exame de PEV-pr, foram seguidas normas e diretrizes da Sociedade Internacional para Eletrofiosiologia Clínica da Visão (ISCEV) e realizados monocularmente no aparelho RETiscan System (Roland Consult, Wiesbaden, Germany, 2010). Fez-se o registro gráfico do potencial elétrico originado da via óptica e córtex occipital, a partir do estímulo gerado por pequenos quadrados de cores pretas e brancas, dispostos de forma semelhante a um tabuleiro de xadrez, que 
possuem luminância constante e se alternam na freqüência pré-determinada, gerando então um estímulo de padrão reverso. A estimulação da retina foi feita através de duas sequências de estímulos com quadrados com $1^{\circ}$ de tamanho e duas sequências com quadrados com $0,25^{\circ}$ de tamanho projetados por um software em uma tela de computador de 20 polegadas, sendo que cada sequência é composta por 80 reversões e o paciente instruído a fixar o olhar no ponto de fixação no centro da tela. Foram colocados 3 eletrodos de disco de ouro na linha média em posições pré-definidas, Fz a $30 \%, \mathrm{Cz}$ a $50 \%$ e Oz a $10 \%$ da distância medida na linha média da região do nasion ao inion (Figura 5) ${ }^{[74]}$.

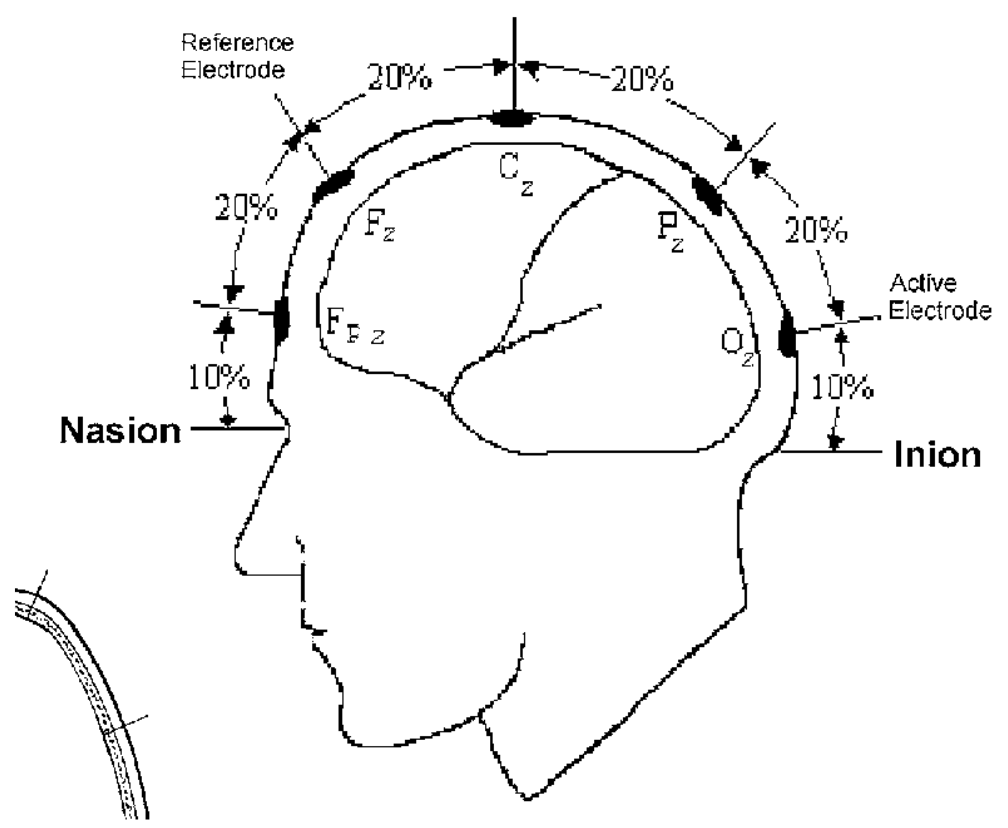

Figura 5: Demonstração esquemática dos marcos anatômicos para realização dos exames eletrofisiológicos. Na figura está representada a linha média que liga o Nasion ao Inion, sendo identificados os pontos de referência $\mathrm{Fz}$ a $30 \%, \mathrm{Cz}$ a $50 \%$ e $\mathrm{Oz}$ a $10 \%$ da distância medida na linha média estabelecida por estes marcos anatômicos e utilizados no exame de PEV-pr ${ }^{[74]}$ 
O exame foi realizado monocularmente com o paciente sentado e as costas apoiadas no encosto da cadeira, à distância de um metro, com uso de correção adequada e oclusão do olho contralateral. O tempo obtido para a realização de cada sequência foi de aproximadamente 54 segundos, sendo feito 2 sequências para cada estímulo $\left(1^{\circ}\right.$ e $\left.0,25^{\circ}\right)$ por olho avaliado.

O valor utilizado do contraste foi de $97 \%$. A luminância utilizada para as áreas brancas no exame foi maior que $80 \mathrm{~cd} / \mathrm{m} 2$ e mantida constante em todos exames. O preparo da pele para colocação dos eletrodos foi realizado com limpeza com água e shampoo neutro na véspera do procedimento, retirando excesso de oleosidade, os cabelos estavam limpos e secos e procedeu-se uma leve escarificação nos pontos onde foram conectados os eletrodos na linha média (Fz, $\mathrm{Cz}$ e Oz, Figura 3). Estes cuidados foram importantes para o obtenção de impedância menor que $5 \mathrm{k} \Omega$ em todos os exames. $\mathrm{O}$ exame exige que o paciente fixe em uma mira vermelha projetada no centro da tela em forma de "X". As pupilas não foram dilatadas. O PEV-pr foi realizado previamente ao exame de $\mathrm{PEV}$-mf para checagem do sinal e padrão de resposta eletrofisiológico tanto dos paciente, quanto dos controles, por ser um exame que possui padronização internacional pela ISCEV.

\subsection{Potencial Evocado Visual Multifocal}

O PEV-mf foi realizado com estímulo padrão constituído de 60 setores organizados e escalonados considerando-se a magnificação cortical (Figura 6-A) no aparelho RETiscan System (Roland Consult, Wiesbaden, Germany, 2010). Cada setor é composto por 16 quadrados ( 08 pretos e 08 brancos), alternando de forma reversa 
através de uma frequência de fase regular (Figura 6-A). Cada um dos 60 setores apresentava um padrão de reversão independente de estímulo que obedecia a uma variação pseudo-randômica numa m-sequência predefinida, com probabilidade de reversão de 0,5 a cada mudança do frame ${ }^{[85]}$. Um filtro de banda de passagem foi configurado entre 1 e $30 \mathrm{~Hz}$ para a captação das respostas.

Para a realização do exame, cada paciente foi confortavelmente sentado com o queixo e testa apoiados e submetido ao exame de forma monocular com a melhor correção óptica numa distância de $30 \mathrm{~cm}$ do monitor de estimulação, sendo estimulada uma área de $54^{\circ}$ de CV nesta distância da tela. Os eletrodos de captação do sinal foram colocados um no inion (referência) e outro $4 \mathrm{~cm}$ acima do inion (ativo) na linha média. Para os eletrodos laterais, dois foram colocados a $1 \mathrm{~cm}$ acima do inion e a $4 \mathrm{~cm}$ a esquerda e a direita, respectivamente, da linha média. $\mathrm{O}$ eletrodo terra foi colocado na localização anatômica $\mathrm{Cz}$ na linha média conforme descrito pela Sociedade Internacional de Eletrofisiologia Clínica da Visão em 2009 (figura 5) $^{[74]}$ com impedância menor que $5 \mathrm{k} \Omega$.

O exame foi realizado com a apresentação de 8 ciclos (cada ciclo com duração de 2 minutos e 21 segundos) de estimulação para completa aquisição das respostas. A duração total de cada exame foi de 19 minutos e 48 segundos por cada olho, contendo um intervalo de 1 minuto de descanso a cada 4 ciclos de captação. Para realização dos exames, os indivíduos foram instruídos a ler um alvo de fixação com texto de leitura no centro da tela durante toda aquisição do sinal. A resposta do PEV-mf foi gravada em quatro canais nas derivações BC-CD-AD-BD, conforme a Figura 6-B. Para a análise dos dados foi gerado pelo programa um quinto canal a partir do registro das melhores respostas obtidas nos quatro canais e removido os picos de interferência com o filtro DSP disponível no software do programa Não 
foram necessárias visitas de seguimento e todas as respostas foram obtidas em uma única sessão de exame.
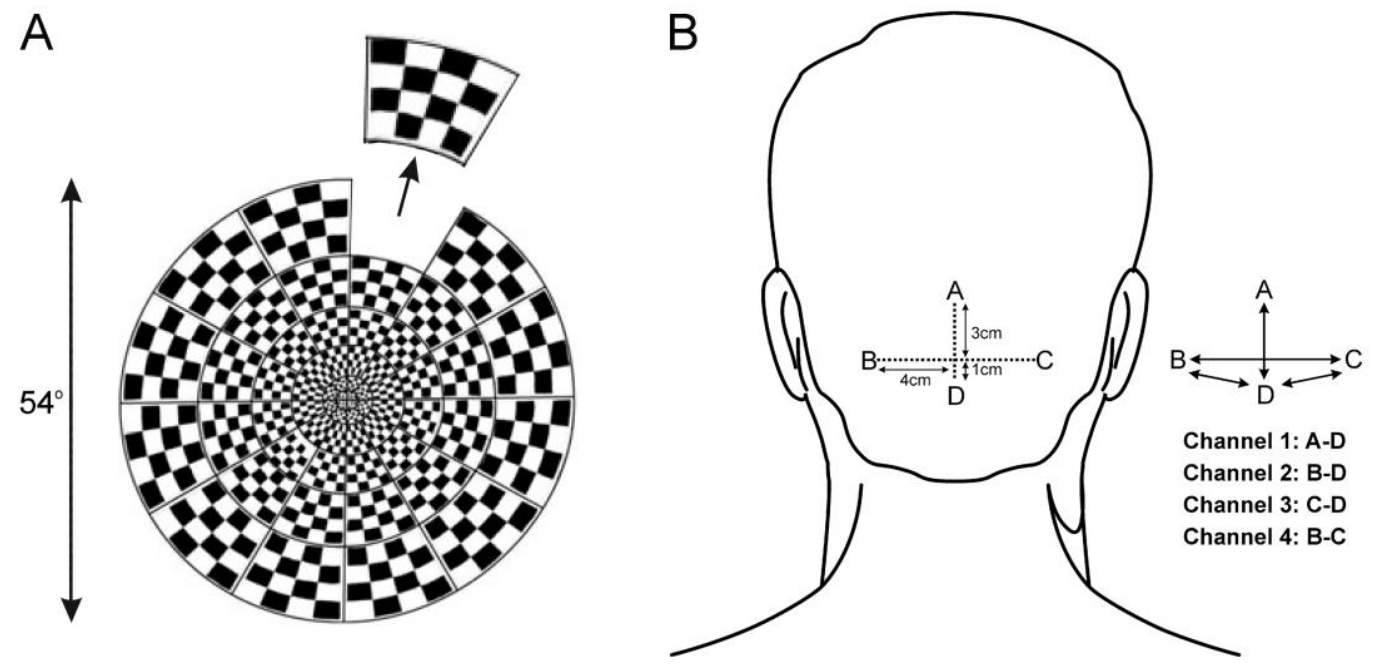

Figure 6: A- Representação esquemática da tela em xadrez de estímulo do PEV-mf. B- Posicionamento dos eletrodos e os canais de respostas obtidas pelo exame

A onda obtida na resposta do PEV-mf é caracterizada por dois picos negativos, $\mathrm{N} 1$ (75 ms) e N2 (135 ms) e um pico positivo P1 (100 ms) similar ao padrão de resposta obtido no PEV-pr, porém com amplitudes menores.

Depois de excluir as 12 respostas mais periféricas (anel externo), a média da amplitude e latência das respostas do PEV-mf (PEV-mf global) foi determinada para os hemicampos temporal e nasal (24 respostas por hemicampo), assim como foi calculada a média das respostas nos quadrantes temporal inferior, temporal superior, nasal superior e nasal inferior (12 respostas obtidas por quadrante) para comparação com os dados do CV 24-2 (Figura 7 A e B).

Já para a comparação com o CV 10-2, todas as respostas dentro do círculo de $10^{\circ}$ centrais do PEV-mf foram analisadas, o que corresponde a cerca de $8^{\circ}$ centrais do CV (PEV-mf central). A média destes valores do PEV-mf central foram calculadas para hemicampos ( 12 respostas) e para os quadrantes (6 respostas) para comparação com o CV 10-2 (Figura 7 C e D). 
A

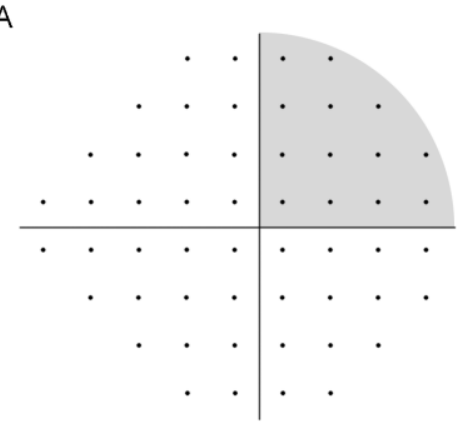

B

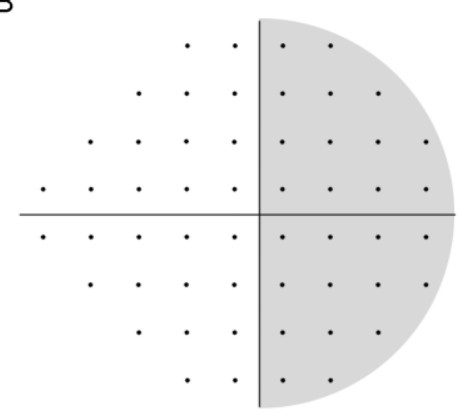

C
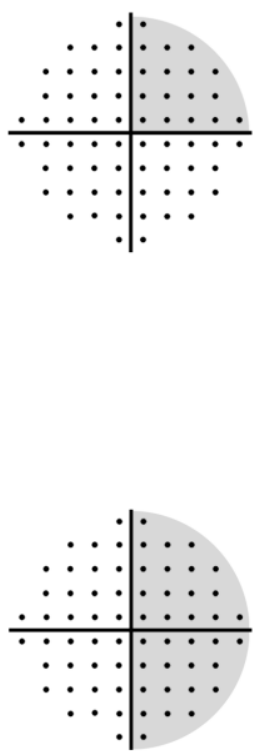
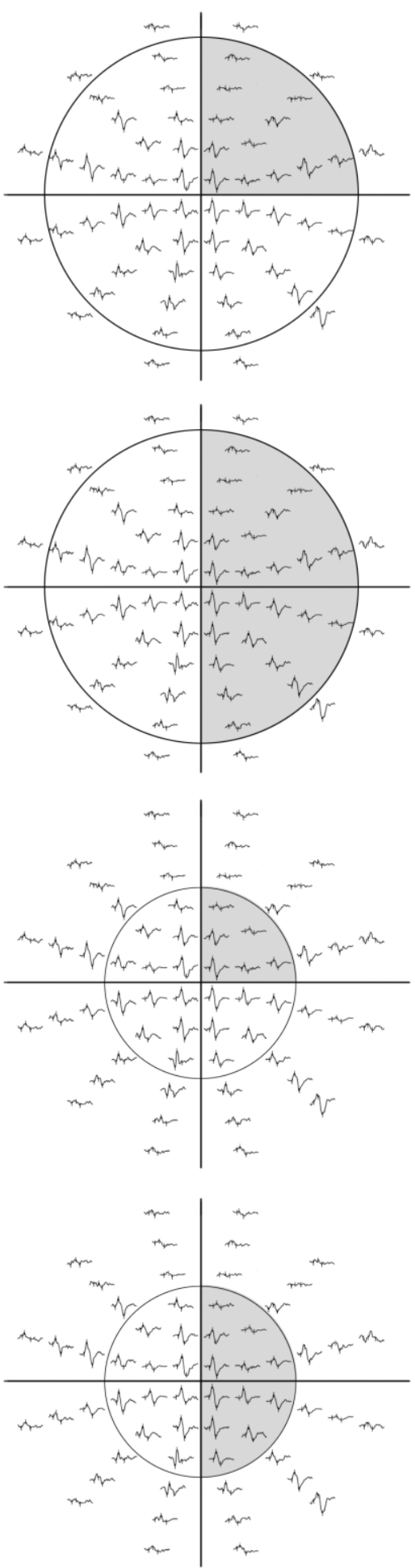

Figure 7: A-B Demonstração esquemática dos locais de resposta do CV 24-2 (a esquerda) e das respostas obtida no PEV-mf global (a direita) nos quadrantes (linha de cima, A ) e hemicampos (linha de baixo, B). C-D Demonstra o local das respostas do CV 10-2 (esquerda) comparado com o PEV-mf central (a direita) para os quadrantes (linha de cima, C ) e para os hemicampos (linha de baixo, D) 
A Figura 8 demonstra esquematicamente como era realizado o PEV-mf na sala de eletrofisiologia, assim como pode ser observado a colocação dos eletrodos na região occipital de um paciente submetido ao exame.
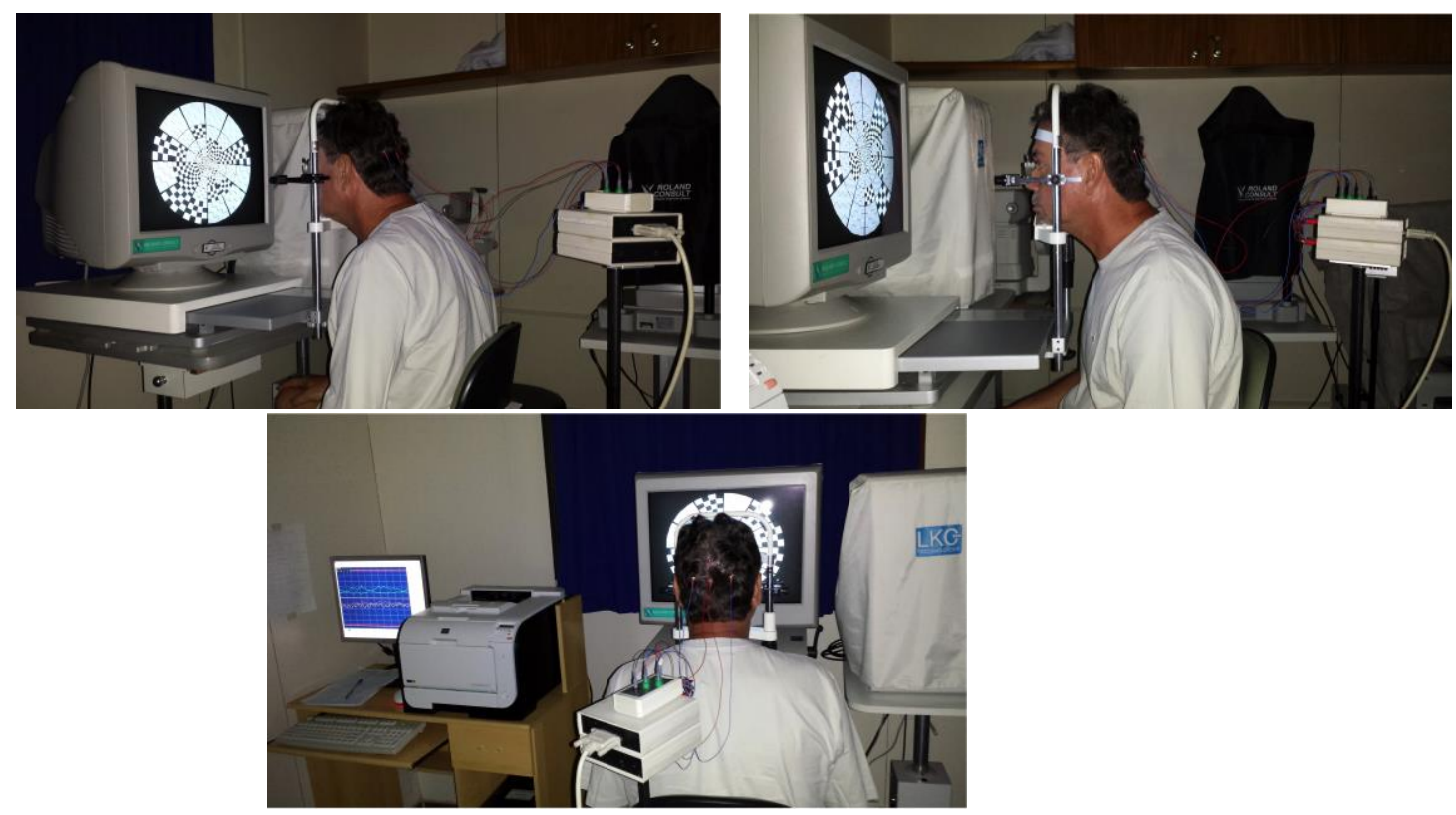

Figure 8: Observa-se no alto à esquerda o paciente confortavelmente sentado com a coluna apoiada durante o exame de PEV-mf. No alto à direita, observa-se a distância do paciente de $30 \mathrm{~cm}$ do monitor de estimulação e, na imagem abaixo, pode-se observar a distribuição dos eletrodos na região occipital do paciente

\subsection{Análise estatística}

Para analise dos dados dos pacientes e controles foram apresentadas as médias \pm desvio padrão para os parâmetros que apresentaram distribuição normal (distribuição Gaussiana) e por mediana e quartis para os parâmetros que não apresentaram distribuição normal. Foi utilizada a análise dos gráficos de histogramas para avaliação da normalidade dos parâmetros estudados, uma vez que a normalidade pode ser checada ao plotar dois histogramas, um de cada amostra, não necessitando o 
gráfico seguir perfeitamente a normalidade, basta que ele seja próximo ao desenho da distribuição normal. Em alguns casos, foi utilizado o teste de Shapiro-Wilk para testar a normalidade em conjunto com a analise de histograma para definição da normalidade de determinado parâmetro.

Ao avaliar os pacientes portadores de hemianopsia temporal e os controles normais, quanto a amplitude e latência no PEV-mf global e central, quanto a sensibilidade em decibéis e 1/Lambert no CV 24-2 e 10-2, assim como quanto as espessuras das camadas da retina na região macular e peri-papilar na TCO, os grupos foram comparados utilizando as análises das equações de estimativa generalizadas (GEE, do inglês "Generalized Estimating Equations"). Este método estatístico possibilita balancear o fato de alguns pacientes e controles estarem tendo os dois olhos analisados no estudo, uma vez que 2 informações correlacionadas tem menos informação que 2 informações independentes, sendo a análise GEE utilizada para compensar o uso de ambos os olhos de alguns indivíduos no estudo ${ }^{[100]}$.

Para efeito de comparação entre os grupos, aceitou-se uma probabilidade máxima de cometer um erro falso-positivo (erro tipo I) de 5\%, quando a hipótese de ausência de diferença entre as médias comparadas for rejeita. Deste modo, o $\alpha$ de 5\% é apropriado para análise de comparações individuais, mas perde poder ao serem realizadas múltiplas comparações simultâneas, podendo levar a interpretações incorretas e rejeitar a hipótese nula quando na verdade ela é correta (erro tipo I). Uma forma de minimizar a chance de erro tipo I é utilizando a correção de Bonferroni ( $\alpha$ / número de comparações), o que foi utilizado na análise das amplitudes e latências obtidas no PEV-mf global e central (12 comparações), aumentando a especificidade ao encontrar as diferenças entre os grupos do estudo. Por outro lado, sabe-se que a utilização da correção de Bonferroni pode levar a erro tipo II (aceita-se a hipótese 
nula, embora ela seja realmente falsa), falso-negativo, sendo este fato levado em consideração para escolha deste método de análise.

A análise quantitativa do desempenho dos parâmetros do PEV-mf global e central em diferenciar pacientes com hemianopsia temporal dos controles normais foi calculada pela área sob a curva ROC ("Receiver Operating Characteristic"). A curva ROC é um gráfico de função linear no qual o eixo Y (vertical) contém os verdadeiros positivos (sensibilidade) e no eixo $\mathrm{X}$ (horizontal) os falso positivos (1-especificidade) para todos os possíveis valores de corte do teste diagnóstico. A curva resultante deste gráfico é conhecida como curva ROC, sendo que um teste diagnóstico perfeito não apresentaria resultado falso negativo (sensibilidade igual a 1) e não teria falso positivo (especificidade igual a 1), produzindo assim uma linha que partiria do 0 no eixo $\mathrm{X}$ em direção ao 1 do eixo $\mathrm{Y}$. Um teste que discrimina de forma razoável indivíduos doentes e sadios apresentaria durante o seu curso uma curva ROC que se aproximaria do eixo vertical à esquerda e do eixo horizontal superior conforme demonstrado no Gráfico 1. A área sob a curva ROC (AROC) é calculada pelo somatório das áreas dos trapézios que dividem a curva e pode ser definida como a probabilidade de um indivíduo portador da doença ter um resultado ao teste diagnóstico de maior magnitude que aquele não doente, isto é, a taxa de verdadeiros positivos maior do que a taxa de falso positivos. Assim, a escolha da combinação ótima da sensibilidade e especificidade para um determinado teste deve levar em conta as consequências médicas de um falso positivo e falso negativo na interpretação do ponto de corte escolhido de uma curva ROC deste teste diagnóstico. O método de DeLong et al. foi utilizado para comparação das áreas sob a curva ROC ${ }^{[101]}$. 
Gráfico 1: Representação esquemática da curva ROC para um determinado teste diagnóstico

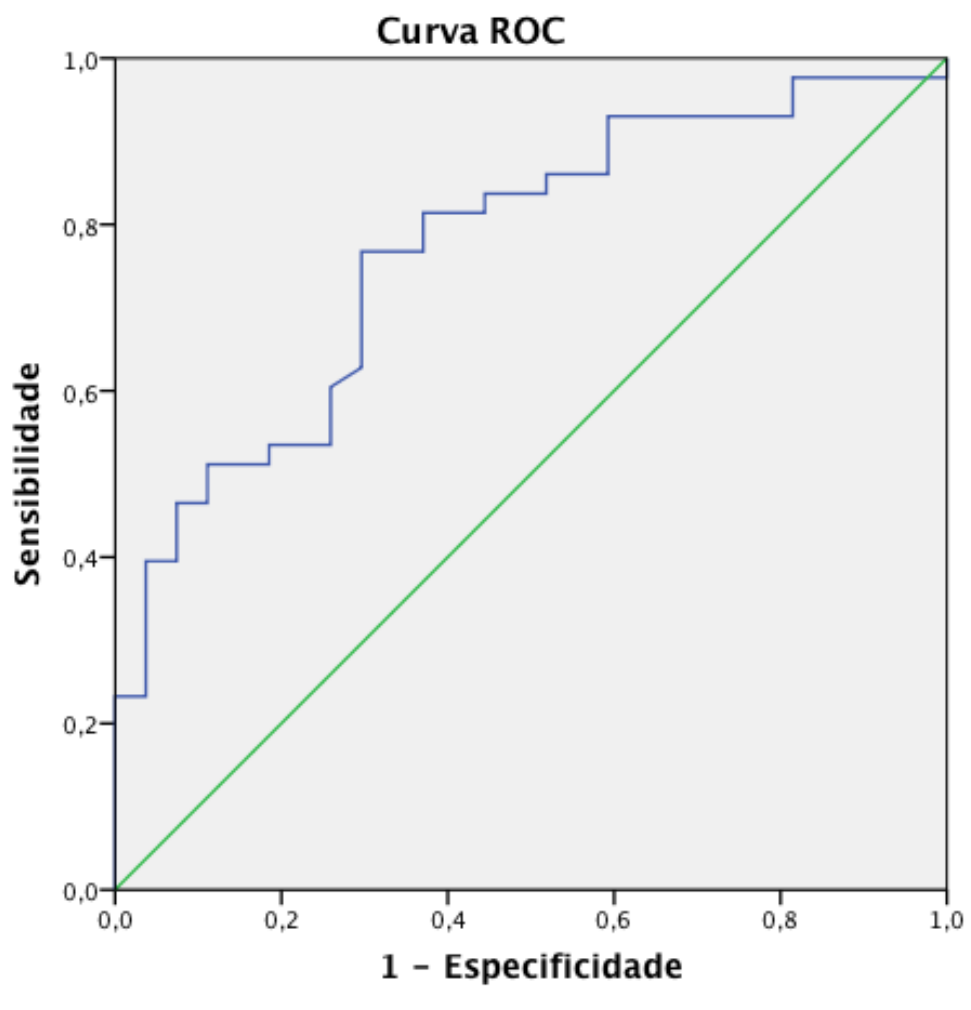

Os segmentos diagonais são produzidos por vínculos.

Intervalos de confiança (IC) de 95\% foram calculados para as AROCs de cada parâmetro do estudo. Isso significa que para um IC de 95\%, ao selecionarmos um número infinito de amostras sempre da mesma forma aleatória, em 95\% delas estarão incluídos os valores "verdadeiros" no intervalo de confiança resultante. Este intervalo de confiança é interessante para melhor visualização do desempenho do teste diagnóstico em questão. Para comparar a performance diagnóstica do PEV-mf e do TCO, foram analisados os olhos classificados como normais e anormais em cada teste. A proporção de olhos classificados como anormais (abaixo do percentil 10 dos olhos dos controles normais do estudo) foi calculada para cada parâmetro do PEV-mf (amplitude) e TCO. Estes resultados foram comparados utilizando o teste de McNemar. 
Com o objetivo de verificar a força de associação entre as variáveis estudadas foram calculados os coeficientes de correlação de Pearson ou de Spearman, dependendo da aderência ou não dos parâmetros à distribuição normal. A fim de determinar o grau de associação entre as medidas realizadas, foi calculado o coeficiente de correlação de Pearson (1/Lambert) e Spearman (dB) entre os seguintes parâmetros: as amplitudes do PEV-mf global e central com a perda de sensibilidade do CV 24-2 e 10-2, as amplitudes do PEV-mf central com a espessura macular na TCO, a perda de sensibilidade do CV 10-2 com a espessura macular na TCO, as amplitudes do PEV-mf global e central com a espessura da CFNR peripapilar na TCO e a perda de sensibilidade do CV 24-2 e 10-2 com a espessura da CFNR peripapilar na TCO.

As análises estatísticas foram realizadas utilizando os pacotes estatísticos SPSS v.15.0 (SPSS inc., Chicago, IL, EUA) e NCSS Software v.07.1.19, 2007 (Kaysville, Utah, EUA). 
5 RESULTADOS 
Um total de 27 olhos de pacientes com hemianopsia temporal e 43 olhos de controles foram estudados. Todos os olhos dos controles foram incluídos no estudo para aumentar o banco de dados de normalidade, entretanto 03 olhos de controles foram excluídos por não preencherem os critérios de inclusão de normalidade do estudo. No grupo de pacientes com hemianopsia temporal 55,6\% dos indivíduos eram do sexo masculino, já no grupo controle $65,1 \%$ eram do sexo masculino. Ao realizar a analise descritiva quanto a lateralidade, observou-se que o grupo de pacientes com hemianopsia temporal era composto com $44,4 \%$ de olhos direitos e o dos controles era composto por $51,2 \%$ de olhos direitos (Gráfico 2). Não foi observada diferença estatisticamente significante entre a lateralidade do olho estudado entre os casos e controles $(p>0,05)$.

Gráfico 2: Gráfico de barras demonstrando a proporção de pacientes portadores de hemianopsia temporal $\mathrm{x}$ controles normais quanto ao sexo e lateralidade dos olhos estudados

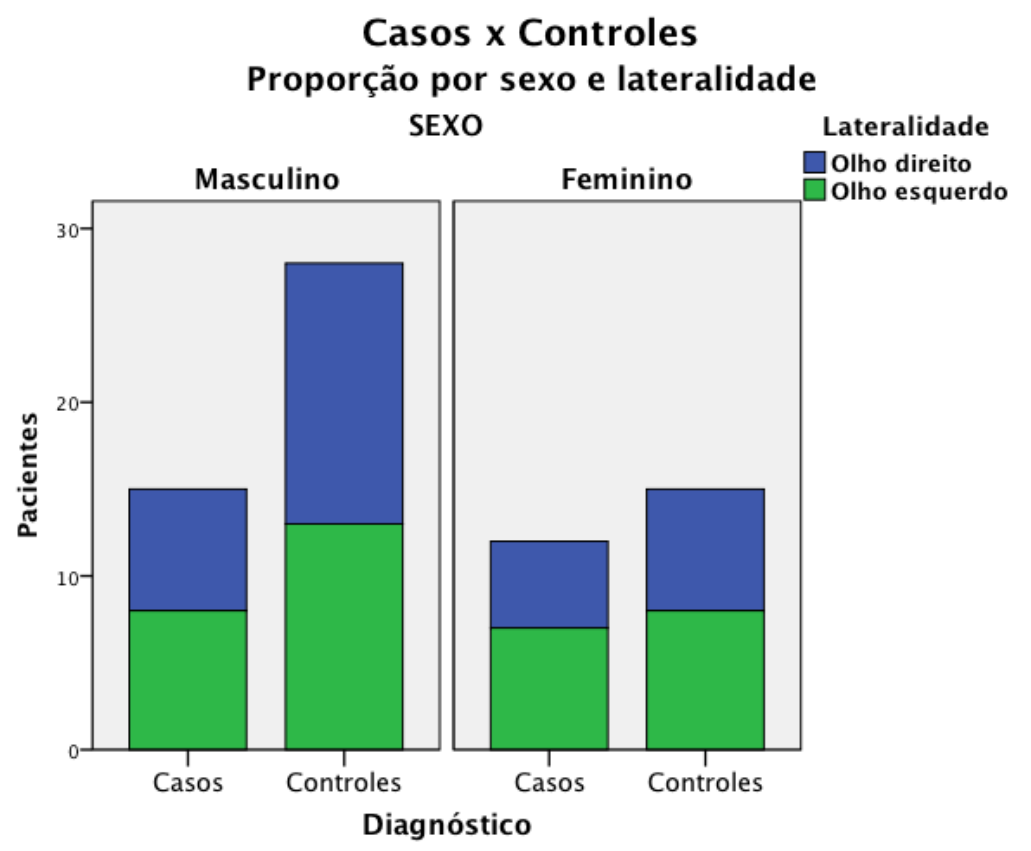


Dados referentes a idade, sexo, olho estudado, AV, MD e defeito de CV dos pacientes com hemianopsia temporal são apresentados na Tabela 1. A idade média \pm desvio padrão (DP) foi de 52,5 \pm 8,6 anos para pacientes com $\mathrm{AB}$ e de 50,1 $\pm 6,0$ anos para os indivíduos normais ( $\mathrm{p}=0,28$; Teste-t de Student). No CV 24-2, 10 olhos tinham hemianopsia temporal completa, 15 olhos tinham defeito temporal parcial maior que um quadrante de $\mathrm{CV}$ e 2 olhos apresentavam defeitos menores que um quadrante de CV. A média do CV 24-2 foi de -7,22 $\pm 4,90 \mathrm{~dB}$ nos pacientes com $\mathrm{AB}$ e de $+0,22 \pm 0,68 \mathrm{~dB}$ nos indivíduos normais.

Tabela 1: Dados de idade, sexo, olho do estudo, acuidade visual e CV 24-2 em 21 pacientes (27 olhos) com defeito de CV temporal secundário a compressão quiasmática

\begin{tabular}{|c|c|c|c|c|c|c|}
\hline Paciente & Idade & Sexo & Olho & AV & MD & Defeito de campo visual \\
\hline 1 & 52 & $\mathrm{~F}$ & $\mathrm{OE}$ & 1 & $-9,72$ & Hemianopsia temporal completa \\
\hline 2 & 38 & M & $\mathrm{OE}$ & 1 & $-2,44$ & Hemianopsia temporal incompleta \\
\hline 3 & 45 & M & OD & 1 & $-12,36$ & Hemianopsia temporal completa \\
\hline 4 & 50 & M & $\mathrm{OE}$ & 1 & $-5,76$ & Hemianopsia temporal incompleta \\
\hline \multirow[t]{2}{*}{5} & 61 & $\mathrm{~F}$ & OD & 1 & $-0,88$ & Pequena hemianopsia temporal incompleta \\
\hline & 61 & $\mathrm{~F}$ & $\mathrm{OE}$ & 1 & $-0,5$ & Pequena hemianopsia temporal incompleta superior \\
\hline 6 & 70 & $\mathrm{~F}$ & $\mathrm{OE}$ & 0,7 & $-6,72$ & Hemianopsia temporal incompleta \\
\hline \multirow[t]{2}{*}{7} & 46 & $\mathrm{~F}$ & OD & 1 & $-4,22$ & Hemianopsia temporal incompleta \\
\hline & 46 & $\mathrm{~F}$ & $\mathrm{OE}$ & 1 & $-1,66$ & Hemianopsia temporal incompleta \\
\hline 8 & 60 & M & $\mathrm{OE}$ & 1 & $-14,6$ & Hemianopsia temporal completa \\
\hline 9 & 57 & M & OD & 1 & $-14,02$ & Hemianopsia temporal completa \\
\hline \multirow[t]{2}{*}{10} & 59 & $\mathrm{~F}$ & OD & 1 & -6 & Hemianopsia temporal incompleta \\
\hline & 59 & $\mathrm{~F}$ & $\mathrm{OE}$ & 1 & $-4,86$ & Hemianopsia temporal incompleta \\
\hline \multirow[t]{2}{*}{11} & 60 & M & OD & 0,8 & $-8,38$ & Hemianopsia temporal completa \\
\hline & 60 & M & OE & 1 & -3 & Hemianopsia temporal incompleta \\
\hline 12 & 35 & M & $\mathrm{OE}$ & 1 & $-2,66$ & Pequena hemianopsia temporal incompleta superior \\
\hline 13 & 63 & M & OD & 1 & $-3,28$ & Hemianopsia temporal incompleta \\
\hline 14 & 57 & M & $\mathrm{OE}$ & 1 & $-13,32$ & Hemianopsia temporal completa \\
\hline 15 & 47 & M & OD & 1 & $-7,56$ & Hemianopsia temporal incompleta \\
\hline 16 & 52 & $\mathrm{~F}$ & OD & 1 & $-13,34$ & Hemianopsia temporal completa \\
\hline 17 & 44 & $\mathrm{~F}$ & $\mathrm{OE}$ & 1 & $-14,48$ & Hemianopsia temporal completa \\
\hline \multirow[t]{2}{*}{18} & 46 & M & OD & 1 & $-6,22$ & Hemianopsia temporal incompleta \\
\hline & 46 & M & $\mathrm{OE}$ & 1 & $-9,86$ & Hemianopsia temporal incompleta \\
\hline \multirow[t]{2}{*}{19} & 50 & M & OD & 1 & 0,64 & Pequena hemianopsia temporal incompleta \\
\hline & 50 & M & $\mathrm{OE}$ & 1 & $-12,86$ & Hemianopsia temporal completa \\
\hline 20 & 56 & $\mathrm{~F}$ & OD & 1 & $-13,28$ & Hemianopsia temporal completa \\
\hline 21 & 55 & $\mathrm{~F}$ & $\mathrm{OE}$ & 1 & $-3,68$ & Hemianopsia temporal incompleta \\
\hline
\end{tabular}

M: masculino; F: feminino; OD: olho direito; OE: olho esquerdo; AV: acuidade visual; MD: mean deviation ; CV: campo visual. 
A Tabela 2 demonstra a média da amplitude do PEV-mf global em olhos com $\mathrm{AB}$ e em controles dos hemicampos e quadrante. A média de amplitude de P1 e N2 temporais (hemicampo temporal, quadrante temporal superior e inferior) do PEV-mf global foram significativamente menores nos pacientes com AB que nos controles, após a correção de Bonferroni ( $\alpha=0,004 ; 12$ comparações). Não houve diferença entre os grupos no que concerne a analise das médias das respostas nasais do PEV-mf global (hemicampo nasal e quadrantes nasais). Por outro lado, a análise da AROC do PEV-mf global indicou que os melhores parâmetros de amplitude de P1 para diferenciação dos pacientes dos indivíduos normais foram os do hemicampo temporal (AROC $=0,75)$, seguido do quadrante TI $(\mathrm{AROC}=0,74)$ e do quadrante TS (AROC=0,73). Em relação a amplitude de N2, os melhores parâmetros do PEV-mf global para separação dos casos dos indivíduos normais foram do quadrante TS $(\mathrm{AROC}=0,81)$, seguido pelo hemicampo temporal e pelo quadrante TI (AROC=0,79). A Tabela 2 também demonstra a proporção de olhos classificados como anormais com base na amplitude de P1 e N2, utilizando o percentil 10 dos normais. 
Tabela 2: Valores médios ( \pm desvio padrão) da amplitude das respostas P1 e N2 $(\mathrm{em} \mu \mathrm{V})$ do PEV-mf global em 27 olhos de pacientes portadores de AB e em 43 olhos de controles normais com suas respectivas áreas sob a curva "receiver operating characteristic"(AROC)

\begin{tabular}{|c|c|c|c|c|c|c|}
\hline \multicolumn{2}{|l|}{ Parâmetro } & $\begin{array}{c}\mathbf{A B} \\
(\mathbf{n}=27)\end{array}$ & $\begin{array}{c}\text { Controles } \\
(n=43)\end{array}$ & $\begin{array}{l}\text { Valor } \\
\text { de } p^{*}\end{array}$ & $\begin{array}{c}\text { AROC } \\
\text { (EP) }\end{array}$ & $\begin{array}{c}\text { Olhos } \\
\text { Anormal/ } \\
\text { normal } * *\end{array}$ \\
\hline \multicolumn{7}{|l|}{ Amplitude } \\
\hline \multicolumn{7}{|c|}{ PEV-mf global $(\mu \mathrm{V})$} \\
\hline \multirow{2}{*}{$\begin{array}{l}\text { Média Nasal } \\
\text { (24 respostas) }\end{array}$} & $\mathrm{P} 1$ & $0,15 \pm 0,07$ & $0,18 \pm 0.09$ & 0.273 & $0.57(0.07)$ & $5 / 27$ \\
\hline & $\mathrm{N} 2$ & $0,28 \pm 0,14$ & $0,33 \pm 0,18$ & 0.259 & $0.57(0.07)$ & $6 / 27$ \\
\hline \multirow{2}{*}{$\begin{array}{l}\text { Média Temporal } \\
\text { (24 respostas) }\end{array}$} & $\mathrm{P} 1$ & $0,10 \pm 0,06$ & $0,17 \pm 0,08$ & 0.002 & $0.75(0.06)$ & $11 / 27$ \\
\hline & $\mathrm{N} 2$ & $0,16 \pm 0,11$ & $0,31 \pm 0,17$ & 0.001 & $0.79(0.06)$ & $15 / 27$ \\
\hline \multirow{2}{*}{$\begin{array}{l}\text { Quadrante TS } \\
\text { (12 respostas) }\end{array}$} & P1 & $0,09 \pm 0,05$ & $0,14 \pm 0,06$ & 0.003 & $0.73(0.06)$ & $10 / 27$ \\
\hline & $\mathrm{N} 2$ & $0,14 \pm 0,08$ & $0,26 \pm 0,13$ & $<0.001$ & $0.81(0.06)$ & $14 / 27$ \\
\hline \multirow{2}{*}{$\begin{array}{l}\text { Quadrante TI } \\
\text { (12 respostas) }\end{array}$} & P1 & $0,12 \pm 0,07$ & $0,20 \pm 0,11$ & 0.003 & $0.74(0.06)$ & $14 / 27$ \\
\hline & $\mathrm{N} 2$ & $0,18 \pm 0,14$ & $0,35 \pm 0,21$ & 0.002 & $0.79(0.06)$ & $17 / 27$ \\
\hline \multirow{2}{*}{$\begin{array}{l}\text { Quadrante NS } \\
\text { (12 respostas) }\end{array}$} & P1 & $0,14 \pm 0,07$ & $0,15 \pm 0,08$ & 0.475 & $0.53(0.07)$ & $4 / 27$ \\
\hline & $\mathrm{N} 2$ & $0,25 \pm 0,13$ & $0,29 \pm 0,15$ & 0.306 & $0.57(0.07)$ & $5 / 27$ \\
\hline \multirow{2}{*}{$\begin{array}{l}\text { Quadrante NI } \\
\text { (12 respostas) }\end{array}$} & $\mathrm{P} 1$ & $0,17 \pm 0,08$ & $0,21 \pm 0,11$ & 0.183 & $0.59(0.07)$ & $5 / 27$ \\
\hline & $\mathrm{N} 2$ & $0,30 \pm 0,16$ & $0,37 \pm 0,21$ & 0.238 & $0.57(0.07)$ & $7 / 27$ \\
\hline
\end{tabular}

* GEE. Valores significantes em itálico. ** Olhos com AB abaixo do percentil 10. $\mathrm{TS}=$ temporal superior; $\mathrm{TI}=$ temporal inferior; $\mathrm{NS}=$ nasal superior; $\mathrm{NI}=$ nasal inferior. $\mathrm{EP}=$ erro padrão

A Tabela 3 demonstra as médias das amplitudes obtidas no PEV-mf central em olhos com $\mathrm{AB}$ e em controles. A média de todas as respostas P1 e N2 temporais (hemicampo temporal, quadrante temporal superior e inferior) do PEV-mf central foram significativamente menores nos pacientes com $\mathrm{AB}$ que nos controles, após a correção de Bonferroni ( $\alpha=0,004 ; 12$ comparações). Não houve diferença entre os grupos no que concerne a análise das médias das respostas nasais do PEV-mf central (hemicampo nasal e quadrantes nasais). Por outro lado, a análise da área sobre a curva ROC (AROC) do PEV-mf central indicou que os melhores parâmetros de amplitude 
de P1 foram do hemicampo temporal e do quadrante TI $(\mathrm{AROC}=0,80)$, seguido do quadrante TS (AROC=0,79). Já em relação a amplitude de N2, os melhores parâmetros do PEV-mf central foram do quadrante TS (AROC=0,84), seguido pelo hemicampo temporal $(\mathrm{AROC}=0,82)$ e pelo quadrante TI (AROC $=0,81)$. A Tabela 3 também demonstra a proporção de olhos classificados como anormais com base na amplitude de P1 e N2, utilizando o percentil 10 dos normais.

Tabela 3: Valores médios ( \pm desvio padrão) da amplitude das respostas P1 e N2 $(\mathrm{em} \mu \mathrm{V})$ do PEV-mf central em 27 olhos de pacientes portadores de $\mathrm{AB}$ e em 43 olhos de controles normais com suas respectivas áreas sob a curva "receiver operating characteristic" (AROC)

\begin{tabular}{lcccccc}
\hline Parâmetro & & $\begin{array}{c}\text { AB } \\
(\mathbf{n}=\mathbf{2 7})\end{array}$ & $\begin{array}{c}\text { Controles } \\
(\mathbf{n = 4 3})\end{array}$ & $\begin{array}{c}\text { Valor } \\
\boldsymbol{d e} \boldsymbol{p}^{*}\end{array}$ & $\begin{array}{c}\text { AROC } \\
(\mathbf{E P})\end{array}$ & $\begin{array}{c}\text { Olhos } \\
\text { Anormal/ } \\
\text { normal ** }\end{array}$ \\
\hline $\begin{array}{l}\text { Amplitude } \\
\text { PEV-mf central }(\boldsymbol{\mu V})\end{array}$ & & & & & & \\
\hline Média Nasal & $\mathrm{P} 1$ & $0,18 \pm 0,09$ & $0,23 \pm 0,12$ & 0.09 & $0.62(0.07)$ & $8 / 27$ \\
(12 respostas) & $\mathrm{N} 2$ & $0,32 \pm 0,17$ & $0,42 \pm 0,23$ & 0.10 & $0.62(0.07)$ & $9 / 27$ \\
\hline Média Temporal & $\mathrm{P} 1$ & $0,11 \pm 0,07$ & $0,22 \pm 0,11$ & $<0.001$ & $0.80(0.05)$ & $12 / 27$ \\
(12 respostas) & $\mathrm{N} 2$ & $0,18 \pm 0,13$ & $0,39 \pm 0,22$ & $<0.001$ & $0.82(0.05)$ & $13 / 27$ \\
\hline Quadrante TS & $\mathrm{P} 1$ & $0,11 \pm 0,06$ & $0,19 \pm 0,09$ & $<0.001$ & $0.79(0.05)$ & $12 / 27$ \\
(6 respostas) & $\mathrm{N} 2$ & $0,16 \pm 0,10$ & $0,34 \pm 0,18$ & $<0.001$ & $0.84(0.05)$ & $15 / 27$ \\
\hline Quadrante TI & $\mathrm{P} 1$ & $0,12 \pm 0,08$ & $0,24 \pm 0,14$ & $<0.001$ & $0.80(0.06)$ & $17 / 27$ \\
(6 respostas) & $\mathrm{N} 2$ & $0,19 \pm 0,16$ & $0,43 \pm 0,27$ & $<0.001$ & $0.81(0.06)$ & $17 / 27$ \\
\hline Quadrante NS & $\mathrm{P} 1$ & $0,17 \pm 0,09$ & $0,21 \pm 0,11$ & 0.19 & $0.58(0.07)$ & $4 / 27$ \\
(6 respostas) & $\mathrm{N} 2$ & $0,31 \pm 0,16$ & $0,38 \pm 0,20$ & 0.18 & $0.58(0.07)$ & $7 / 27$ \\
\hline Quadrante NI & $\mathrm{P} 1$ & $0,19 \pm 0,10$ & $0,26 \pm 0,14$ & 0.05 & $0.65(0.07)$ & $5 / 27$ \\
\hline 6 respostas) & $\mathrm{N} 2$ & $0,34 \pm 0,18$ & $0,46 \pm 0,27$ & 0.07 & $0.63(0.07)$ & $9 / 27$ \\
\hline
\end{tabular}

GEE. Valores significantes em itálico. ** Olhos com AB abaixo do percentil 10. $\mathrm{TS}=$ temporal superior; $\mathrm{TI}=$ temporal inferior; $\mathrm{NS}=$ nasal superior; $\mathrm{NI}=$ nasal inferior. $\mathrm{EP}=$ erro padrão 
Os valores médios das latências (ms) tanto no PEV-mf global (Tabela 4), quanto no PEV-mf central (Tabela 5) foram calculados e não apresentaram diferenças entre os grupos ao se aplicar a correção de Bonferroni ( $\alpha=0,004 ; 12$ comparações).

Tabela 4: Valores médios ( \pm desvio padrão) da latência das respostas P1 e N2 (em ms) do PEV-m global em 27 olhos de pacientes portadores de AB e em 43 olhos de controles normais

\begin{tabular}{llc}
\hline Parâmetro & AB \\
$(\mathrm{n}=27)$ & Controles & Valor de $p^{*}$ \\
& $(\mathrm{n}=43)$ & \\
\hline
\end{tabular}

\section{Latência}

PEV-mf global (ms)

\begin{tabular}{lcccc}
\hline & P1 & $100,83 \pm 6,38$ & $100,78 \pm 5,29$ & 0,97 \\
Média Nasal (24 respostas) & N2 & $151,03 \pm 7,30$ & $151,41 \pm 6,16$ & 0,85 \\
\hline \multirow{2}{*}{ Média Temporal (24 respostas) } & P1 & $103,02 \pm 5,51$ & $100,71 \pm 4,98$ & 0,12 \\
\hline & N2 & $154,87 \pm 6,48$ & $150,87 \pm 6,13$ & $<0,05$ \\
\hline Quadrante TS (12 respostas) & P1 & $104,25 \pm 6,22$ & $102,22 \pm 6,15$ & 0,25 \\
\hline & N2 & $155,77 \pm 6,38$ & $152,27 \pm 6,69$ & 0,06 \\
\hline Quadrante TI (12 respostas) & P1 & $101,79 \pm 6,27$ & $99,20 \pm 5,05$ & 0,09 \\
\hline & N2 & $153,97 \pm 8,68$ & $149,46 \pm 6,64$ & $<0,05$ \\
\hline Quadrante NS (12 respostas) & P1 & $101,51 \pm 7,14$ & $101,30 \pm 6,47$ & 0,91 \\
\hline & N2 & $151,11 \pm 8,12$ & $151,60 \pm 6,41$ & 0,81 \\
\hline
\end{tabular}

* GEE. Valores significantes em itálico. TS $=$ temporal superior; $\mathrm{TI}=$ temporal inferior; $\mathrm{NS}=$ nasal superior; $\mathrm{NI}=$ nasal inferior 
Tabela 5: Valores médios ( \pm desvio padrão) da latência das respostas P1 e N2 (em ms) do PEV-mf central em 27 olhos de pacientes portadores de AB e em 43 olhos de controles normais

\begin{tabular}{|c|c|c|c|c|}
\hline Parâmetro & & $\begin{array}{l}A B \\
(n=27)\end{array}$ & $\begin{array}{l}\text { Controles } \\
\qquad(n=43)\end{array}$ & Valor de $p^{*}$ \\
\hline \multicolumn{5}{|l|}{ Latência } \\
\hline \multicolumn{5}{|l|}{ PEV-mf central (ms) } \\
\hline \multirow{2}{*}{ Média Nasal (12 respostas) } & $\mathrm{P} 1$ & $103,70 \pm 7,09$ & $102,57 \pm 5,96$ & 0,53 \\
\hline & $\mathrm{N} 2$ & $153,07 \pm 7,83$ & $151,04 \pm 6,97$ & 0,34 \\
\hline \multirow{2}{*}{ Média Temporal (12 respostas) } & $\mathrm{P} 1$ & $105,19 \pm 5,49$ & $103,04 \pm 6,50$ & 0,20 \\
\hline & $\mathrm{N} 2$ & $157,27 \pm 7,72$ & $151,30 \pm 7,51$ & $<0,05$ \\
\hline \multirow{2}{*}{ Quadrante TS (6 respostas) } & $\mathrm{P} 1$ & $106,87 \pm 6,38$ & $104,81 \pm 7,20$ & 0,28 \\
\hline & $\mathrm{N} 2$ & $158,45 \pm 8,48$ & $152,53 \pm 7,56$ & $<0,05$ \\
\hline \multirow{2}{*}{ Quadrante TI (6 respostas) } & $\mathrm{P} 1$ & $103,51 \pm 7,73$ & $101,26 \pm 7,04$ & 0,22 \\
\hline & $\mathrm{N} 2$ & $156,10 \pm 10,34$ & $150,06 \pm 8,50$ & $<0,05$ \\
\hline \multirow{2}{*}{ Quadrante NS (6 respostas) } & $\mathrm{P} 1$ & $104,82 \pm 7,62$ & $104,19 \pm 7,45$ & 0,75 \\
\hline & $\mathrm{N} 2$ & $153,34 \pm 9,97$ & $152,28 \pm 8,08$ & 0,67 \\
\hline \multirow{2}{*}{ Quadrante NI (6 respostas) } & $\mathrm{P} 1$ & $102,57 \pm 8,89$ & $100,96 \pm 6,05$ & 0,41 \\
\hline & $\mathrm{N} 2$ & $152,80 \pm 9,06$ & $149,81 \pm 7,80$ & 0,20 \\
\hline
\end{tabular}

* GEE. Valores significantes em itálico. TS = temporal superior; $\mathrm{TI}=$ temporal inferior; $\mathrm{NS}=$ nasal superior; $\mathrm{NI}=$ nasal inferior.

A Tabela 6 demonstra as comparações entre a média \pm desvio padrão dos dados obtidos na perimetria Humphrey dos pacientes com AB com os dados obtidos dos controle normais. O desvio da normalidade dos dados do CV 24-2 foram calculados em 50 pontos de teste do CV divididos em quadrantes e hemicampos temporal e nasal. Da mesma forma, os desvios da normalidade da perimetria 10-2 correspondente aos 68 pontos de teste do $\mathrm{CV}$ foram calculados em quadrantes e hemicampos temporal e nasal e encontram-se plotados na tabela 4. Observam-se diferenças estatisticamente significativa em cada quadrante e hemicampo nos olhos com AB quando comparado com olhos de controles normais $(\mathrm{P}<0,001)$ no CV 24-2. 
Por outro lado, embora observe-se diferença estatística em todas as médias calculadas no CV 10-2 entre os dois grupos, esta diferença estatística não se manteve entre os grupos no que concerne as médias dos quadrantes nasal inferior (na analise em $\mathrm{dB}$ e 1/Lambert) e no quadrante nasal superior (analise em dB) após aplicada a correção de Bonferroni ( $\alpha=0,004 ; 12$ comparações).

Tabela 6: Comparação entre a média \pm desvio padrão das medidas do CV $24-2$ e 10-2 entre os pacientes portadores de $\mathrm{AB}$ e os controles normais.

\begin{tabular}{|c|c|c|c|c|}
\hline $\begin{array}{c}\text { CV } \\
\text { (desvio da média) }\end{array}$ & & $\begin{array}{c}\mathbf{A B} \\
(\mathbf{n}=27)\end{array}$ & $\begin{array}{c}\text { Controles } \\
(n=43)\end{array}$ & Valor de $p^{*}$ \\
\hline \multicolumn{5}{|l|}{ Perimetria 24-2 } \\
\hline \multirow{2}{*}{ Hemicampo nasal } & $\mathrm{dB}$ & $-1,04 \pm 0,95$ & $0,13 \pm 0,76$ & $<0,001$ \\
\hline & $1 / \mathrm{L}$ & $0,81 \pm 0,19$ & $1,05 \pm 0,18$ & $<0,001$ \\
\hline \multirow{2}{*}{ Hemicampo temporal } & $\mathrm{dB}$ & $-15,09 \pm 10,67$ & $0,34 \pm 0,75$ & $<0,001$ \\
\hline & $1 / \mathrm{L}$ & $0,17 \pm 0,25$ & $1,10 \pm 0,20$ & $<0,001$ \\
\hline \multirow{2}{*}{ Quadrante TS } & $\mathrm{dB}$ & $-16,60 \pm 10,15$ & $0,40 \pm 0,93$ & $<0,001$ \\
\hline & $1 / \mathrm{L}$ & $0,13 \pm 0,21$ & $1,12 \pm 0,25$ & $<0,001$ \\
\hline \multirow{2}{*}{ Quadrante TI } & $\mathrm{dB}$ & $-13,57 \pm 11,53$ & $0,28 \pm 0,69$ & $<0,001$ \\
\hline & $1 / \mathrm{L}$ & $0,26 \pm 0,32$ & $1,08 \pm 0,18$ & $<0,001$ \\
\hline \multirow{2}{*}{ Quadrante NS } & $\mathrm{dB}$ & $-0,93 \pm 0,97$ & $0,31 \pm 0,97$ & $<0,001$ \\
\hline & $1 / \mathrm{L}$ & $0,83 \pm 0,19$ & $1,10 \pm 0,23$ & $<0,001$ \\
\hline \multirow{2}{*}{ Quadrante NI } & $\mathrm{dB}$ & $-1,16 \pm 1,15$ & $-0,04 \pm 0,74$ & $<0,001$ \\
\hline & $1 / \mathrm{L}$ & $0,79 \pm 0,23$ & $1,00 \pm 0,17$ & $<0,001$ \\
\hline \multicolumn{5}{|l|}{ Perimetria 10-2 } \\
\hline \multirow{2}{*}{ Hemicampo nasal } & $\mathrm{dB}$ & $-0,83 \pm 1,16$ & $0,05 \pm 0,75$ & $<0,001$ \\
\hline & $1 / \mathrm{L}$ & $0,85 \pm 0,22$ & $1,03 \pm 0,16$ & $<0,001$ \\
\hline \multirow{2}{*}{ Hemicampo temporal } & $\mathrm{dB}$ & $-13,64 \pm 12,27$ & $-0,11 \pm 0,73$ & $<0,001$ \\
\hline & $1 / \mathrm{L}$ & $0,27 \pm 0,32$ & $0,99 \pm 0,15$ & $<0,001$ \\
\hline \multirow{2}{*}{ Quadrante TS } & $\mathrm{dB}$ & $-13,07 \pm 11,80$ & $-0,05 \pm 0,80$ & $<0,001$ \\
\hline & $1 / \mathrm{L}$ & $0,27 \pm 0,29$ & $1,00 \pm 0,17$ & $<0,001$ \\
\hline \multirow{2}{*}{ Quadrante TI } & $\mathrm{dB}$ & $-14,22 \pm 13,09$ & $-0,17 \pm 0,74$ & $<0,001$ \\
\hline & $1 / \mathrm{L}$ & $0,29 \pm 0,36$ & $0,97 \pm 0,16$ & $<0,001$ \\
\hline \multirow{2}{*}{ Quadrante NS } & $\mathrm{dB}$ & $-0,55 \pm 0,92$ & $0,22 \pm 0,83$ & $<0,05$ \\
\hline & $1 / \mathrm{L}$ & $0,90 \pm 0,19$ & $1,07 \pm 0,19$ & $<0,001$ \\
\hline \multirow{2}{*}{ Quadrante NI } & $\mathrm{dB}$ & $-1,12 \pm 1,65$ & $-0,12 \pm 0,75$ & $<0,05$ \\
\hline & $1 / \mathrm{L}$ & $0,82 \pm 0,27$ & $0,99 \pm 0,17$ & $<0,05$ \\
\hline
\end{tabular}

* GEE. Valores significantes em itálico. TS = temporal superior; TI = temporal inferior; NS = nasal superior; $\mathrm{NI}=$ nasal inferior. 
Foram analisadas as correlações entre os exames de PEV-mf global e central com os exames de CV 24-2 e 10-2 para os hemicampos e quadrantes (Tabela 7), sendo posteriormente destacadas as principais correlações (Gráficos 3 e 4).

Tabela 7: Correlação entre os parâmetros das amplitudes do PEV-mf global e central com os parâmetros de sensibilidade calculados a partir do CV 24-2 e do CV 10-2

\begin{tabular}{|c|c|c|c|c|c|c|c|c|c|c|c|c|}
\hline \multicolumn{13}{|c|}{ Parâmetros do Campo Visual } \\
\hline & \multicolumn{12}{|c|}{ CV 24-2 (50 pontos de teste) } \\
\hline & \multicolumn{2}{|c|}{$\mathbf{H N}$} & \multicolumn{2}{|c|}{ HT } & \multicolumn{2}{|c|}{ NS } & \multicolumn{2}{|c|}{ NI } & \multicolumn{2}{|c|}{ TS } & \multicolumn{2}{|c|}{ TI } \\
\hline $\begin{array}{l}\text { Parâmetros do } \\
\text { PEV-mf }\end{array}$ & $\mathrm{dB}$ & $1 / \mathrm{L}$ & $\mathrm{dB}$ & $1 / \mathrm{L}$ & $\mathrm{dB}$ & $1 / \mathrm{L}$ & $\mathrm{dB}$ & $1 / \mathrm{L}$ & $\mathrm{dB}$ & $1 / \mathrm{L}$ & $\mathrm{dB}$ & $1 / \mathrm{L}$ \\
\hline \multicolumn{13}{|l|}{ Média Global } \\
\hline P1 hemicampo nasal & $-0,01$ & $-0,07$ & 0,23 & 0,18 & $-0,04$ & $-0,10$ & 0,02 & $-0,02$ & 0,21 & 0,17 & 0,24 & 0,19 \\
\hline N2 hemicampo nasal & $-0,01$ & $-0,07$ & 0,24 & 0,18 & $-0,04$ & $-0,11$ & 0,04 & $-0,01$ & 0,21 & 0,17 & 0,25 & 0,19 \\
\hline P1 hemicampo temporal & 0,26 & 0,16 & $\underline{\mathbf{0 , 5 0}}$ & $\underline{0,42}$ & 0,21 & 0,13 & 0,27 & 0,16 & $\underline{0,47}$ & $\underline{0,40}$ & $\underline{0,51}$ & $\underline{0,43}$ \\
\hline N2 hemicampo temporal & $\underline{\mathbf{0 , 3 3}}$ & 0,18 & $\underline{0,58}$ & $\underline{0,47}$ & 0,29 & 0,15 & $\underline{\mathbf{0 , 3 3}}$ & 0,18 & $\underline{0,56}$ & $\underline{0,45}$ & $\underline{\mathbf{0 , 5 9}}$ & $\underline{0,48}$ \\
\hline P1 Quadrante NS & $-0,04$ & $-0,09$ & 0,15 & 0,10 & $-0,04$ & $-0,09$ & $-0,04$ & $-0,07$ & 0,14 & 0,10 & 0,15 & 0,11 \\
\hline N2 Quadrante NS & 0,02 & $-0,06$ & 0,22 & 0,16 & 0,01 & $-0,08$ & 0,02 & $-0,03$ & 0,20 & 0,16 & 0,22 & 0,17 \\
\hline P1 Quadrante TS & 0,22 & 0,15 & $\underline{0,44}$ & $\underline{0,38}$ & 0,20 & 0,14 & 0,20 & 0,13 & $\underline{0,42}$ & $\underline{0,37}$ & $\underline{0,45}$ & $\underline{0,39}$ \\
\hline N2 Quadrante TS & $\underline{\mathbf{0 , 3 1}}$ & 0,19 & $\underline{0,58}$ & $\underline{\mathbf{0 , 4 8}}$ & 0,28 & 0,17 & $\mathbf{0 , 3 0}$ & 0,18 & $\underline{\mathbf{0 , 5 6}}$ & $\underline{0,47}$ & $\underline{\mathbf{0 , 5 8}}$ & $\underline{\mathbf{0 , 4 8}}$ \\
\hline P1 Quadrante NI & $-0,01$ & $-0,05$ & 0,28 & 0,22 & $-0,05$ & $-0,10$ & 0,05 & 0,01 & 0,26 & 0,21 & $\mathbf{0 , 3 0}$ & 0,24 \\
\hline N2 Quadrante NI & $-0,01$ & $-0,07$ & 0,25 & 0,19 & $-0,06$ & $-0,13$ & 0,05 & $-0,00$ & 0,22 & 0,18 & 0,26 & 0,21 \\
\hline P1 Quadrante TI & 0,28 & 0,16 & $\underline{0,52}$ & $\underline{0,42}$ & 0,22 & 0,11 & $\mathbf{0 , 3 0}$ & 0,17 & $\underline{0,49}$ & $\underline{0,40}$ & $\underline{0,55}$ & $\underline{0,44}$ \\
\hline \multirow[t]{3}{*}{ N2 Quadrante TI } & $\underline{0,35}$ & 0,17 & $\underline{0,58}$ & $\underline{0,45}$ & 0,30 & 0,14 & $\underline{0,35}$ & 0,18 & $\underline{0,55}$ & $\underline{0,42}$ & $\underline{0,60}$ & $\underline{0,47}$ \\
\hline & \multicolumn{12}{|c|}{ CV 10-2 (68 pontos de teste) } \\
\hline & \multicolumn{2}{|c|}{ HN } & \multicolumn{2}{|c|}{ HT } & \multicolumn{2}{|c|}{ NS } & \multicolumn{2}{|c|}{ NI } & \multicolumn{2}{|c|}{ TS } & \multicolumn{2}{|c|}{ TI } \\
\hline $\begin{array}{l}\text { Parâmetros do } \\
\text { PEV-mf }\end{array}$ & $\mathrm{dB}$ & $1 / \mathrm{L}$ & $\mathrm{dB}$ & $1 / \mathrm{L}$ & $\mathrm{dB}$ & $1 / \mathrm{L}$ & $\mathrm{dB}$ & $1 / \mathrm{L}$ & $\mathrm{dB}$ & $1 / \mathrm{L}$ & $\mathrm{dB}$ & $1 / \mathrm{L}$ \\
\hline \multicolumn{13}{|l|}{ Média Central } \\
\hline P1 hemicampo nasal & 0,15 & 0,11 & 0,26 & 0,23 & 0,15 & 0,09 & 0,10 & 0,09 & 0,26 & 0,24 & 0,26 & 0,22 \\
\hline N2 hemicampo nasal & 0,15 & 0,10 & 0,26 & 0,22 & 0,16 & 0,09 & 0,11 & 0,08 & 0,26 & 0,23 & 0,26 & 0,21 \\
\hline P1 hemicampo temporal & $\underline{\mathbf{0 , 3 8}}$ & 0,29 & $\underline{0,56}$ & $\underline{0,47}$ & $\underline{0,39}$ & 0,29 & $\underline{\mathbf{0 , 3 1}}$ & 0,25 & $\underline{\mathbf{0 , 5 6}}$ & $\underline{0,48}$ & $\underline{\mathbf{0 , 5 4}}$ & $\underline{\mathbf{0 , 4 6}}$ \\
\hline $\mathrm{N} 2$ hemicampo temporal & $\underline{\mathbf{0 , 4 0}}$ & 0,29 & $\underline{0,59}$ & $\underline{0,49}$ & $\underline{0,41}$ & 0,28 & $\underline{\mathbf{0 , 3 3}}$ & 0,25 & $\underline{\mathbf{0 , 6 0}}$ & $\underline{0,49}$ & $\underline{0,57}$ & $\underline{0,48}$ \\
\hline P1 Quadrante NS & 0,06 & 0,04 & 0,15 & 0,13 & 0,11 & 0,05 & $-0,01$ & 0,00 & 0,16 & 0,14 & 0,13 & 0,11 \\
\hline N2 Quadrante NS & 0,06 & 0,04 & 0,17 & 0,15 & 0,10 & 0,05 & 0,00 & 0,02 & 0,17 & 0,16 & 0,16 & 0,14 \\
\hline P1 Quadrante TS & $\underline{0,34}$ & 0,27 & $\underline{\mathbf{0 , 5 0}}$ & $\underline{\mathbf{0 , 4 4}}$ & $\underline{0,35}$ & 0,27 & 0,26 & 0,22 & $\underline{\mathbf{0 , 5 2}}$ & $\underline{0,45}$ & $\underline{0,47}$ & $\underline{0,42}$ \\
\hline N2 Quadrante TS & $\underline{0,37}$ & 0,27 & $\underline{0,58}$ & $\underline{0,48}$ & $\underline{0,38}$ & 0,27 & 0,29 & 0,23 & $\underline{0,60}$ & $\underline{0,50}$ & $\underline{0,54}$ & $\underline{0,46}$ \\
\hline P1 Quadrante NI & 0,20 & 0,15 & $\underline{0,35}$ & 0,29 & 0,16 & 0,12 & 0,17 & 0,15 & $\underline{\mathbf{0 , 3 3}}$ & $\mathbf{0 , 3 0}$ & $\underline{0,36}$ & 0,29 \\
\hline N2 Quadrante NI & 0,19 & 0,14 & $\mathbf{0 , 3 1}$ & 0,27 & 0,17 & 0,11 & 0,15 & 0,13 & $\mathbf{0 , 3 0}$ & 0,28 & $\mathbf{0 , 3 1}$ & 0,25 \\
\hline P1 Quadrante TI & $\underline{\mathbf{0 , 4 0}}$ & 0,29 & $\underline{0,58}$ & $\underline{0,47}$ & $\underline{0,41}$ & 0,29 & $\underline{\mathbf{0 , 3 3}}$ & 0,25 & $\underline{\mathbf{0 , 5 8}}$ & $\underline{0,47}$ & $\underline{0,57}$ & $\underline{0,46}$ \\
\hline N2 Quadrante TI & $\underline{0,42}$ & 0,29 & $\underline{0,59}$ & $\underline{0,48}$ & $\underline{0,41}$ & 0,28 & $\underline{0,35}$ & 0,25 & $\underline{\mathbf{0 , 5 8}}$ & $\underline{0,48}$ & $\underline{\mathbf{0 , 5 9}}$ & $\underline{0,47}$ \\
\hline
\end{tabular}

$\mathrm{N}=70$. Dados com coeficientes obtidos a partir da correlação de Pearson (1/Lambert) e de Spearman (decibel). negrito $=p<0,05$; negrito e sublinhado $=p \leq 0,01$. HN $=$ hemicampo nasal, $\mathrm{HT}=$ hemicampo temporal, $\mathrm{TS}=$ temporal superior; $\mathrm{TI}=$ temporal inferior; $\mathrm{NS}=$ nasal superior; $\mathrm{NI}=$ nasal inferior . 
O Gráfico 3 demonstra a correlação entre a média dos parâmetros temporais do CV 24-2 em dB e as médias das amplitudes temporais obtidas no PEV-mf global. Observou-se correlação significativa entre todos os parâmetros analisados utilizando a correção de Bonferroni( $\alpha=0,004 ; 12$ comparações). A correlação mais relevante foi encontrada entre a média da amplitude N2 do quadrante temporal inferior e a média da sensibilidade em dB do quadrante temporal inferior $(r=0,60)$, seguida da média da amplitude do hemicampo temporal e a média da sensibilidade em dB do hemicampo temporal $(\mathrm{r}=0,58)$. A correlação mais fraca entre os grupos foi observada para a média da amplitude do quadrante temporal superior e a média da sensibilidade em dB do quadrante temporal superior $(\mathrm{r}=0,42)$. Porém, todas as comparações entre os grupos no setor temporal demonstraram correlação moderada no que concerne a média das amplitudes do PEV-mf global e a média da sensibilidade em dB do CV 24-2.

O Gráfico 4 demonstra a correlação entre a média dos parâmetros temporais do CV 24-2 em escala linear (1/Lambert) e a média das amplitudes temporais obtidas pelo PEV-mf global. Observou-se correlação estatisticamente significante entre todos os parâmetros analisados do setor temporal, entretanto a correlação observada foi mais fraca do que a encontrada entre a média das amplitudes do PEV-mf global e a média da sensibilidade em $\mathrm{dB}$ da perimetria 24-2. A correlação mais relevante ocorreu entre a média da sensibilidade em 1/Lambert do CV 24-2 e a média da amplitude do PEV-mf global no hemicampo temporal, no quadrante temporal superior e no quadrante temporal inferior $(\mathrm{r}=0,47 ; \mathrm{p}<0,001$, para todos os três parâmetros anteriores). Por outro lado, a correlação mais fraca foi observada entre a média da amplitude do quadrante temporal superior quando comparada a média da sensibilidade em 1/Lambert do quadrante temporal superior $(\mathrm{r}=0,37)$, o que corresponde ao mesmo local da mais fraca correlação obtida entre a média das amplitudes do PEV-mf global e a sensibilidade do CV 24-2 em escala logarítmica (dB). 
Gráfico 3: Gráficos de dispersão das médias temporais (hemicampo e quadrantes) da perimetria objetiva 24-2 (PEV-mf global) em $\mu$ Volts para amplitude de P1 (coluna da esquerda) e para amplitude de N2 (coluna da direita) plotadas contra as médias da sensibilidade da perimetria subjetiva CV 24-2 em escala logarítmica (decibéis). Em cada gráfico de dispersão é dado o valor da correlação de Spearman (r) e a significância da associação (p)
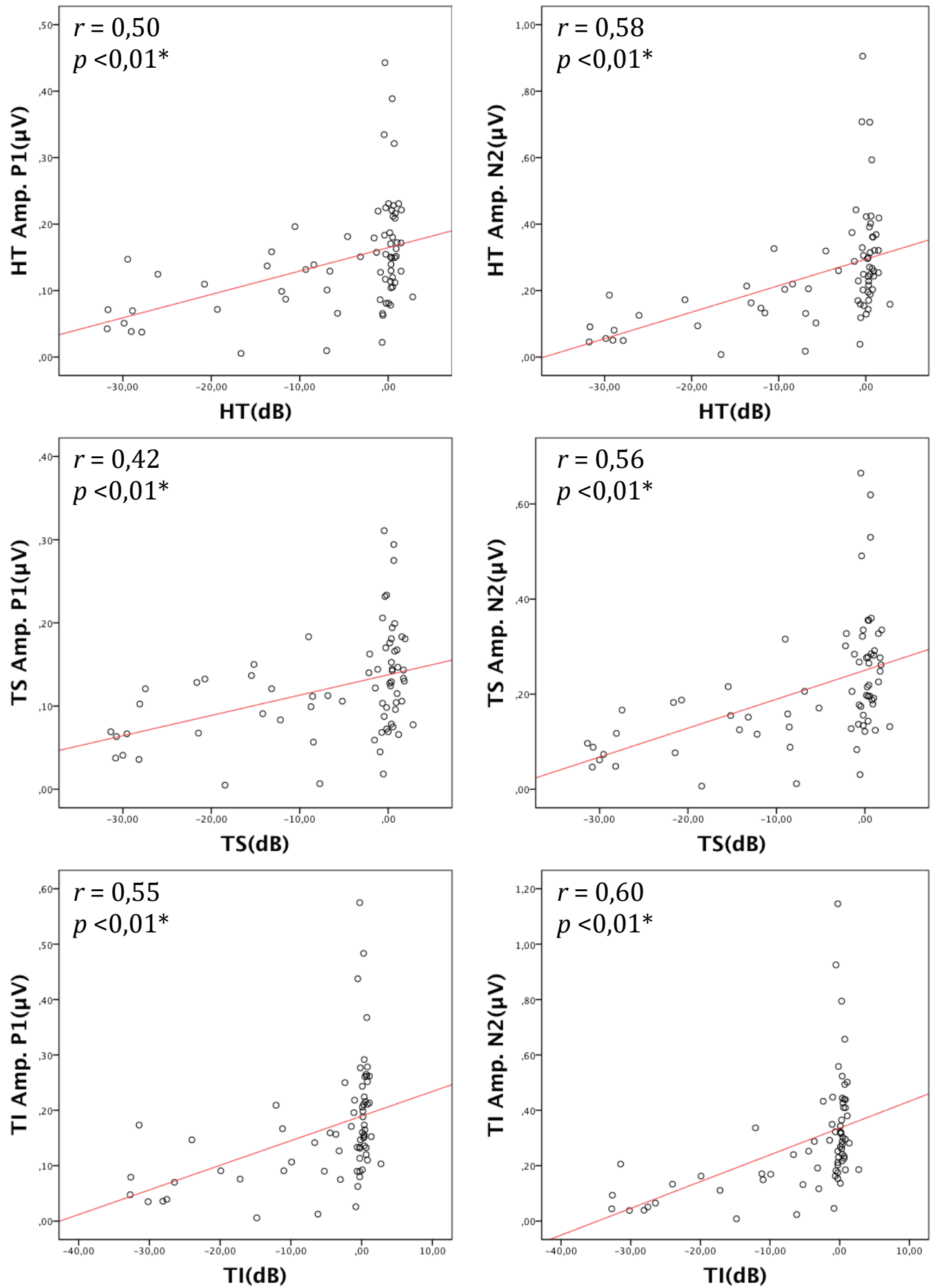

$\mathrm{HT}=$ hemicampo temporal; $\mathrm{TS}=$ temporal superior; $\mathrm{TI}=$ temporal inferior 
Gráfico 4: Gráficos de dispersão das médias temporais (hemicampo e quadrantes) da perimetria objetiva 24-2 (PEV-mf global) em $\mu$ Volts para amplitude de P1 (coluna da esquerda) e para amplitude de N2 (coluna da direita) plotadas contra as médias da sensibilidade da perimetria subjetiva CV 24-2 em escala linear (1/Lambert). Em cada gráfico de dispersão é dado o valor da correlação de Pearson (r) e a significância da associação (p)
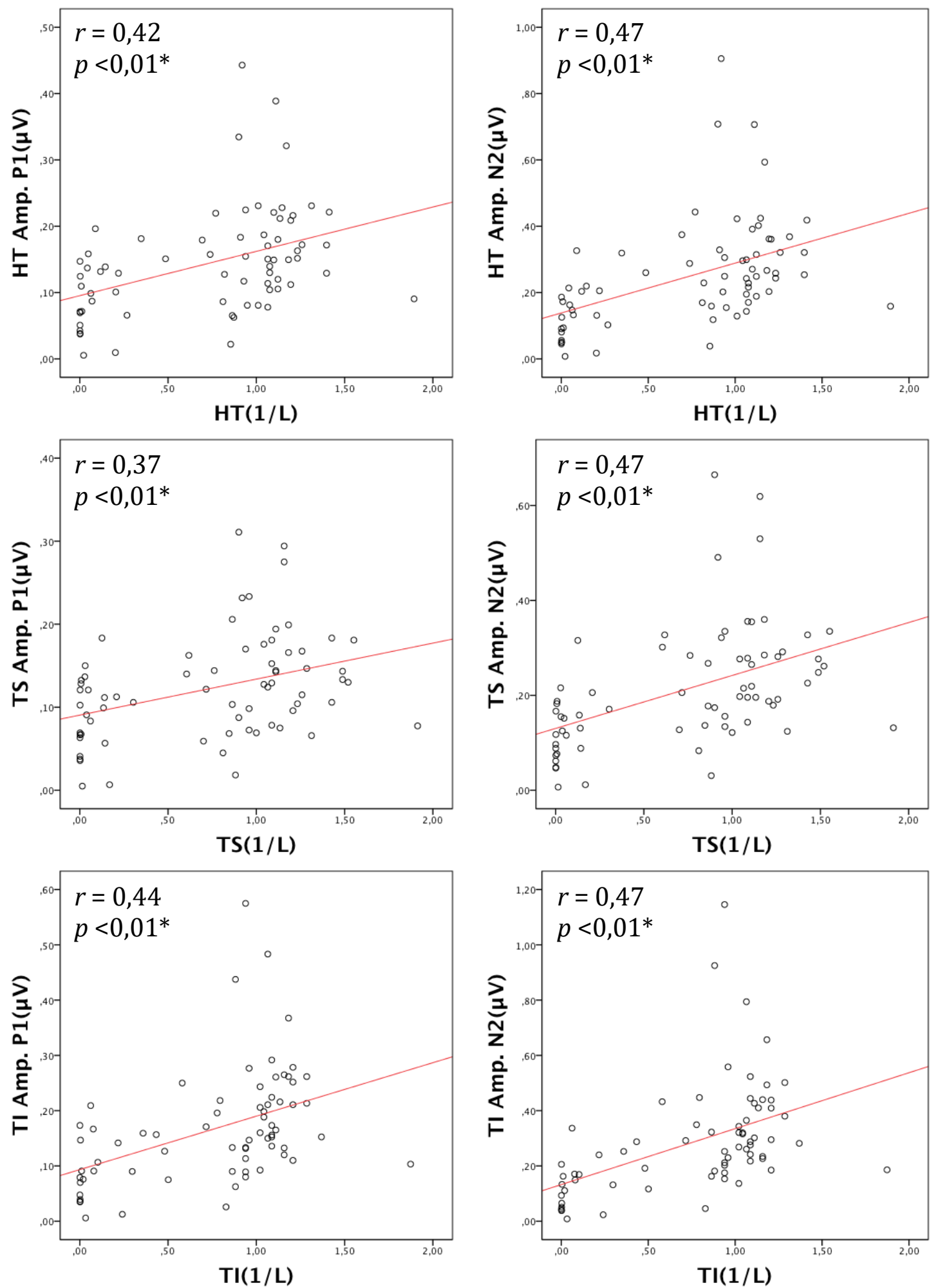

$\mathrm{HT}=$ hemicampo temporal; $\mathrm{TS}=$ temporal superior; $\mathrm{TI}=$ temporal inferior 
Ao analisar os dados de estrutura obtidos pelo TCO-dF, foi observada a média da espessura macular total de $236,85 \mu \mathrm{m}$ nos pacientes com $\mathrm{AB}$ e de $259,57 \mu \mathrm{m}$ nos controles normais ( $\mathrm{p}<0.001)$; e a média da espessura da CFNR peripapilar total de 81,63 $\mu \mathrm{m}$ nos pacientes com $\mathrm{AB}$ e de $108,17 \mu \mathrm{m}$ nos controles $(\mathrm{p}<0,001)$. A Tabela 8 demonstra os resultado das comparações entre os dados de estrutura do TCO-dF da espessura da CFNR peripapilar e da espessura macular $(\mathrm{em} \mu \mathrm{m})$ entre os portadores de $\mathrm{AB}$ e os controles. Todas as medidas foram significativamente menores nos olhos com AB que nos controles ( $<<0,001)$. A análise da curva ROC indicou que a melhor performance para o TCO de espessura macular foi para o quadrante NS (AROC $=0.98$ ) ou para espessura da hemirretina nasal $(A R O C=0.98)$, seguida pela espessura do quadrante NI $($ AROC $=0.97)$. Já a melhor performance para os dados do TCO da CFNR peripapilar correspondeu a média dos segmentos $8,7,6$ e 5 em horas de relógio (AROC= 0.94), seguida pela média dos segmentos $10,11,12$ e 1 em horas de relógio (AROC= 0.93) e pela média dos segmentos 9,8 e 7 em horas de relógio $(\mathrm{AROC}=0.88)$. A Tabela 8 também demonstra a proporção de olhos classificados como anormais com base na espessura macular e peripapilar obtidas pelo TCO, utilizando o percentil 10 dos normais.

As Tabelas 2, 3 e 8 demonstram a proporção de olhos classificados como anormais com base no banco de dados da normalidade do estudo, utilizando o percentil 10 dos normais para o PEV-mf e para o TCO. Sobre estas condições, a melhor capacidade em discriminar anormais obtida pelo PEV-mf foi observada para média da amplitude de N2 obtida no PEV-mf global no quadrante TI (17/27), para média da amplitude de N2 obtida no PEV-mf central no quadrante TI (17/27) e para média da amplitude de P1 obtida no PEV-mf central no quadrante TI (17/27). No TCO a melhor capacidade em discriminar anormais foi observada para a espessura macular do quadrante NS (26/27), para a espessura macular do quadrante NI (24/27) e para a 
espessura da hemirretina nasal (24/27). Não foi encontrada diferença significativa entre os parâmetros do PEV-mf e do TCO que obtiveram a melhor capacidade de discriminar anormais descritos acima ( $p>0,05$, Teste de McNemar). Não foi realizada a comparação da habilidade do CV de discriminar os anormais com os exames de PEV-mf e de TCO, pois o CV fazia parte dos critérios de inclusão do estudo.

Em pacientes com $\mathrm{AB}$, a espessura da CFNR peripapilar foi calculada em grupos para melhor comparação com o CV 24-2 e 10-2. Para correlação com as médias dos quadrantes e hemicampos da perimetria subjetiva $24-2$ e da perimetria objetiva $24-2$, a espessura CFNR peripapilar foi dividida em média \pm desvio padrão dos segmentos superiores: $10,11,12$ e 1 para correlação com o quadrante nasal superior $(\mathrm{r}=0,48$ para sensibilidade em $\mathrm{dB}, \mathrm{r}=0,49$ para sensibilidade em $1 /$ Lambert, $r=0,02$ para amplitude de P1 e r = 0,12 para amplitude de N2) e em 9, 10 e 11 para correlação com o quadrante temporal superior $(r=0,59$ para sensibilidade em $d B, r=0,60$ para a sensibilidade em 1/Lambert, $r=0,29$ para a amplitude de P1 e $r=0,42$ para amplitude de N2). Por outro lado, a espessura da CFNR foi calculada em média \pm desvio padrão dos segmentos inferiores: 8, 7, 6 e 5 para correlação com o quadrante nasal inferior $(\mathrm{r}=0,34$ para sensibilidade em $\mathrm{dB}, \mathrm{r}=0,30$ para sensibilidade em $1 /$ Lambert, $r=0,21$ para amplitude de P1 and $r=0,21$ para amplitude de N2) e em 9, 8 e 7 para correlação com o quadrante temporal inferior $(r=0,55$ para sensibilidade em $\mathrm{dB}, \mathrm{r}=0,58$ para sensibilidade em 1/Lambert, $r=0,34$ para amplitude de P1 e $r=0,42$ para amplitude de $\mathrm{N} 2$ ). As correspondentes divisões foram calculadas em média \pm desvio padrão para correlação com a perimetria subjetiva 10-2 e com a perimetria objetiva central e a espessura da CFNR peripapilar foi dividida nos segmentos: 9 e 10 para correlação com o quadrante nasal superior $(r=0,28$ para sensibilidade em $d B, r=0,26$ para a sensibilidade em 1/Lambert, $r=0,25$ para amplitude de $\mathrm{P} 1$ e $\mathrm{r}=0,30$ para amplitude de N2); 10 e 11 para correlação com o quadrante temporal superior $(r=0,52$ para sensibilidade em $\mathrm{dB}$, 
$r=0,58$ para sensibilidade em $1 /$ Lambert, $r=0,35$ para amplitude de $\mathrm{P} 1$ e $r=0,44$ para amplitude de N2); 8 e 7 para correlação com o quadrante nasal inferior ( $\mathrm{r}=0,32$ para sensibilidade em $\mathrm{dB}, \mathrm{r}=0,35$ para sensibilidade em $1 /$ Lambert, $r=0,27$ para amplitude de P1 e r = 0,26 para amplitude de N2); e 8 e 9 para correlação com o quadrante temporal inferior $(r=0,39$ para sensibilidade em $\mathrm{dB}, \mathrm{r}=0,41$ para sensibilidade em 1/Lambert, $\mathrm{r}$ $=0,36$ para amplitude de P1 e $\mathrm{r}=0,39$ para amplitude de $\mathrm{N} 2$ ). Todas as médias das espessuras maculares e dos grupos de segmentos da CFNR foram significativamente menores nos pacientes com $\mathrm{AB}$ quando comparados aos controles normais $(\mathrm{p}<0,001)$.

Tabela 8: Valores médios ( \pm desvio padrão) da espessura da CFNR peripapilar e da espessura macular (em $\mu \mathrm{m}$ ) obtidas pelo TCO em 27 olhos de pacientes portadores de $\mathrm{AB}$ e em 43 olhos de controles normais com suas respectivas áreas sob a curva "receiver operating characteristic" (AROC)

\begin{tabular}{|c|c|c|c|c|c|}
\hline Parâmetro & $\begin{array}{c}\mathbf{A B} \\
(\mathbf{n}=27)\end{array}$ & $\begin{array}{l}\text { Controles } \\
(n=43)\end{array}$ & $\begin{array}{l}\text { Valor } \\
\text { de } p^{*}\end{array}$ & $\begin{array}{l}\text { AROC } \\
(\text { EP })\end{array}$ & $\begin{array}{c}\text { Olhos } \\
\text { Anormal/ } \\
\text { normal ** }\end{array}$ \\
\hline \multicolumn{6}{|l|}{$\begin{array}{l}\text { TCO de espessura } \\
\text { macular }(\mu \mathrm{m})\end{array}$} \\
\hline Hemirretina Nasal & $240.02 \pm 11.12$ & $274.52 \pm 12.38$ & $<0.001$ & $0.98(0.01)$ & $24 / 27$ \\
\hline Hemirretina Temporal & $233.69 \pm 8.88$ & $244.63 \pm 10.00$ & $<0.001$ & $0.79(0.05)$ & $8 / 27$ \\
\hline Quadrante TS & $234.37 \pm 9.55$ & $245.49 \pm 9.93$ & $<0.001$ & $0.79(0.05)$ & $9 / 27$ \\
\hline Quadrante TI & $233.00 \pm 9.03$ & $243.76 \pm 10.78$ & $<0.001$ & $0.77(0.06)$ & $11 / 27$ \\
\hline Quadrante NS & $241.47 \pm 11.85$ & $276.82 \pm 12.33$ & $<0.001$ & $0.98(0.01)$ & $26 / 27$ \\
\hline Quadrante NI & $238.58 \pm 11.26$ & $272.21 \pm 13.27$ & $<0.001$ & $0.97(0.02)$ & $24 / 27$ \\
\hline \multicolumn{6}{|l|}{$\begin{array}{l}\text { TCO de espessura da } \\
\text { CFNR peripapilar }(\mu \mathrm{m})\end{array}$} \\
\hline $\begin{array}{l}\text { Média dos segmentos } \\
\text { 10,11,12 e } 1 \text { em horas de } \\
\text { relógio }\end{array}$ & $88.92 \pm 13.18$ & $117.16 \pm 11.71$ & $<0.001$ & $0.93(0.03)$ & $22 / 27$ \\
\hline $\begin{array}{l}\text { Média dos segmentos } 8,7 \\
6 \text { e } 5 \text { em horas de relógio }\end{array}$ & $90.14 \pm 11.26$ & $117.72 \pm 11.86$ & $<0.001$ & $0.94(0.03)$ & $23 / 27$ \\
\hline $\begin{array}{l}\text { Média dos segmentos } 9,10 \\
\text { e } 11 \text { em horas de relógio }\end{array}$ & $80.15 \pm 15.36$ & $100.26 \pm 13.46$ & $<0.001$ & $0.84(0.05)$ & $19 / 27$ \\
\hline $\begin{array}{l}\text { Média dos segmentos } 9 \text {, } \\
8 \text { e } 7 \text { em horas de relógio }\end{array}$ & $76.67 \pm 12.41$ & $97.09 \pm 12.63$ & $<0.001$ & $0.88(0.04)$ & $19 / 27$ \\
\hline
\end{tabular}


A Tabela 9 demonstra a correlação entre os parâmetros de espessura macular e a severidade da perda de CV 10-2 calculado pelos 68 pontos de teste da perimetria subjetiva (em decibéis e em 1/Lambert). Foi encontrada correlação estatisticamente significante para a maioria dos parâmetros analisados. As correlações mais relevantes foram encontradas entre a média da espessura macular da hemirretina nasal com o quadrante temporal superior do CV 10-2 ( $\rho=0,73, \mathrm{p}<0,01)$, entre a média da espessura macular da hemirretina nasal com o hemicampo temporal do CV 10-2, entre a média de espessura macular do quadrante nasal superior com o hemicampo temporal do CV 10-2, entre a espessura macular do quadrante nasal superior com o quadrante temporal superior do CV 10-2, entre a espessura macular do quadrante nasal inferior com o quadrante temporal superior do CV 10-2 ( $\rho=0,72$ para todas as correlações mencionadas anteriormente, $\mathrm{p}<0,01$ ), entre a espessura macular do quadrante nasal superior com o quadrante temporal inferior do CV 10-2 e entre a espessura macular do quadrante nasal inferior com o hemicampo temporal do CV 10-2 $(\rho=0,71$ para ambas correlações mencionadas anteriormente, $p<0,01)$.

Tabela 9: Correlação entre os parâmetros de espessura macular da TCO e os parâmetros de sensibilidade calculados a partir dos 68 pontos de teste do CV 10-2 (perimetria subjetiva)

\begin{tabular}{|c|c|c|c|c|c|c|c|c|c|c|c|c|}
\hline \multirow{3}{*}{$\begin{array}{l}\text { Espessura } \\
\text { macular } \\
\text { Parâmetros }\end{array}$} & \multicolumn{12}{|c|}{ Perimetria subjetiva CV 10-2 } \\
\hline & \multicolumn{2}{|c|}{ HT } & \multicolumn{2}{|c|}{ HN } & \multicolumn{2}{|c|}{ TS } & \multicolumn{2}{|c|}{ TI } & \multicolumn{2}{|c|}{ NS } & \multicolumn{2}{|c|}{ NI } \\
\hline & $d B$ & $1 / L$ & $d B$ & $1 / L$ & $d B$ & $1 / L$ & $d B$ & $1 / L$ & $d B$ & $1 / L$ & $d B$ & $1 / L$ \\
\hline Mácula total & $\underline{0,51}$ & $\underline{0,64}$ & 0,23 & 0,29 & $\underline{0,53}$ & $\underline{0,63}$ & $\underline{0,50}$ & $\underline{0,62}$ & 0,22 & 0,25 & 0,21 & 0,28 \\
\hline NS & $\underline{0,58}$ & $\underline{\mathbf{0 , 7 2}}$ & $\mathbf{0 , 2 7}$ & $\underline{0,34}$ & $\underline{0,61}$ & $\underline{\mathbf{0 , 7 2}}$ & $\underline{0,56}$ & $\underline{0,71}$ & 0,26 & 0,29 & 0,24 & $\underline{0,32}$ \\
\hline NI & $\underline{0,59}$ & $\underline{\mathbf{0 , 7 1}}$ & $\underline{\mathbf{0 , 3 2}}$ & $\underline{0,36}$ & $\underline{0,63}$ & $\underline{0,72}$ & $\underline{0,55}$ & $\underline{0,68}$ & $\underline{0,33}$ & $\underline{0,33}$ & 0,28 & $\underline{0,33}$ \\
\hline TS & 0,27 & $\underline{0,39}$ & 0,08 & 0,11 & 0,28 & $\underline{0,36}$ & $\underline{0,29}$ & $\underline{\mathbf{0 , 4 0}}$ & 0,05 & 0,04 & 0,10 & 0,14 \\
\hline TI & 0,28 & $\underline{\mathbf{0 , 3 9}}$ & 0,13 & 0,17 & $\mathbf{0 , 3 0}$ & $\underline{0,38}$ & 0,28 & $\underline{0,39}$ & 0,13 & 0,14 & 0,13 & 0,16 \\
\hline $\begin{array}{l}\text { Hemirretina } \\
\text { nasal }\end{array}$ & $\underline{\mathbf{0 , 5 9}}$ & $\underline{\mathbf{0 , 7 2}}$ & $\underline{\mathbf{0 , 3 1}}$ & $\underline{\mathbf{0 , 3 5}}$ & $\underline{0,62}$ & $\underline{0,73}$ & $\underline{0,57}$ & $\underline{\mathbf{0 , 7 0}}$ & $\underline{\mathbf{0 , 3 1}}$ & $\underline{\mathbf{0 , 3 2}}$ & $\mathbf{0 , 2 7}$ & $\underline{\mathbf{0 , 3 3}}$ \\
\hline $\begin{array}{l}\text { Hemirretina } \\
\text { temporal }\end{array}$ & 0,30 & $\underline{0,40}$ & 0,11 & 0,14 & $\underline{\mathbf{0 , 3 1}}$ & $\underline{0,38}$ & $\underline{\mathbf{0 , 3 1}}$ & $\underline{0,40}$ & 0,09 & 0,09 & 0,12 & 0,15 \\
\hline
\end{tabular}

Abreviações: HT, hemicampo temporal; HN, hemicampo nasal; TS, quadrante temporal superior; TI, quadrante temporal inferior; NS, quadrante nasal superior; NI, quadrante nasal inferior. Coeficiente de correlação de Spearman (decibel) e de correlação de Pearson (1/Lambert). Negrito $=\mathrm{p}<0,05$ e negrito com sublinhado $=\mathrm{p}<0,01$. Em destaque amarelo as mais relevantes correlações. 
Tabela 10 demonstra a correlação entre os parâmetros de espessura macular e a gravidade da perda visual baseada nas 24 respostas do PEV-mf central (em $\mu$ Volts). Correlação estatística significante foi encontrada para a maioria dos parâmetros. As correlações mais relevantes foram entre a média da espessura macular do quadrante nasal inferior com a amplitude $\mathrm{N} 2$ do quadrante temporal superior $(\rho=0,54, \mathrm{P}<0,01)$, entre a média da espessura macular da hemirretina nasal com a amplitude N2 do quadrante temporal superior $(\rho=0,52, \mathrm{P}<0,01)$. Os dados apresentados demonstraram forte correlação entre parâmetros da perimetria subjetiva com os achados da espessura macular para a maioria dos parâmetros analisado, ao passo que os parâmetros da perimetria objetiva demonstraram correlação moderada com dados da espessura macular para a maioria dos parâmetros analisados.

Tabela 10: Correlação entre os parâmetros de espessura macular da TCO e os parâmetros de sensibilidade calculados a partir das 24 respostas de amplitude em $\mu$ Volts da perimetria objetiva central (PEV-mf central)

\begin{tabular}{|c|c|c|c|c|c|c|c|c|c|c|c|c|}
\hline \multirow{3}{*}{$\begin{array}{c}\text { Espessura } \\
\text { macular } \\
\text { Parâmetros }\end{array}$} & \multicolumn{12}{|c|}{ Perimetria objetiva central (PEV-mf central) } \\
\hline & \multicolumn{2}{|c|}{ HT } & \multicolumn{2}{|c|}{ HN } & \multicolumn{2}{|c|}{ TS } & \multicolumn{2}{|c|}{ TI } & \multicolumn{2}{|c|}{ NS } & \multicolumn{2}{|c|}{ NI } \\
\hline & $P 1$ & $N 2$ & $P 1$ & $N 2$ & $P 1$ & $N 2$ & $P 1$ & $N 2$ & $P 1$ & $N 2$ & $P 1$ & $N 2$ \\
\hline Mácula total & $\underline{0,44}$ & $\underline{0,47}$ & 0,24 & 0,25 & $\underline{0,41}$ & $\underline{0,49}$ & $\underline{0,41}$ & $\underline{0,45}$ & 0,19 & 0,23 & 0,27 & 0,23 \\
\hline NS & $\underline{0,44}$ & $\underline{0,48}$ & 0,21 & 0,22 & $\underline{0,41}$ & $\underline{0,50}$ & $\underline{0,42}$ & $\underline{0,47}$ & 0,15 & 0,20 & 0,26 & 0,22 \\
\hline NI & $\underline{0,48}$ & $\underline{0,51}$ & 0,26 & 0,26 & $\underline{0,46}$ & $\underline{0,54}$ & $\underline{0,45}$ & $\underline{0,48}$ & 0,20 & 0,23 & 0,28 & 0,25 \\
\hline TS & $\underline{0,34}$ & $\underline{0,35}$ & 0,20 & 0,19 & 0,29 & $\underline{0,34}$ & $\underline{0,33}$ & $\underline{0,36}$ & 0,16 & 0,21 & 0,22 & 0,17 \\
\hline TI & $\underline{0,34}$ & $\underline{0,35}$ & 0,21 & 0,22 & $\underline{0,32}$ & $\underline{0,36}$ & $\underline{0,31}$ & $\underline{0,34}$ & 0,18 & 0,24 & 0,21 & 0,18 \\
\hline $\begin{array}{l}\text { Hemirretina } \\
\text { nasal }\end{array}$ & $\underline{0,47}$ & $\underline{\mathbf{0 , 5 1}}$ & 0,25 & 0,25 & $\underline{0,44}$ & $\underline{\mathbf{0 , 5 2}}$ & $\underline{0,45}$ & $\underline{0,49}$ & 0,18 & 0,22 & 0,29 & 0,25 \\
\hline $\begin{array}{l}\text { Hemirretina } \\
\text { temporal }\end{array}$ & $\underline{\mathbf{0 , 3 5}}$ & $\underline{0,37}$ & 0,21 & 0,21 & $\underline{0,31}$ & $\underline{0,36}$ & $\underline{\mathbf{0 , 3 3}}$ & $\underline{0,36}$ & 0,17 & 0,22 & 0,21 & 0,18 \\
\hline
\end{tabular}

Abreviações: HT, hemicampo temporal; HN, hemicampo nasal; TS, quadrante temporal superior; TI, quadrante temporal inferior; NS, quadrante nasal superior; NI, quadrante nasal inferior. Coeficiente de correlação de Spearman (decibel) e de correlação de Pearson (1/Lambert). Negrito $=p<0,05$ e negrito com sublinhado $=p<0,01$. Em destaque amarelo as mais relevantes correlações. 


\section{DISCUSSÃO}


Os resultados do presente estudo demonstram que as médias da amplitude do PEV-mf global e central foram significativamente menores em olhos com AB quando comparadas aos olhos de controles normais. Esses achados estão em concordância com estudos prévios em portadores de glaucoma $^{[32,85,102,103]}$, de neuropatia óptica isquêmica ${ }^{[104]}$ e de neurite óptica ${ }^{[93,105,106]}$, assim como em portadores de neuropatia óptica compressiva, nos quais foram demonstradas alterações no PEV-mf ${ }^{[3,94-96]}$.

Sabe-se que ao avaliar pacientes com doenças da via visual anterior é importante entender melhor a correlação estrutura-função utilizando diferentes tecnologias, sendo, assim, o principal objetivo deste estudo foi avaliar a relação existente entre os parâmetros da TCO-dF, do PEV-mf (global e central) e do CV (24-2 e 10-2). Pois, ao passo que os exames de perimetria subjetiva (CV 24-2 e 10-2) e perimetria objetiva (PEV-mf global e central) demonstram um déficit de CV que possivelmente pode ser revertido com a descompressão da via visual em pacientes com neuropatia óptica compressiva ${ }^{[2,97]}$, os exames de estrutura, como a TCO-dF, indicam certo grau de disfunção permanente. Portanto, em pacientes com defeito de CV e achados da TCO-dF dentro da normalidade apresentam um prognóstico visual melhor com a descompressão da via óptica ${ }^{[97,98]}$. Contudo, algumas alterações da TCO-dF podem ser encontradas mesmo em pacientes com bom prognóstico visual, sendo importante quantificar estas alterações e sua correlação com os achados de perimetria subjetiva e objetiva como indicador de recuperação de CV após o tratamento.

Estudos prévios avaliaram a correlação estrutura-função entre a sensibilidade da perimetria Humphrey ${ }^{\mathrm{TM}}$ e os achados da TCO e do PEV-mf em pacientes portadores de 
glaucoma. Moschos et al. ${ }^{[107]}$ demonstraram que o PEV-mf tem correlação com a espessura da CFNR peripapilar da TCO em pacientes com GPAA e resultados similares foram encontrados por Wizer et al. ${ }^{[108]}$. A concordância entre os testes de perimetria (subjetiva e objetiva) e com a espessura da CFNR peripapilar obtida pela TCO Stratus ${ }^{\mathrm{TM}}$ foi avaliada em pacientes portadores de neurite óptica, sendo observado concordância moderada entre a TCO Stratus ${ }^{\mathrm{TM}}$ e PEV-mf, porém a correlação aumentou ao ser avaliada concordância entre a TCO Stratus ${ }^{\mathrm{TM}}$ e as duas perimetrias combinadas (subjetiva e objetiva) ${ }^{[93]}$. Neste mesmo sentido, Ziccardi L et al. demonstraram correlação estatisticamente significante das alterações dos dois anéis internos do PEV-mf com a redução na espessura da CFNR peripapilar temporal em 17 pacientes portadores da neuropatia óptica hereditária de Leber quando comparado a 22 controles normais ${ }^{[109]}$.

Porém, um estudo comparando alterações estruturais do NO por estereofotografia e da CFNR da TCO com os achados do PEV-mf e da perimetria subjetiva (CV 24-2 e frequency doubling perimetry -FDT) demonstrou uma fraca concordância entre a medidas de estrutura e função na avaliação da progressão em pacientes portadores de glaucoma ${ }^{[110]}$. Os autores atribuíram essa fraca concordância a limitações de desenho do estudo e ressaltaram a importância em combinar testes no seguimento de pacientes com glaucoma. Entretanto, estes resultados estão em discordância com estudo prévio em portadores de glaucoma que demonstrou uma boa concordância entre os achados do CV 10-2, do PEV-mf central e da espessura macular obtida pela TCO em pacientes portadores desta patologia ${ }^{[33]}$. Estes resultados foram corroborados por estudos posteriores de estrutura-função em pacientes portadores de GPAA que comparou os achados do PEV-mf do hemicampo superior com os parâmetros do hemisfério inferior do HRT (Heidelberg Retinal Tomography) e viceversa, demonstrando boa correlação estrutura-função nestas analises ${ }^{[88]}$. 
Os resultados obtidos no presente estudo indicam uma correlação moderada entre as amplitudes do PEV-mf (global e central) com a perimetria subjetiva (CV 24-2 e 10-2) ou com a TCO-dF (da espessura macular e de CFNR peripapilar). Embora a correlação da perimetria subjetiva (CV 10-2) com os achados de espessura macular da TCO-dF seja mais forte que a obtida com o PEV-mf central, sabe-se que uma dificuldade em avaliar novas tecnologias é que as tecnologia antigas são utilizadas como padrão ouro e isso pode implicar em alguma discordância pelas diferentes formas de aquisição das medidas pelos aparelhos. A perimetria Humphrey ${ }^{\mathrm{TM}}$ é baseada no limiar de estimulação e o PEV-mf é uma medida objetiva da amplitude e latência das ondas eletroencefálicas do córtex visual captadas por eletrodos colocados na pele nesta topografia, refletindo a integridade da via visual e possivelmente implicando em algumas limitações nas analises dos dados. Assim, existem fraquezas no desenho deste estudo que sem dúvida contribuem para uma concordância apenas moderada entre os testes, apesar da melhor correlação estrutura-função ser obtida ao analisar a correspondência topográfica existente entre o CV 10-2 e o PEV-mf central com a espessura macular da TCO por obvia correlação estrutura-função ${ }^{[33]}$.

Entretanto, no presente estudo, a média das latências não foi diferente estatisticamente entre os casos e os controles para todos os quadrantes e hemicampos, o que é diferente dos achados de estudos prévios que demonstraram prolongamento da latência em pacientes portadores de neuropatia óptica compressiva ${ }^{[94,}{ }^{96}$. Provavelmente, isto ocorreu, porque os pacientes do presente estudo eram doentes sequelares, ou seja com defeito de campo por compressão prévia e não atual, com CV estável há pelo menos 01 ano, enquanto que os pacientes de outros estudos prévios apresentavam neuropatia óptica compressiva ativa ${ }^{[2,94,96,97]}$. 
No nosso conhecimento, este é o primeiro estudo a avaliar a relação entre o PEV-mf (global e central), a TCO-dF (espessura macular e CFNR peripapilar) e perda de sensibilidade do CV (24-2 e 10-2) em pacientes com neuropatia óptica compressiva sequelar. Recentemente, um estudo investigou a associação entre a CFNR peripapilar medida na TCO-dF, o PEV-mf e perda de sensibilidade do CV 24-2 em portadores de compressão quiasmática secundária a adenoma de hipófise ${ }^{[98]}$. Os autores demonstraram concordância entre a TCO e o CV 24-2 em apenas $21,5 \%$ dos casos e entre a TCO e o PEV-mf em apenas 24,2\%. Entretanto, os autores não investigaram a associação entre as medidas da TCO de espessura macular com as respostas dos PEV-mf. No presente estudo, foi demonstrada correlação moderada estrutura-função entre os testes da TCO-dF de espessura macular e dados da perimetria objetiva (PEV-mf central), embora a correlação seja forte quando analisados os dados do CV 10-2 com a espessura macular da TCO-dF. Além disso, foi demonstrado que a analise de correlação ao agrupar alguns setores obtidos a partir do gráfico de 12 divisões da CFNR peripapilar da TCO-dF com os correspondentes setores do $\mathrm{CV}$ tanto na perimetria subjetiva, quanto na objetiva, apresentou correlação moderada entre os exames.

Recentemente, Raz N et al. analisaram um paciente portador de compressão quiasmática secundária a meningioma antes e depois da resseção cirúrgica com exames eletrofisiológicos e de imagem (TCO da CFNR peripapilar e RNM por difusão ${ }^{[111]}$. O autor observou que a preservação da latência mesmo com importante redução de amplitude no PEV-mf neste paciente, quando associada a preservação maior que $50 \%$, da espessura de CFNR peripapilar na TCO, se correlacionou com melhor recuperação do $\mathrm{CV}$ neste paciente dentro de 02 anos do procedimento ${ }^{[111]}$. Por outro lado, em outro modelo de lesão neuronal do NO, Alshowaeir D et al. demonstraram que em portadores de neurite óptica a redução da amplitude do PEVmf é um marcador precoce de perda axonal da CFNR peripapilar na $\mathrm{TCO}^{[112]}$. 
O presente estudo apresenta como limitação a ausência da analise signal-to-noise ration (SNR), destinada a minimizar a interferência do ruído na precisão da analise das ondas obtidas na janela de resposta, uma vez que o software utilizado não dispunha de tal recurso. Entretanto, o estudo dispôs da presença de um grupo controle adequado para aumentar a precisão das analises dos resultados dos testes eletrofisiológicos (PEV-mf), minimizando desta forma este viés da ausência do cálculo SNR.

Pelo nosso conhecimento, este foi o primeiro estudo a analisar as correlações entre o CV 10-2, o PEV-mf central e a medida de espessura macular obtida pela TCO, permitindo uma maior correlação estrutura-função por razões obvias e demonstrando correlação moderada entre os exames. Além disso, o presente estudo analisou, numa amostra maior de pacientes e controles, a correlação entre o CV 24-2, o PEV-global e CFNR peripapilar na TCO, demonstrando uma correlação moderada entre os exames ao analisar um número maior de pacientes do que estudos prévios ${ }^{[94,96,98]}$.

Pode-se concluir pelo presente estudo que a média das amplitudes do PEV-mf (global e central) foi capaz de diferenciar olhos com hemianopsia temporal devido a neuropatia óptica compressiva sequelar de olhos de controles normais, se correlacionando com a gravidade do defeito de CV medido na estratégia 24-2 e 10-2, assim como com a alteração estrutural medida pela TCO-dF. Porém, são necessários estudos futuros para melhor compreensão de como estudos eletrofisiológicos e anatômicos podem ser combinados para prever a perda de função visual em portadores de neuropatia óptica compressiva. 


\section{CONCLUSÕES}


Os resultados desse estudo possibilitaram as seguintes conclusões:

1. O PEV-mf foi capaz de discriminar os pacientes portadores de $A B$ ao avaliar as alterações das respostas de amplitude dos setores temporais (hemicampo e quadrantes), não sendo observada diferença significativa entre a capacidade das melhores respostas do PEV-mf e do TCO em identificar os anormais.

2. O PEV-mf global e central foi capaz de diferenciar olhos normais daqueles de pacientes com neuropatia óptica compressiva quiasmática.

3. Foi encontrada correlação moderada entre a amplitude das respostas P1 e N2 do PEV-mf global com a sensibilidade em decibéis e 1/Lambert do CV 24-2 nos setores temporais (quadrantes e hemicampo), assim como ocorreu correlação moderada ligeiramente maior entre a amplitude das respostas P1 e N2 do PEV-mf central com a sensibilidade em decibéis e 1/Lambert do CV 10-2 nos setores temporais (quadrantes e hemicampo).

4. As melhores correlações estrutura-função do PEV-mf global com a CFNR peripapilar na $\mathrm{TCO}$ em grupos foram moderadas e ocorreram entre os setores 9, 10 e 11 da CFNR peripapilar com o quadrante temporal superior para amplitude de N2 e nos setores 9, 8 e 7 para correlação com o quadrante temporal inferior para amplitude de N2.

5. As melhores correlações estrutura-função do PEV-mf central com a CFNR peripapilar na TCO em grupos ocorreram entre os setores 10 e 11 para correlação com o quadrante temporal superior para amplitude de N2 e nos 
setores 8 e 9 para correlação com o quadrante temporal inferior para amplitude de N2. Entretanto, apesar de moderada a correlação encontrada entres os setores da CFNR peripapilar na TCO com os respectivos quadrantes da CV 10-2, as correlações foram similares àquelas encontradas pelo PEV-mf central. Entretanto, a análise que apresentou melhor resultado na correlação estrutura-função foi entre os exames de PEV-mf central com a espessura macular em quadrantes na TCO. Isso ocorreu na correlação do quadrante macular nasal inferior com o quadrante temporal superior do PEV-mf central e na correlação do quadrante macular nasal superior com o quadrante temporal inferior do PEV-mf central, ambos apresentando correlação moderada. Já nesta mesma análise, a correlação entre a espessura macular com o CV 10-2, apresentou correlação forte, sendo superior a correlação encontrada na perimetria objetiva. 


\section{REFERÊNCIAS}


1. Anderson, D., et al., Pituitary tumors and the ophthalmologist. Ophthalmology, 1983. 90(11): p. 1265-70.

2. Xue, K., et al., Multifocal visual evoked potentials in unilateral compressive optic neuropathy secondary to orbital tumors. Eur J Ophthalmol, 2013. 23(4): p. 571-7.

3. Danesh-Meyer, H.V., et al., Correlation of the multifocal visual evoked potential and standard automated perimetry in compressive optic neuropathies. Invest Ophthalmol Vis Sci, 2006. 47(4): p. 1458-63.

4. Foroozan, R., Chiasmal syndromes. Curr Opin Ophthalmol, 2003. 14(6): p. 325-31.

5. Danesh-Meyer, H.V., et al., In vivo retinal nerve fiber layer thickness measured by optical coherence tomography predicts visual recovery after surgery for parachiasmal tumors. Invest Ophthalmol Vis Sci, 2008. 49(5): p. 1879-85.

6. Jonas, J.B. and A. Dichtl, Evaluation of the retinal nerve fiber layer. Surv Ophthalmol, 1996. 40(5): p. 369-78.

7. Savino, P.J., Evaluation of the retinal nerve fiber layer: descriptive or predictive? J Neuroophthalmol, 2009. 29(3): p. 245-9.

8. Loo, J.L., et al., Use of optical coherence tomography in predicting posttreatment visual outcome in anterior visual pathway meningiomas. $\mathrm{Br} \mathrm{J}$ Ophthalmol, 2013. 97(11): p. 1455-8.

9. Cohen, A.R., et al., Visual recovery after transsphenoidal removal of pituitary adenomas. Neurosurgery, 1985. 17(3): p. 446-52.

10. Barzaghi, L.R., et al., Prognostic factors of visual field improvement after transsphenoidal approach for pituitary macroadenomas: review of the literature and analysis by quantitative method. Neurosurg Rev, 2012. 35(3): p. 369-78; discussion 378-9.

11. Monteiro, M.L., B.K. Zambon, and L.P. Cunha, Predictive factors for the development of visual loss in patients with pituitary macroadenomas and for visual recovery after optic pathway decompression. Can J Ophthalmol, 2010. 45(4): p. 404-8.

12. Musluman, A.M., et al., Surgical results of large and giant pituitary adenomas with special consideration of ophthalmologic outcomes. World Neurosurg, 2011. 76(1-2): p. 141-8; discussion 63-6. 
13. Jonas, J.B., N.X. Nguyen, and G.O. Naumann, The retinal nerve fiber layer in normal eyes. Ophthalmology, 1989. 96(5): p. 627-32.

14. Dubis, A.M., et al., Evaluation of normal human foveal development using optical coherence tomography and histologic examination. Arch Ophthalmol, 2012. 130(10): p. 1291-300.

15. Horton, J.C. and W.F. Hoyt, The representation of the visual field in human striate cortex. A revision of the classic Holmes map. Arch Ophthalmol, 1991. 109(6): p. 816-24.

16. Horton, J.C. and W.F. Hoyt, Quadrantic visual field defects. A hallmark of lesions in extrastriate (V2/V3) cortex. Brain, 1991. 114 ( Pt 4): p. 1703-18.

17. Daniel, P.M. and D. Whitteridge, The representation of the visual field on the cerebral cortex in monkeys. J Physiol, 1961. 159(2): p. 203-21.

18. Jain, N.S., et al., Visualization of Nerve Fiber Orientations in the Human Optic Chiasm Using Photomicrographic Image Analysis. Invest Ophthalmol Vis Sci, 2015. 56(11): p. 6734-9.

19. Guillery, R.W., C.A. Mason, and J.S. Taylor, Developmental determinants at the mammalian optic chiasm. J Neurosci, 1995. 15(7 Pt 1): p. 4727-37.

20. Unsold, R. and W.F. Hoyt, Band atrophy of the optic nerve. The histology of temporal hemianopsia. Arch Ophthalmol, 1980. 98(9): p. 1637-8.

21. Mikelberg, F.S. and H.M. Yidegiligne, Axonal loss in band atrophy of the optic nerve in craniopharyngioma: a quantitative analysis. Can J Ophthalmol, 1993. 28(2): p. 69-71.

22. Vannas, A., C. Raitta, and S. Lemberg, Photography of the nerve fiber layer in retinal disturbances. Acta Ophthalmol (Copenh), 1977. 55(1): p. 79-87.

23. Hood, D.C. and R.H. Kardon, A framework for comparing structural and functional measures of glaucomatous damage. Prog Retin Eye Res, 2007. 26(6): p. 688-710.

24. Ferreras, A., et al., Mapping standard automated perimetry to the peripapillary retinal nerve fiber layer in glaucoma. Invest Ophthalmol Vis Sci, 2008. 49(7): p. 3018-25.

25. Danesh-Meyer, H.V., et al., Relationship between retinal nerve fiber layer and visual field sensitivity as measured by optical coherence tomography in chiasmal compression. Invest Ophthalmol Vis Sci, 2006. 47(11): p. 4827-35. 
26. Lederer, D.E., et al., Analysis of macular volume in normal and glaucomatous eyes using optical coherence tomography. Am J Ophthalmol, 2003. 135(6): p. 838-43.

27. Gonul, S., et al., Comparison of the ganglion cell complex and retinal nerve fibre layer measurements using Fourier domain optical coherence tomography to detect ganglion cell loss in non-arteritic anterior ischaemic optic neuropathy. $\mathrm{Br}$ J Ophthalmol, 2013. 97(8): p. 1045-50.

28. Moura, F.C., F.A. Medeiros, and M.L. Monteiro, Evaluation of macular thickness measurements for detection of band atrophy of the optic nerve using optical coherence tomography. Ophthalmology, 2007. 114(1): p. 175-81.

29. Doshi, A. and K. Singh, Cost-effective evaluation of the glaucoma suspect. Curr Opin Ophthalmol, 2007. 18(2): p. 97-103.

30. Mejico, L.J., N.R. Miller, and L.M. Dong, Clinical features associated with lesions other than pituitary adenoma in patients with an optic chiasmal syndrome. Am J Ophthalmol, 2004. 137(5): p. 908-13.

31. Wangsupadilok, B., et al., A method to detect progression of glaucoma using the multifocal visual evoked potential technique. Doc Ophthalmol, 2009. 118(2): p.139-50.

32. Fortune, B., et al., Comparing multifocal VEP and standard automated perimetry in high-risk ocular hypertension and early glaucoma. Invest Ophthalmol Vis Sci, 2007. 48(3): p. 1173-80.

33. Kanadani, F.N., et al., Structural and functional assessment of the macular region in patients with glaucoma. Br J Ophthalmol, 2006. 90(11): p. 1393-7.

34. Menjot de Champfleur, N., et al., Imaging of the optic chiasm and retrochiasmal visual pathways. Diagn Interv Imaging, 2013. 94(10): p. 957-71.

35. Monteiro, M.L., et al., Relationship between optical coherence tomography, pattern electroretinogram and automated perimetry in eyes with temporal hemianopia from chiasmal compression. Invest Ophthalmol Vis Sci, 2009. 50(8): p. 3535-41.

36. Zhu, H., et al., Predicting visual function from the measurements of retinal nerve fiber layer structure. Invest Ophthalmol Vis Sci, 2010. 51(11): p. 5657-66.

37. Sriram, P., et al., Relationship between optical coherence tomography and electrophysiology of the visual pathway in non-optic neuritis eyes of multiple sclerosis patients. PLoS One, 2014. 9(8): p. e102546.

38. Arevalo, J.F., Retinal Angiography and Optical Coherence Tomography. 2009:

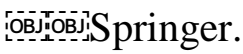


39. Alkabes, M., et al., En face optical coherence tomography of inner retinal defects after internal limiting membrane peeling for idiopathic macular hole. Invest Ophthalmol Vis Sci, 2011. 52(11): p. 8349-55.

40. Guo, L., et al., En face optical coherence tomography: a new method to analyse structural changes of the optic nerve head in rat glaucoma. Br J Ophthalmol, 2005. 89(9): p. 1210-6.

41. Rispoli, M., et al., Retinal surface en face optical coherence tomography: a new imaging approach in epiretinal membrane surgery. Retina, 2012. 32(10): p. 2070-6.

42. Huang, D., et al., Optical coherence tomography. Science, 1991. 254(5035): p. 1178-81.

43. Hee, M.R., et al., Optical coherence tomography of the human retina. Arch Ophthalmol, 1995. 113(3): p. 325-32.

44. Srinivasan, V.J., et al., High-definition and 3-dimensional imaging of macular pathologies with high-speed ultrahigh-resolution optical coherence tomography. Ophthalmology, 2006. 113(11): p. 2054 e1-14.

45. Schuman, J.S., et al., Quantification of nerve fiber layer thickness in normal and glaucomatous eyes using optical coherence tomography. Arch Ophthalmol, 1995. 113(5): p. 586-96.

46. Zangwill, L.M., et al., A comparison of optical coherence tomography and retinal nerve fiber layer photography for detection of nerve fiber layer damage in glaucoma. Ophthalmology, 2000. 107(7): p. 1309-15.

47. Wollstein, G., et al., Optical coherence tomography longitudinal evaluation of retinal nerve fiber layer thickness in glaucoma. Arch Ophthalmol, 2005. 123(4): p. 464-70.

48. Monteiro, M.L., et al., Optical coherence tomography analysis of axonal loss in band atrophy of the optic nerve. Br J Ophthalmol, 2004. 88(7): p. 896-9.

49. Kanamori, A., et al., Optical coherence tomography detects characteristic retinal nerve fiber layer thickness corresponding to band atrophy of the optic discs. Ophthalmology, 2004. 111(12): p. 2278-83.

50. Leal, B.C., F.C. Moura, and M.L. Monteiro, [Comparison of Scanning Laser Polarimetry, Optical coherence tomography 1 and Stratus OCT for the detection of axonal loss in band atrophy of the optic nerve]. Arq Bras Oftalmol, 2006. 69(4).

51. Monteiro, M.L., et al., Comparison of retinal nerve fibre layer measurements using optical coherence tomography versions 1 and 3 in eyes with band atrophy of the optic nerve and normal controls. Eye, 2005. 
52. Costa-Cunha, L.V., et al., Comparison of Fourier-domain and time-domain optical coherence tomography in the detection of band atrophy of the optic nerve. Am J Ophthalmol, 2009. 147(1): p. 56-63 e2.

53. Zeimer, R., et al., Quantitative detection of glaucomatous damage at the posterior pole by retinal thickness mapping. A pilot study. Ophthalmology, 1998. 105(2): p. 224-31.

54. Kendell, K.R., et al., Primary open-angle glaucoma is not associated with photoreceptor loss. Invest Ophthalmol Vis Sci, 1995. 36(1): p. 200-5.

55. Glovinsky, Y., H.A. Quigley, and M.E. Pease, Foveal ganglion cell loss is size dependent in experimental glaucoma. Invest Ophthalmol Vis Sci, 1993. 34(2): p. 395-400.

56. Frishman, L.J., et al., The scotopic electroretinogram of macaque after retinal ganglion cell loss from experimental glaucoma. Invest Ophthalmol Vis Sci, 1996. 37(1): p. 125-41.

57. Monteiro, M.L., et al., Correlation between macular and retinal nerve fibre layer Fourier-domain OCT measurements and visual field loss in chiasmal compression. Eye (Lond), 2010. 24(8): p. 1382-90.

58. Akashi, A., et al., The detection of macular analysis by SD-OCT for optic chiasmal compression neuropathy and nasotemporal overlap. Invest Ophthalmol Vis Sci, 2014. 55(7): p. 4667-72.

59. Monteiro, M.L., et al., Evaluation of inner retinal layers in eyes with temporal hemianopic visual loss from chiasmal compression using optical coherence tomography. Invest Ophthalmol Vis Sci, 2014. 55(5): p. 3328-36.

60. Abegg, M., M. Zinkernagel, and S. Wolf, Microcystic macular degeneration from optic neuropathy. Brain, 2012. 135(Pt 12): p. e225.

61. Gills, J.P., Jr. and J.A. Wadsworth, Degeneration of the inner nuclear layer of the retina following lesions of the optic nerve. Trans Am Ophthalmol Soc, 1966. 64: p. 66-88.

62. Gelfand, J.M., et al., Microcystic inner nuclear layer abnormalities and neuromyelitis optica. JAMA Neurol, 2013. 70(5): p. 629-33.

63. Gelfand, J.M., et al., Microcystic macular oedema in multiple sclerosis is associated with disease severity. Brain, 2012. 135(Pt 6): p. 1786-93.

64. Saidha, S., et al., Microcystic macular oedema, thickness of the inner nuclear layer of the retina, and disease characteristics in multiple sclerosis: a retrospective study. Lancet Neurol, 2012. 11(11): p. 963-72. 
65. Gelfand, J.M. and A.J. Green, Reply: Microcystic macular degeneration from optic neuropathy: not inflammatory, not trans-synaptic degeneration. Brain, 2013. 136(Pt 7): p. e240.

66. Wolff, B., et al., RETINAL INNER NUCLEAR LAYER MICROCYSTIC CHANGES IN OPTIC NERVE ATROPHY: A Novel Spectral-Domain OCT Finding. Retina, 2013.

67. Jindahra, P., A. Petrie, and G.T. Plant, Retrograde trans-synaptic retinal ganglion cell loss identified by optical coherence tomography. Brain, 2009. 132(Pt 3): p. 628-34.

68. Sriram, P., et al., Transsynaptic retinal degeneration in optic neuropathies: optical coherence tomography study. Invest Ophthalmol Vis Sci, 2012. 53(3): p. 1271-5.

69. Ryan, S. and G.B. Arden, Electrophysiological discrimination between retinal and optic nerve disorders. Doc Ophthalmol, 1988. 68(3-4): p. 247-55.

70. Bach, M., Electrophysiological approaches for early detection of glaucoma. Eur J Ophthalmol, 2001. 11 Suppl 2: p. S41-9.

71. Parisi, V., et al., Correlation between optical coherence tomography, pattern electroretinogram, and visual evoked potentials in open-angle glaucoma patients. Ophthalmology, 2001. 108(5): p. 905-12.

72. Holder, G.E., et al., Electrodiagnostic assessment in optic nerve disease. Curr Opin Neurol, 2009. 22(1): p. 3-10.

73. Heckenlively JR, A.G., Principles and Practice of Clinical Electrophysiology of Vision. 1991: Mosby Year Book.

74. Odom, J.V., et al., ISCEV standard for clinical visual evoked potentials (2009 update). Doc Ophthalmol, 2010. 120(1): p. 111-9.

75. Jampel, H.D., et al., Assessment of visual function in glaucoma: a report by the American Academy of Ophthalmology. Ophthalmology, 2011. 118(5): p. 9861002.

76. Baseler, H.A., et al., The topography of visual evoked response properties across the visual field. Electroencephalogr Clin Neurophysiol, 1994. 90(1): p. 65-81.

77. Kanski, J.J., Clinical Ophthalmology: A Systematic Approach. Sixth ed. 2007: Butterworth Heinemann Elsevier.

78. Baseler, H.A. and E.E. Sutter, $M$ and $P$ components of the VEP and their visual field distribution. Vision Res, 1997. 37(6): p. 675-90.

79. Hood, D.C., J.G. Odel, and B.J. Winn, The multifocal visual evoked potential. J Neuroophthalmol, 2003. 23(4): p. 279-89. 
80. Halliday, A.M., W.I. McDonald, and J. Mushin, Delayed visual evoked response in optic neuritis. Lancet, 1972. 1(7758): p. 982-5.

81. Halliday, A.M., W.I. McDonald, and J. Mushin, Visual evoked response in diagnosis of multiple sclerosis. Br Med J, 1973. 4(5893): p. 661-4.

82. Graham, S.L., et al., Objective VEP perimetry in glaucoma: asymmetry analysis to identify early deficits. J Glaucoma, 2000. 9(1): p. 10-9.

83. Hood, D.C., X. Zhang, and B.J. Winn, Detecting glaucomatous damage with multifocal visual evoked potentials: how can a monocular test work? J Glaucoma, 2003. 12(1): p. 3-15.

84. Goldberg, I., S.L. Graham, and A.I. Klistorner, Multifocal objective perimetry in the detection of glaucomatous field loss. Am J Ophthalmol, 2002. 133(1): p. 29-39.

85. Hood, D.C. and V.C. Greenstein, Multifocal VEP and ganglion cell damage: applications and limitations for the study of glaucoma. Prog Retin Eye Res, 2003. 22(2): p. 201-51.

86. Inoue, Y., et al., Reproducibility in the global indices for multifocal visual evoked potentials and Humphrey visual fields in controls and glaucomatous eyes within a 2-year period. Doc Ophthalmol, 2015. 131(2): p. 115-24.

87. Narayanan, D., et al., Reproducibility of multifocal visual evoked potential and traditional visual evoked potential in normal and multiple sclerosis eyes. Doc Ophthalmol, 2015. 130(1): p. 31-41.

88. Punjabi, O.S., et al., Topographic comparison of the visual function on multifocal visual evoked potentials with optic nerve structure on heidelberg retinal tomography. Ophthalmology, 2008. 115(3): p. 440-6.

89. Fortune, B., et al., Effect of recording duration on the diagnostic performance of multifocal visual-evoked potentials in high-risk ocular hypertension and early glaucoma. J Glaucoma, 2008. 17(3): p. 175-82.

90. Jindal, A.P., et al., Effects of acutely lowering intraocular pressure on the results of multifocal visual evoked potential testing. Acta Ophthalmol, 2011. 89(7): p. e550-4.

91. De Moraes, C.G., et al., Beta-zone parapapillary atrophy and multifocal visual evoked potentials in eyes with glaucomatous optic neuropathy. Doc Ophthalmol, 2011. 123(1): p. 43-50.

92. Fernandes, D.B., et al., Evaluation of Inner Retinal Layers in Patients with Multiple Sclerosis or Neuromyelitis Optica Using Optical Coherence Tomography. Ophthalmology, 2012. 
93. Laron, M., et al., Comparison of multifocal visual evoked potential, standard automated perimetry and optical coherence tomography in assessing visual pathway in multiple sclerosis patients. Mult Scler, 2010. 16(4): p. 412-26.

94. Semela, L., et al., Multifocal visual-evoked potential in unilateral compressive optic neuropathy. Br J Ophthalmol, 2007. 91(4): p. 445-8.

95. Semela, L., T.R. Hedges, and L. Vuong, Serial multifocal visual Evoked potential recordings in compressive optic neuropathy. Ophthalmic Surg Lasers Imaging, 2007. 38(3): p. 250-3.

96. Jayaraman, M., et al., Multifocal visual evoked potential recordings in compressive optic neuropathy secondary to pituitary adenoma. Doc Ophthalmol, 2010. 121(3): p. 197-204.

97. Perez-Rico, C., et al., Evaluation of multifocal visual evoked potentials in patients with Graves' orbitopathy and subclinical optic nerve involvement. Doc Ophthalmol, 2012. 125(1): p. 11-9.

98. Qiao, N., et al., Comparison of multifocal visual evoked potential, static automated perimetry, and optical coherence tomography findings for assessing visual pathways in patients with pituitary adenomas. Pituitary, 2015. 18(5): p. 598-603.

99. Garway-Heath, D.F., et al., Relationship between electrophysiological, psychophysical, and anatomical measurements in glaucoma. Invest Ophthalmol Vis Sci, 2002. 43(7): p. 2213-20.

100. Hanley, J.A., et al., Statistical analysis of correlated data using generalized estimating equations: an orientation. Am J Epidemiol, 2003. 157(4): p. 364-75.

101. DeLong, E.R., D.M. DeLong, and D.L. Clarke-Pearson, Comparing the areas under two or more correlated receiver operating characteristic curves: a nonparametric approach. Biometrics, 1988. 44(3): p. 837-45.

102. Hood, D.C., et al., Detecting early to mild glaucomatous damage: a comparison of the multifocal VEP and automated perimetry. Invest Ophthalmol Vis Sci, 2004. 45(2): p. 492-8.

103. Hood, D.C., et al., An interocular comparison of the multifocal VEP: a possible technique for detecting local damage to the optic nerve. Invest Ophthalmol Vis Sci, 2000. 41(6): p. 1580-7.

104. Hood, D.C., et al., Visual field defects and multifocal visual evoked potentials: evidence of a linear relationship. Arch Ophthalmol, 2002. 120(12): p. 1672-81. 
105. Laron, M., et al., Assessing visual pathway function in multiple sclerosis patients with multifocal visual evoked potentials. Mult Scler, 2009. 15(12): p. 1431-41.

106. Blanco, R., et al., Functional assessment of the visual pathway with multifocal visual evoked potentials, and their relationship with disability in patients with multiple sclerosis. Mult Scler, 2014. 20(2): p. 183-91.

107. Moschos, M.M., et al., Multifocal VEP and OCT findings in patients with primary open angle glaucoma: a cross-sectional study. BMC Ophthalmol, 2012. 12: p. 34.

108. Weizer, J.S., et al., Multifocal visual evoked potentials for early glaucoma detection. Ophthalmic Surg Lasers Imaging, 2012. 43(4): p. 335-40.

109. Ziccardi, L., et al., Multifocal VEP provide electrophysiological evidence of predominant dysfunction of the optic nerve fibers derived from the central retina in Leber's hereditary optic neuropathy. Graefes Arch Clin Exp Ophthalmol, 2015. 253(9): p. 1591-600.

110. Xin, D., et al., A comparison of functional and structural measures for identifying progression of glaucoma. Invest Ophthalmol Vis Sci, 2011. 52(1): p. 519-26.

111. Raz, N., et al., Physiological Correlates and Predictors of Functional Recovery After Chiasmal Decompression. J Neuroophthalmol, 2015. 35(4): p. 348-52.

112. Alshowaeir, D., et al., Multifocal VEP assessment of optic neuritis evolution. Clin Neurophysiol, 2015. 126(8): p. 1617-23. 